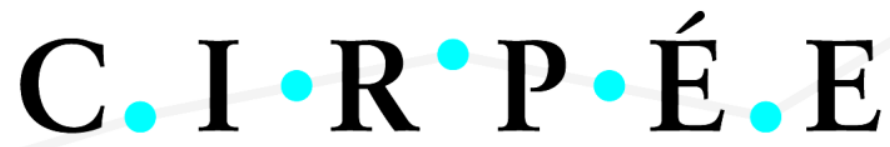

Centre Interuniversitaire sur le Risque, les Politiques Économiques et l'Emploi

Cahier de recherche/Working Paper 12-25

\section{Pro-Poor Growth in Andean Countries}

Abdelkrim Araar

Juin/June 2012

Araar: Département d'économique and CIRPÉE, Université Laval, Québec, Canada aabd@ecn.ulaval.ca

This work was carried out with funding from the Inter American Development Bank (IADP) Research Division. I am also grateful to Omar Alonso Zambrano and Jean-Yves Duclos for their valuable comments. I also thank to Laos Carbajal, Silvia Denisse for assistance with the data. 


\begin{abstract}
:
This paper studies the pro-poor growth in the Latino American Andean countries. We first present different definitions of pro-poorness and the related methods in order to generate the statistically robust results for classes of pro-poor measures. Also, we present the non anonymous pro-poor approach and we propose also a new method to study the inter-temporal pro-poor growth with the aim to capture the change of wellbeing of the poor over time. We apply these procedures to five L.A. countries, which are Ecuador, Colombia, Peru, Bolivia and Venezuela for the period between 2005 and 2010. In general, we find strong statistical evidence that the Andean L.A. countries growths have been absolutely and relatively pro-poor for the period between 2005 and 2010 . However, the 2008 world economic crisis has affected temporarily growth and the latter was not absolutely pro-poor during this economic crisis. Starting from 2009, the L.A. countries have registered a remarkable economic recovery. This recovery has helped to growth to absolutely pro-poor and thus, to continue to reduce poverty in this region of world.
\end{abstract}

Keywords: Pro-poor growth, poverty, inequality

JEL Classification: D63, D64 


\section{Table of Contents}

1 Introduction 1

1.1 Background . . . . . . . . . . . . . . . . . 1

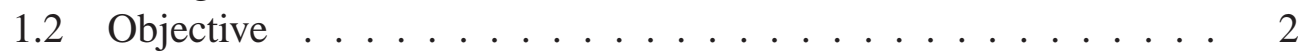

2 The theoretical framework 3

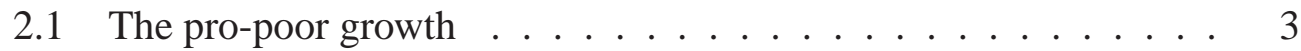

2.1 .1 Relative pro-poor judgements .......... . 5

2.1.2 Evaluating absolute pro-poorness . . . . . . . . 7

2.2 Pro-poor growth and poverty reduction . . . . . . . . . . . 8

2.3 Anonymous and non-anonymous pro-poverty . . . . . . . . . 9

2.4 Inter-temporal wellbeing and pro-poor growth . . . . . . . . 11

$3 \quad$ Estimation and statistical inference 12

3.1 Null and alternative hypotheses for testing pro-poorness of growth 12

3.2 Estimation and sampling variability . . . . . . . . . . . 14

4 Has growth in Andean economies been pro-poor between 2005 and 2010? 17

4.1 The Peruvian case . . . . . . . . . . . . . . . 17

4.1.1 The Peruvian data ............. . . . 17

4.1.2 Growth, poverty and inequality trends in Peru . . . . . . . 18

4.1.3 The pro-poorness of growth in Peru . . . . . . . . . . 19

4.1.4 The non-anonymous pro-poorness of growth and mobility in Peru 20

4.2 The Ecuadorian case ... . . . . . . . . . . 21

4.2.1 The Ecuadorian data . . . . . . . . . . . . . 21

4.2.2 Growth, poverty and inequality trends in Ecuador . . . . . 22

4.2.3 The pro-poorness of growth in Ecuador . . . . . . . . 23

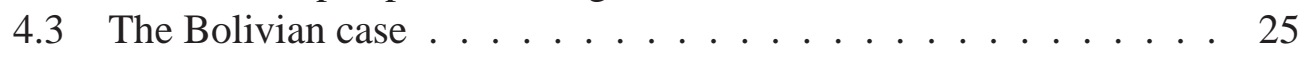

4.3 .1 The Bolivian data . . . . . . . . . . . . . . 25

4.3.2 Growth, poverty and inequality trends in Bolivia . . . . 26

4.3.3 The pro-poorness of growth in Bolivia . . . . . . . . . . 26

4.4 The venezuelan case . . . . . . . . . . . . . . . . . 27

4.4 .1 The venezuelan data .............. . 27

4.4.2 The trend of growth, poverty and inequality in Venezuela . 28

4.4.3 The pro-poorness of growth in Venezuela . . . . . . . . . 28

4.5 The Colombian case . . . . . . . . . . . . . . . . . . . . . 29

4.5.1 The Colombian data ............... . . 29

4.5.2 The trend of growth, poverty and inequality in Colombia . 30 
4.5 .3 The pro-poorness of growth in Colombia . . . . . . . 30

5 A comparative analvsis of pro-poorness of growth in the L.A. Andean countries 31 5.1 The trend of growth, poverty and inequality ... . . . . . 32

5.2 The absolute and relative pro-poorness of growth in LA countries . 33

6 Lessons and conclusions 33

$\begin{array}{ll}\text { The Peruvian results } & 37\end{array}$

$\begin{array}{ll}\text { The Ecuadorian results } & 57\end{array}$

$\begin{array}{ll}\text { The Bolivian results } & 71\end{array}$

The Venezuelan results $\quad 88$

The Colombian results 102

The Latino American Andean countries results 116 


\section{Introduction}

\subsection{Background}

During the two last decades, the level of interdependence between the country economies has increased sharply. This has been associated with a combination of events including the fall of socialist economic system, the acceleration of international trade liberalization, the birth of new economic communities such as the European Community, and the revolution in communications and information management. Even if the environment of this new era has contributed to improved economic efficiency at the global level, the associated distributive effects remain poorly documented. Greater economic interdependence has also strengthened linkages of economic shocks. In recent years, economists have become more familiar with the global nature of economic shocks and how economic troubles in one country may deeply affect the economy of another. For fragile developing countries, it is crucial to understand the nature of each economic shock and how it can affect theirs various economic sectors. The increasing frequency of the world economic crisis makes the economic performance of developing countries more volatile. Public interventions are thus required to ensure an economic environment that better supports the poor and to help the most affected populations during periods of economic crisis. For many decades, Latin America (L.A. ) in general — and Andean countries in particular — was the most unequal region in the world. Its achievements with respect to poverty reduction are vulnerable to a reversal in the pace of growth. In this region, many social programs were designed and implemented to support the extremely poor and to help vulnerable populations return to economic activity. The design and targeting of these social programs have been continuously improved. Over the last decade, the economic performance of Latin American countries has been good, but their economic growth was deeply impacted by the 2008 economic crisis.

Progress in poverty reduction strategies across the region has been reported in all Andean countries, especially over the second half of the last decade. However, little is known about the distributional effects of this recent period of rapid growth and how it compares with the previous growth periods in terms of poverty reduction. Assessing the pro-poorness of growth, and its consequences, has become a common topic for policy discussion in development economics circles. Analyzing distributional changes during the expansion phase of the economic cycle and determining how pro-poor these changes is an area of research that continues to be conceptually and empirically challenging. For instance, policy-oriented dis- 
cussions on how to define pro-poor growth or on the proper measure of poverty to be used 1 have been recently followed by theoretical works about the importance of income mobility when analyzing the pro-poorness of growth.2 Whether considering its absolute or relative definition, and under both anonymous or nonanonymous assumptions, the analysis of the pro-poorness of changes in the income distribution presents a question that calls for an empirical answer.

Given the falling poverty headcount ratios in the Andean region, it can easily be assumed that recent growth has been pro-poor according to the broader (absolute and anonymous) definition. However, the question of whether this absolute pro-poor growth is also relatively pro-poor (even non-anonymously) has yet to be answered. More importantly, the potential sources of absolute pro-poor growth also need to be determined. For example, some authors (e.g. Kraay (2004)) apply standard poverty decomposition techniques to identify three potential sources of pro-poor growth: $(C 1)$ a high rate of growth of average incomes; $(C 2)$ a high sensitivity of poverty to growth in average incomes; and $(C 3)$ a poverty-reducing pattern of growth in relative incomes. The analysis of the pro-poorness of the most recent growth episode in the Andean countries has yet to have been carried out rigorously. An empirical response to related questions would contribute to the ongoing debate about the distributional effects of the recent period of rapid growth experienced in the Latin American and Caribbean region.

\subsection{Objective}

The main objective of this paper is to empirically assess the pro-poorness of distributive changes over the last cycle of expansion, contraction and recovery (2005-2010) in five Andean countries (Ecuador, Colombia, Peru, Bolivia and Venezuela). The goal is to empirically evaluate the pro-poorness of distributive changes using the framework developed in Duclos and Wodon (2004) and following the methodological approach of Araar, Duclos, Audet, and Makdissi (2007).

\footnotetext{
${ }^{1}$ First, we have absolute pro-poor growth, which is growth that reduces poverty (Ravallion and Chen (2003)). Secondly, there is relative pro-poor growth, which refers to a situation where poverty falls by more than it would have if all incomes had grown at the same rate (McCulloch and Baulch (2000); Kakwani and Pernia (2000))

${ }^{2}$ Most conventional growth incidence analysis is presented in a framework of anonymity, which in this context refers to the assumption that exchanging the incomes of any two individuals in any given distribution should not affect the evaluation of pro-poorness. Most recent contributions (Araar, Duclos, Audet, and Makdissi (2009); Bourguignon (2011)) lift this assumption and explore the consequences on distributional analyses
} 
We aim to apply these techniques: to obtain judgments for absolute and relative pro-poorness of growth in the 2005-10 period; to assess the marginal pro-poorness of the collapse in growth in 2008/09 and the subsequent recovery in 2009/10; to learn about the effects on income mobility and the durability of the distributional effects; and to find some conclusions and implications for policy from the regional comparisons. Among the criticisms that can be leveled at the non-anonymous propoor growth approach is its dependence on a reference period to define the poor (see Bourguignon (2011)). Our work contains a new theoretical framework to analyze pro-poor growth in a dynamic manner, where the poor are considered in the initial and final period.

In practice, household surveys are needed to check whether growth is propoor. We must therefore consider issues relating to estimation, sampling variability and statistical inference. We start by proposing sets of null and alternative hypotheses to test for the absolute and relative pro-poorness of growth. We then define various estimators of the statistics of interest and derive their sampling distribution taking full account of the complexity of the usual sampling design, and of the fact that these statistics of interest typically involve non-linear combinations of estimators from different, though sometimes dependent samples. This enables us, among other things, to estimate confidence intervals around the differences that must be signed in order to conclude that a change has been robustly pro-poor or not.

The rest of the paper is structured as follows. Section 2 presents the measurement framework. Section 3 deals with issues of estimation and statistical inference. Section 4 applies measurement and statistical techniques to study pro-poor growth in each of the five Latin American countries being studied. A comparative study and summary of the results with respect to pro-poorness is presented in section 5.2. Section 6 concludes.

\section{The theoretical framework}

\subsection{The pro-poor growth}

There is a direct connection between the normative judgment of poverty and that of pro-poorness 3 Two distinct norms to define poverty can be found in the

\footnotetext{
${ }^{3}$ See, among many recent contributions to the debate, Bourguignon (2003), Bruno, Ravallion, and Squire (1998), Dollar and Kraay (2002), Eastwood and Lipton (2001), United Nations (2000), and World Bank (2000).
} 
literature. The first is absolute poverty and refers to people with an income below a predefined shortcut cutoff. With this absolute norm, we only consider the individual's ability to consume and to meet their basic requirements. The second is relative poverty and refers to people with an income below some threshold relative to the wealth of the general population. We can start from here to state that the definition of pro-poorness is closely linked to that of poverty. We can also claim that a distributive change is pro-poor if it helps reduce poverty, as can be defined above.

In this paper, we follow the definition of pro-poorness used by Duclos (2009) 4 Absolute pro-poorness refers to a situation where incomes of the poor grow by an absolute amount that is no less than some norm (often set to zero). Relative pro-poorness requires the increase in the incomes of the poor to be greater than some norm (often mean income growth) 5 The framework of Duclos (2009) also makes it possible to overcome the difficulty of having to choose 1) a poverty line to separate the poor from the non-poor, and 2) a set of normative weights to differentiate among the poor. The framework does this by investigating how evaluations of pro-poorness can be made robust across a wide classes of pro-poor evaluation functions and over a range of poverty lines.6

Formally, let $\mathbf{y}_{1}=\left(y_{1}^{1}, y_{2}^{1}, \cdots, y_{n_{1}}^{1}\right) \in \Re_{+}^{n_{1}}$ be a vector of non-negative initial incomes] (at time 1) of size $n_{1}$, and let $\mathbf{y}_{2}=\left(y_{1}^{2}, y_{2}^{2}, \cdots, y_{n_{2}}^{2}\right)$ be an analogous vector of incomes (at time 2) of size $n_{2}$.

First consider the case of a relative standard, which is simply the average growth rate, denoted by $g$. Let $W\left(\mathbf{y}_{1}, \mathbf{y}_{2}, g, z\right)$ be the pro-poor evaluation function that we want to use, where $z>0$ denotes the poverty line. It is defined as

\footnotetext{
${ }^{4}$ Also see Araar, Duclos, Audet, and Makdissi (2009)

${ }^{5}$ Although absolute poverty is usually of greater concern in developing countries, interest in relative poverty has nevertheless gained significant ground in developed economies (see among many other Atkinson, Cantillon, Marlier, and Nolan 2002) and it is also emerging as an important issue in developing countries too. This emerging importance may be because inequality may limit growth (see for instance Alesina and Rodrik 1994 and Deininger and Squire 1998), because it is typically associated with lower poverty reductions for a given level of economic growth, because it breeds relative deprivation, economic isolation and social exclusion, or because it can be deemed a problem in and of itself for well-known ethical reasons-such as those developed in Rawls (1971).

${ }^{6}$ Many different approaches have been proposed to distinguish between the poor and the non-poor, and to compute and aggregate pro-poorness indices. See, for instance, McCulloch and Baulch (1999), Kakwani, Khandker, and Son (2003), Kakwani and Pernia (2000), Ravallion and Chen (2003), Klasen (2004), Essama-Nssah (2005), Ravallion and Datt (2002), Son (2004) and Essama-Nssah and Lambert (forthcoming).

${ }^{7}$ Or consumption, wealth, or any other welfare indicator of interest. Also see Klasen (2008) for a discussion of measurement issues in non-income dimensions.
} 
the difference between two evaluation functions $\Pi\left(\mathbf{y}_{1}, z\right)$ and $\Pi^{*}\left(\mathbf{y}_{2}, g, z\right)$, each for time 1 and time 2, respectively, and which are analogous to poverty indices for each of the two time periods:

$$
W\left(\mathbf{y}_{1}, \mathbf{y}_{2}, g, z\right) \equiv \Pi^{*}\left(\mathbf{y}_{2}, g, z\right)-\Pi\left(\mathbf{y}_{1}, z\right) .
$$

The change from $\mathbf{y}_{1}$ to $\mathbf{y}_{\mathbf{2}}$ will be deemed pro-poor if $W\left(\mathbf{y}_{1}, \mathbf{y}_{2}, g, z\right) \leq 0$. The social welfare function of $W$ have the following basic axioms. The first is a focus axiom, through which $W$ is not sensitive to marginal changes in values of $\mathbf{y}_{1}$ that exceed $z$. The second is a population invariance axiom, which says that adding a replication of a population to that same population has no impact on $W$. A third axiom is that of anonymity: permuting the incomes of any two persons in any given distribution should not affect pro-poor judgements. A fourth normalization axiom says that in the absence of distributional change (and also with no change in mean income), then $W=0$. A fifth monotonicity axiom imposes that, for a given $g$, if anyone's posterior income increases, $W$ should not increase, and may sometimes fall. A sixth distribution sensitivity axiom says that the evaluation functions $\Pi$ should give more weight to the poorer than to the not-so-poor among the poor: shifting incomes from the richer to the poorer is by itself a pro-poor distributional change. This axiom is also known as the Pigou-Dalton principle in the welfare literature.

\subsubsection{Relative pro-poor judgements}

Let $F_{j}(y)$ be the distribution function of distribution $j$. Also define as $Q_{j}(p)$ the quantile function for distribution $F_{j}$. This is formally defined as $Q_{j}(p)=$ $\inf \left\{s \geq 0 \mid F_{j}(s) \geq p\right\}$ for $p \in[0,1]$. With a continuous distribution and a strictly positive income density, $Q(p)$ is simply the inverse of the distribution function, and is the income of the individual at rank $p$ in the distribution. The FGT indices (Foster, Greer, and Thorbecke 1984) are then given by:

$$
P_{j}(z ; \alpha)=\int_{0}^{F_{j}(z)}\left(1-Q_{j}(p) / z\right)^{\alpha} d p .
$$

$P_{j}(z ; \alpha=0)$ is the headcount index (and the distribution function) at $z$, and $P_{j}(z ; \alpha=1)$ is the average poverty gap.

The class $\Omega^{1}\left(g, z^{+}\right)$regroups all of the functions $W$ that satisfy the focus, population invariance, anonymity, monotonicity, normalization and relative axioms, 
and for which $z \leq z^{+}$. Duclos (2009) shows that a movement from $\mathbf{y}_{\mathbf{1}}$ to $\mathbf{y}_{\mathbf{2}}$ will be judged as pro-poor by all such functions if and only if

$$
P_{2}((1+g) z ; \alpha=0) \leq P_{1}(z ; \alpha=0) \text { for all } z \in\left[0, z^{+}\right] .
$$

Verifying (3) simply involves checking whether-over the range of poverty lines $\left[0, z^{+}\right]$- the headcount index in the initial distribution is larger than the headcount index in the posterior distribution when that distribution is normalized by $1+g$. An alternative and equivalent way of checking whether a distributional change can be declared first-order relatively pro-poor is to compare the ratio of the quantiles and $(1+g)$, or, if $g$ is growth in mean income, to compare the growth of the quantiles to growth of the mean. That is, we check whether, for all $p \in\left[0, F_{1}\left(z^{+}\right)\right]$,

$$
\operatorname{an}-\operatorname{GIC}(p)=\frac{Q_{2}(p)-Q_{1}(p)}{Q_{1}(p)} \geq g .
$$

Using (4) is equivalent to Ravallion and Chen (2003)'s suggestion to use "growth incidence curves" to check whether growth is pro-poor. These curves show the growth rates of living standards at different ranks in the population.

The class $\Omega^{2}\left(g, z^{+}\right)$is a sub set of $\Omega^{1}\left(g, z^{+}\right)$and where the evaluation function obeys to the distribution sensitivity axiom (sensitive to the situation of the poorer group). First-order pro-poor judgements can be demanding in expansion periods. A movement from $\mathbf{y}_{\mathbf{1}}$ to $\mathbf{y}_{\mathbf{2}}$ will be judged pro-poor by all pro-poor evaluation function $\Omega^{2}\left(g, z^{+}\right)$if and only if

$$
P_{2}((1+g) z ; \alpha=1) \leq P_{1}(z ; \alpha=1) \text { for all } z \in\left[0, z^{+}\right] .
$$

Verifying (5) simply involves checking whether the average poverty gap in the initial distribution is larger than that in the posterior distribution when that distribution is normalized by $1+g$ and this, over the range of poverty lines $\left[0, z^{+}\right]$. An alternative way of checking condition is by using the Generalized Lorenz curve. A distributional change is second-order relatively pro-poor if for all $p \in\left[0, F_{2}\left((1+g) z^{+}\right)\right]$,

$$
\lambda(p) \equiv \frac{C_{2}(p)}{C_{1}(p)} \geq 1+g .
$$

Expression (6) involves computing the growth rates in the cumulative incomes of proportions $p$ of the poorest, and to compare 8 those growth rates to $g$. For $1+g$

\footnotetext{
${ }^{8}$ This is similar to a condition provided by Son (2004), with the difference that (6) is there
} 
equal to the ratio of mean income, condition (6) is equivalent to checking whether the Lorenz curve for $\mathbf{y}_{2}$ is above that of $\mathbf{y}_{1}$ for the range of $p \in\left[0, F_{2}\left((1+g) z^{+}\right)\right]$.

\subsubsection{Evaluating absolute pro-poorness}

Absolute pro-poorness can be confirmed by comparing the absolute change in the income of the poor to some standard, denoted by $a$ and usually set to zero. The axiom of absolute pro-poorness essentially says that $\Pi^{*}$ should be "translation invariant" in $\mathbf{y}$ and $a$, i.e., that the evaluation with respect to pro-poorness should be neutral whenever the absolute gains of the poor are the same as the standard $a$. This reference point is consistent with the view that a change is good for the poor if it increases the poor's absolute living standards (e.g., Ravallion and Chen 2003). Hence, the absolute axiom requires that if $\mathbf{y}+a=\mathbf{y}^{\prime}$, then $W\left(\mathbf{y}, \mathbf{y}^{\prime}, \mathbf{a}, \mathbf{z}\right)=0$.

This allows us to formally define the class of first-order absolute pro-poor evaluation functions $\tilde{\Omega}^{1}\left(a, z^{+}\right)$as being comprised of all functions $W(\cdot, \cdot, a, z)$ that satisfy the focus, population, anonymity, monotonicity, normalization and absolute axioms, and for which $z \leq z^{+}$. We will later set $a$ to zero in the empirical section of this paper.

It can then be shown that a movement from $\mathbf{y}_{1}$ to $\mathbf{y}_{\mathbf{2}}$ is deemed to be first-order absolutely pro-poor (that is, pro-poor by all evaluation functions $W(\cdot, \cdot, a, z)$ that are members of $\left.\tilde{\Omega}^{1}\left(a, z^{+}\right)\right)$if and only if

$$
P_{2}(z+a ; \alpha=0) \leq P_{1}(z ; \alpha=0) \text { for all } z \in\left[0, z^{+}\right] .
$$

An equivalent way of checking whether a distributional change can be declared to be first-order absolutely pro-poor is to compare the absolute change in the values of the quantiles for all $p \in\left[0, F_{1}\left(z^{+}\right)\right]$:

$$
Q_{2}(p)-Q_{1}(p) \geq a .
$$

A similar condition holds when evaluating absolute second-order propoorness. These evaluations are based on the $\tilde{\Omega}^{2}\left(a, z^{+}\right)$class of indices, which is defined similarly to $\tilde{\Omega}^{1}\left(a, z^{+}\right)$, but with the additional requirement of distribution sensitivity. A movement from $\mathbf{y}_{1}$ to $\mathbf{y}_{\mathbf{2}}$ is then said to be second-order absolutely pro-poor if and only if

$$
(z+a) P_{2}\left((z+a ; \alpha=1) \leq z P_{1}(z ; \alpha=1) \text { for all } z \in\left[0, z^{+}\right] .\right.
$$

checked over all $p \in[0,1]$. 
A sufficient condition for (9) is then to verify whether, for all $p \in\left[0, F_{2}\left(z^{+}+a\right)\right]$, the change in the average income of the bottom $p$ proportion of the population is larger than $a$ :

$$
\frac{C_{2}(p)-C_{1}(p)}{p} \geq a
$$

\subsection{Pro-poor growth and poverty reduction}

To clearly show the connection between the growth pattern and poverty, Kraay (2004) proposes decomposition of a change in poverty over time into three components: $(C 1)$ the growth rate of average incomes; $(C 2)$ the sensitivity of poverty to growth in average incomes; and (C3) a poverty-reducing pattern of growth in relative incomes. In this paper, we propose to use this approach to show the importance of each of these three components for changes in poverty. For the class of additive poverty indices, their general definition can take the following form:

$$
P(\pi, z)=\int_{0}^{1} \pi(Q(p), z) d p .
$$

where $\pi(Q(p), z)$ is the contribution of those with an income of $Q(p)$ to the total poverty index. It follows that over time $(t)$, the change in poverty is indicated by the change in quantile values. If we denote the semi-elasticity of $\pi(Q(p), z)$ with respect to $Q(p)$ by $\eta(p)=(\partial \pi(Q(p), z) / \partial Q(p)) Q(p)$, we can write:

$$
\frac{d P(\pi, z)}{d t}=\int_{0}^{1} \eta(p) g(p) d p
$$

where $g(p)$ is the growth rate at the $p^{\text {th }}$ percentile of income 9 Starting from equation (12), Kraay (2004) proposes developing this formula as follows:

$$
\frac{d P(\pi, z)}{d t}=g \int_{0}^{1} \eta(p) d p+\int_{0}^{1} \eta(p)(g(p)-g) d p .
$$

The first term of equation (13) captures two sources of pro-poor growth, namely, the growth in average income and the sensitivity of the poverty index to growth.

\footnotetext{
${ }^{9}$ Note that for the class of Foster, Greer, and Thorbecke (1984) poverty indices, when $\alpha \geq 1$, $\eta(p)=-\frac{\alpha Q(p)}{z}(1-Q(p) / z)_{+}^{\alpha-1}$. When $\alpha=0$, we have $\eta(p)=-z$ if $Q(p)=z$, and is 0 otherwise. In such cases, we have $d P(\pi, z) / d t=-z f(z) g\left(F^{-1}(z)\right)$.
} 
The second part captures the impact of changes in relative incomes. Starting from this, we can conclude that the significant decrease in poverty may result from higher sensitivity of poverty to growth or from higher growth in average income. Of course, this will also depend on the index used to quantify poverty. Further, the proposed decomposition converges to that proposed by Datt and Ravallion (1992), the first part of which can be assigned to the growth component, and the second can be assigned to the redistribution or inequality component. Let $g(p)_{+}=g(p)$ if $Q(p)<z$ and zero otherwise. Starting from equation (12), one can propose another form of decomposition:

$$
\frac{d P(\pi, z)}{d t}=\bar{g} \bar{\eta}+\operatorname{Cov}(g(p), \eta(p)) .
$$

where $\bar{g}$ and $\bar{\eta}$ are the averages of the $g(p)_{+}$and $\eta(p)$ respectively. If $g_{p}$ is used to denote the growth in average income of the poor, we arrive at an extended decomposition.

$$
\frac{d P(\pi, z)}{d t}=\frac{g_{p}}{g} \frac{\bar{g}}{g_{p}} g \bar{\eta}+\operatorname{Cov}(g(p), \eta(p)) .
$$

Hence, the optimal path of growth to quickly and substantially reduce poverty comes from a combination of higher income growth among the poor and higher sensitivity of poverty to income growth. The last condition in turn implies higher covariance between $g(p)$ and $\eta(p)$. Equation (14) shows that poverty can coexist with greater inequality when income growth among the poor is sufficient to enable them to escape poverty. To what extent is the observed path optimal to efficiently reduce poverty? The income of a given poor person $i$ must grow by $\left(z / y_{1, i}-1\right)$ to escape poverty. The $\gamma\left(p=F\left(y_{i}\right)\right)=\left(y_{2, i}-y_{1, i}\right) /\left(z-y_{1, i}\right)$ ratio quantifies the change in income relative to the poverty line. The $\gamma(p)$ curve may be useful to show whether the observed growth path converges to the optimal state.

\subsection{Anonymous and non-anonymous pro-poverty}

As reported already, among the basic tools to assess pro-poor growth is the Growth Incidence Curve proposed by Ravallion and Chen (2003). This curve simply shows the growth of the $p^{t h}$ percentile income. Obviously, the $p^{t h}$ percentile or quantile of income does not refer to the same person after income growth has occurred. This conforms to the anonymous axiom that most of distributive indices must obey. What do we fail to capture by maintaining this axiom? Even with propoor growth, chronic poverty may persist or grow. Moreover, it is socially less 
desirable to design growth policies that can lead to the horizontal inequity. This follows the Pareto principal in that it states that an improvement in the wellbeing of one person should not reduce the wellbeing of another person in a society.

The non-anonymous growth incidence curve (henceforth na-GIC) measures the income growth rate of the same individual. Bourguignon(2011) and Grimm (2007a) have already suggested relaxing the anonymity axiom in cases where the na-GIC curves may reveal additional information about income mobility. Jenkins and Kerm (2006), Kerm (2009) and Grimm (2007b) have shown how different results can be obtained from standard and non-anonymous GICs. Relaxing the anonymous axiom makes it possible to re-formalize a problem in order to focus on other topics that involve non-anonymous changes in incomes, such as income mobility, progressivity, etc. In this paper, we propose to continue to focus on the welfare of the poor, and do this by considering them in two periods. Two main related ethical questions can be raised:

- Is the situation of the poor, defined in the initial period, is better than that in the final period?

- Is the situation of the poor, defined in the finale period, is worse than that in the initial period?

Measures of anonymous pro-poor can fail to capture the impact of re-ranking or mobility on poverty. Non-anonymous curves, based on the initial or final reference periods, can provide additional information. Socially, it is desirable to observe that the non-anonymous GIC curves with the two periods of reference lie above the null horizontal line. This would indicate a situation of pro-poor growth without re-ranking or a downward mobility. Let $\Phi\left(\mathbf{y}_{\mathbf{i}} \mid \mathbf{y}_{\mathbf{j}}\right)$ denote the conditional income distribution function in period $i$, conditional on incomes in period $j$. Let $r$ denote the reference period ( $r \in\{1=$ initial, $2=$ final $\}$ ). The non-anonymous GIC, with the initial period as the point of reference can be defined as follows:

$$
\text { na-GIC }_{1}(p, r=1)=\frac{\int y_{2} d \Phi\left(y_{2} \mid Q 1(p)\right)}{Q_{1}(p)}-1 \text {. }
$$

The definitional framework is similar to that of Bourguignon (2011). The numerator $\int y_{2} d \Phi\left(y_{2} \mid Q_{1}(p)\right)$ can be viewed as the expected income of individuals with an initial income of $Q 1(p)$; this makes the na-GIC smooth and allows us to have a continuous distribution of incomes across the population. By considering the poor group in final period, the non-anonymous GIC with the initial period as the 
point of reference can be defined as follows:

$$
\text { na-GIC }_{2}(p, r=1)=\frac{Q 2(p)}{\int y_{1} d \Phi\left(y_{1} \mid Q 2(p)\right)}-1 \text {. }
$$

This curve estimates the proportional change in initial period incomes (reference period $r=1$ ) of those with incomes $Q_{2}(p)$ (the ranking is that of the final period). Thus, this curve can be used to show the income growth of the poor. Another way to assess the proportion of the change in income of the poor in the final period is to use the final period as the point of reference. Formally, we can write:

$$
\text { na-GIC }_{2}(p, r=2)=1-\frac{\int y_{1} d \Phi\left(y_{1} \mid Q 2(p)\right)}{Q_{2}(p)} .
$$

How can we interpret this curve? Assume that the income of poor individual $i$ in the final period is $y_{i, 2}=Q_{2}(p=0.3, r=2)=8$, and his income in the first period is $Q_{i, 1, r=2}(p=0.3)=5$. Then, the increase in income with the final period as the reference period is $3 / 8$. Thus, this curve simply expresses the proportion of change in income relative to the final period income. For pro-poor curves, which usually show income growth (unidirectional change in wellbeing) it is trivial that we have to express the change with respect to the initial period. As we will see below, expressing the change with respect to the final period may support analysis of the change in the wellbeing of the poor over time.

\subsection{Inter-temporal wellbeing and pro-poor growth}

Here, we propose to move beyond the classical view of pro-poor growth and to put it into its larger context. More specifically, in this subsection we develop what we can call intertemporal pro-poor growth. Mainly, we aim to avoid arbitrariness in selecting the reference period used to specify who is poor. Evidently, it is socially desirable to focus on the dynamics of the wellbeing of the poor outside of the reference period. How can we deal with this? Assume that the $(*)$ denotes the merged distributions of the two periods. Formally, $Q^{*}(p)$ is the income of the $p^{\text {th }}$ percentile person with an income of $y=Q^{*}(p)$ in either of the two periods. Why do we use this trick?

- In this merged distribution, poor individuals with the same level of income in the initial and final periods are treated equally and will have the same percentile or rank. 
- Also, since each individual appears twice in this merged distribution, we can weigh the estimated statistics in the additive indices by half.

The expected proportional change in income of the poor $\left(Q^{*}(p)<z\right)$ is then:

$$
\begin{aligned}
\operatorname{IGIC}(p) & =0.5\left[\left(\frac{\int y_{2} d \Phi\left(y_{2} \mid Q^{*}(p)\right)}{Q^{*}(p)}-1\right)+\left(1-\frac{\int y_{1} d \Phi\left(y_{1} \mid Q^{*}(p)\right)}{Q^{*}(p)}\right)\right] \\
& =0.5\left[\int y_{2} d \Phi\left(y_{2} \mid Q^{*}(p)\right)-\int y_{1} d \Phi\left(y_{1} \mid Q^{*}(p)\right)\right] / Q^{*}(p)
\end{aligned}
$$

When the IGIC curve lies above the null horizontal line, we can conclude that the proportion of individual that have an income of $y=Q^{*}(p)<z$ and experience a negative income movement is lower than that of those with a positive movement of income. In such as case, we have a pro-poor income mobility (the case of a predominant upward structural mobility), since the income of the poor is more likely to increase in the long term.

\section{Estimation and statistical inference}

We use household data surveys to estimate distributive indices or curves. However, this type of data only covers a subset of the reference population. Even when every effort is made to obtain a representative sample across the population, sampling error still occurs. This forces us to deal with issues of estimation, sampling variability and statistical inference. Indeed, an empirical difference in some statistical results between samples may not be strong enough to reach a statistically significant conclusion. Although the importance of this point is increasingly well understood in the literature on applied poverty measurement, it raises methodological issues that are not straightforward in the context of this paper. Namely, we are presently interested in dominance tests over ranges of parameter values, and in statistics that are non-linear functions of estimators estimated in different (dependent or independent) samples. We consider these issues in turn.

\subsection{Null and alternative hypotheses for testing pro-poorness of growth}

Verifying each of the conditions noted above in sections 2.1.1 and 2.1.2 involves testing whether $\Delta^{s}(z) \leq 0$ or $\Delta^{s}(p) \geq 0$ over some range of $z$ or $p$. This 
thus requires joint tests over a set of null hypotheses. For primal tests of propoorness (tests which use estimators based on monetary thresholds $z$ ), our null hypothesis is thus formed as a union of null hypotheses,

$$
H_{0}: \Delta^{s}(z)>0 \text { for some } z \in\left[0, z^{+}\right],
$$

to be tested against an alternative hypothesis that considers an intersection of alternative hypotheses,

$$
H_{1}: \Delta^{s}(z) \leq 0 \text { for all } z \in\left[0, z^{+}\right] .
$$

For dual tests (those that use estimators based on percentiles $p$ ), we formulate a union of null hypotheses,

$$
H_{0}: \Delta^{s}(p)<0 \text { for some } p \in\left[0, \mathbb{F}\left(z^{+}\right)\right],
$$

to be tested against an intersection of alternative hypotheses,

$$
H_{1}: \Delta^{s}(p) \geq 0 \text { for all } p \in\left[0, \mathbb{F}\left(z^{+}\right)\right],
$$

where $\mathbb{F}\left(z^{+}\right)$is a function of $z^{+}$. Our decision rule is to only reject the union set of null hypotheses in favour of the intersection set of alternative hypotheses if we can reject each of the individual hypotheses in the null set at a $100 \cdot \theta \%$ significance level. This can be conveniently done by calculating the $100 \cdot(1-$ $\theta) \%$ one-sided confidence intervals, an approach that we use repeatedly in the empirical application below.

More specifically, let $\hat{\Delta}^{s}(z)$ be the sample estimator of $\Delta^{s}(z)$, let $\Delta_{0}^{s}(z)$ be its sample value, and let $\sigma_{\hat{\Delta}^{s}(z)}^{2}$ be the sampling variance of $\hat{\Delta}^{s}(z)$. Also, let $\zeta(\theta)$ be the $(1-\theta)^{t h}$ quantile of the normal distribution. Given that, by the law of large numbers and the central limit theorem, all of the estimators used in this paper can be shown to be consistent and asymptotically normally distributed, we can use $\Delta_{0}^{s}(z)+\sigma_{\hat{\Delta}^{s}(z)} \zeta(\theta)$ as the upper bound of a one-sided confidence interval for $\Delta^{s}(z)$. A confidence interval with an upper bound of $\Delta_{0}^{s}(z)+\sigma_{\hat{\Delta}^{s}(z)} \zeta(\theta)$ shows all values of $\eta$ for which we cannot reject null hypothesis $H_{0}: \Delta^{s}(z)>\eta$ in favour of $H_{1}: \Delta^{s}(z) \leq \eta$. Setting $\eta=0$ (see (20) and (21)), our decision rule is then to reject the set of null hypotheses (20) in favour of (21) if:

$$
\Delta_{0}^{s}(z)+\sigma_{\hat{\Delta}^{s}(z)} \zeta(\theta)<0 \forall z \in\left[0, z^{+}\right] .
$$

For dual tests, we proceed with a similarly approach to (24), except that the 
signs in (22) and (23) are inverted. We thus obtain a confidence interval of $\Delta_{0}^{s}(p)-$ $\sigma_{\hat{\Delta}^{s}(p)} \zeta(\theta)$ and reject (22) in favour of (23) if

$$
\Delta_{0}^{s}(p)-\sigma_{\hat{\Delta}^{s}(p)} \zeta(\theta)>0 \forall p \in\left[0, F\left(z^{+}\right)\right]
$$

for some distribution function $F$.

\subsection{Estimation and sampling variability}

We now need to define and assess $\hat{\Delta}^{s}(z), \hat{\Delta}^{s}(p), \sigma_{\hat{\Delta}^{s}(z)}$ and $\sigma_{\hat{\Delta}^{s}(p)}$. As we will see, these statistics are non-linear functions of estimators that are estimated across different (dependent or independent) samples, so estimating their sampling variability involves difficulties that do not arise for simpler statistics (such as for FGT indices with deterministic poverty lines).

Let $N_{j}$ be a number of independently and identically distributed sample observations of incomes drawn from distribution $j: y_{j}^{1}, \ldots, y_{j}^{N}$. With $f_{+}=\max (f, 0)$, a natural estimator of the FGT index $P_{j}((1+g) z ; \alpha)$ is given by

$$
\hat{P}_{j}((1+\hat{g}) z ; \alpha)=N_{j}^{-1} \sum_{h=1}^{N_{j}}\left(\frac{(1+\hat{g}) z-y_{j}^{h}}{(1+\hat{g}) z}\right)_{+}^{\alpha}
$$

where

$$
1+\hat{g}=\hat{\mu}_{2} / \hat{\mu}_{1}
$$

and

$$
\hat{\mu}_{j}=N_{j}^{-1} \sum_{h=1}^{N_{j}} y_{j}^{h}
$$

The $p^{t h}$ quantile $Q_{j}(p)$ is estimated as

$$
\hat{Q}_{j}(p)=\min \left(y \mid \hat{F}_{j}(y) \geq p\right)
$$


and the empirical distribution function is given by

$$
\hat{F}_{j}(y)=\hat{P}_{j}(z ; 0)
$$

Note that there are two sources of sampling variability in (26): the first comes from the summation of random sample observations (assuming $g$ is known),

$$
\hat{P}_{j}((1+g) z ; \alpha)=N_{j}^{-1} \sum_{h=1}^{N_{j}}\left(\frac{(1+g) z-y_{j}^{h}}{(1+g) z}\right)_{+}^{\alpha}
$$

and the second comes from sampling variability in the estimator $\hat{g}$. A first-order approximation to (26) yields

$$
\begin{aligned}
& \hat{P}_{2}((1+\hat{g}) z ; \alpha)-P_{2}((1+g) z ; \alpha)=\hat{P}_{2}((1+g) z ; \alpha)-P_{2}((1+g) z ; \alpha) \\
& \quad+((1+g) z) P_{2}^{g z}((1+g) z ; \alpha)\left(\frac{\hat{\mu}_{2}-\mu_{2}}{\mu_{2}}-\frac{\hat{\mu}_{1}-\mu_{1}}{\mu_{1}}\right) \\
& \quad+o\left(N_{2}^{-1 / 2}\right)
\end{aligned}
$$

where

$$
\begin{aligned}
& P_{2}^{g z}((1+g) z ; \alpha)=\alpha((1+g) z)^{-1}\left(P_{2}((1+g) z ; \alpha-1)-P_{2}((1+g) z ; \alpha)\right)(33 \\
& \quad \text { for } \alpha>0 \text { and }
\end{aligned}
$$

$$
P_{2}^{g z}((1+g) z ; 0)=f_{2}((1+g) z)>0
$$

which is the density at $(1+g) z$ for $\alpha=0$. The $P_{2}^{g z}((1+g) z ; \alpha)$ terms are constants that can be estimated from the samples and are proportional to the effect of $\hat{g}$ 's sampling variability on the sampling variability of $\hat{P}_{2}((1+\hat{g}) z ; \alpha)$. The small order term $o\left(N_{2}^{-1 / 2}\right)$ decreases at a faster rate than $N_{2}^{1 / 2}$.

Therefore, we can express $\hat{\Delta}^{s}(z)-\Delta^{s}(z)$ as 


$$
\hat{\Delta}^{s}(z)-\Delta^{s}(z)=\hat{A}-\hat{B}+o\left(N^{-1 / 2}\right)
$$

where

$$
\begin{aligned}
\hat{A} & =\left(\hat{P}_{2}((1+g) z ; \alpha)-P_{2}((1+g) z ; \alpha)\right) \\
& +((1+g) z) P_{2}^{g z}((1+g) z ; \alpha)\left(\frac{\hat{\mu}_{2}-\mu_{2}}{\mu_{2}}\right)
\end{aligned}
$$

and

$$
\begin{aligned}
\hat{B} & =\left(\hat{P}_{1}(z ; \alpha)-P_{1}(z ; \alpha)\right) \\
& -((1+g) z) P_{2}^{g z}((1+g) z ; \alpha)\left(\frac{\hat{\mu}_{1}-\mu_{1}}{\mu_{1}}\right) .
\end{aligned}
$$

The small order term $o\left(N_{j}^{-1 / 2}\right)$ in (35) decreases faster than $N_{1}^{1 / 2}$ and $N_{2}^{1 / 2}$, and $\hat{A}$ and $\hat{B}$ decrease as $N_{1}$ and $N_{2}$ increase towards infinity, so we can ignore it asymptotically. By (27) and (31), $\hat{A}$ and $\hat{B}$ respectively in (36) and (37) are a sum of independently and identically distributed (iid) sample observations.

Suppose that the two empirical distributions also come from independent samples, i.e., the selection of the sampling units is independent in each sample. With $N_{1}$ and $N_{2}$ trending to infinity, we then have:

$$
\operatorname{var}\left(\hat{\Delta}^{s}(z)-\Delta^{s}(z)\right) \cong \operatorname{var}(\hat{A})+\operatorname{var}(\hat{B}) .
$$

If, however, the two samples are dependent because, for instance, they come from the same panel data, then the asymptotic variance must be estimated jointly over the two samples. We then have

$$
\operatorname{var}\left(\hat{\Delta}^{s}(z)-\Delta^{s}(z)\right) \cong \operatorname{var}(\hat{A})+\operatorname{var}(\hat{B})-2 \operatorname{cov}(\hat{A}, \hat{B}) .
$$

For the dual (or percentile) approach, first-order approximations of the sampling distribution of the quantile estimator, $\hat{Q}(p)$, and of its cumulative function up to percentile $p, \hat{C}(p)$, are (omitting the subscript $j$ ) given by: 


$$
\hat{Q}(p)-Q(p)=N^{-1} \frac{\sum\left(I\left[y^{h}<Q(p)\right]-p\right)}{f(Q(p))}+o\left(N^{-1 / 2}\right)
$$

and

$$
\begin{aligned}
& \quad \hat{C}(p)-C(p)= \\
& N^{-1} \sum_{+o\left(N^{-1 / 2}\right),}\left\{\left(I\left[y^{h}<Q(p)\right]-p\right) Q(p)+y^{h} I\left[y^{h}<Q(p)\right]-C(p)\right\}
\end{aligned}
$$

where $I\left[y^{h}<Q(p)\right]$ is an indicator function taking the value of 1 if its argument is true and 0 otherwise - see Bahadur (1966) and Davidson and Duclos (1997). Again, we can asymptotically ignore the $o\left(N^{-1 / 2}\right)$ terms. The rest of the expressions are sums of iid variables whose asymptotic sampling distribution can be readily estimated using sample estimates.

\section{Has growth in Andean economies been pro-poor between 2005 and 2010 ?}

\subsection{The Peruvian case}

\subsubsection{The Peruvian data}

There are two types of household surveys in Peru. The first is the National Household Questionnaire Survey (ENAHO: Encuesta Nacional de Hogares) administered by the National Institute of Statistics and Information (INEI: Instituto Nacional de Estadistica e Informitica). The second is the National Survey on Living Standards (ENNIV: Encuesta Nacional sobre Niveles de Vida) administered by the Instituto Cuanto. The ENAHO provides continuous annual data, while the ENNIV provided its last data in 2000. Thus, for this study, we will use ENAHO, a survey that began to be carried out in 1995 . Until 2002, this nationally representative survey was collected in the fourth quarter of the year in each of following geographic domain: Urban Costa, Rural Costa, Urban Sierra, Rural Sierra, Urban Selva, Rural Selva and Metropolitan Lima. In May 2003, ENAHO became a continuous survey that records information 52 weeks year. Starting in 2008, the sample sizes of the ENAHO increased to more than 22000 private homes and the 
sampling frame was updated using 2007 census information. It should be noted here that ENAHO is a stratified and multistage sample. 10 In this study, we will focus on the 2005-2010 period during which the 2008 world economic crisis occurred, followed by a recovery period. In addition to the cross-sectional surveys, we will also use a national representative Peruvian panel of 2,561 observations, which covers 2007-2010. From 2007 to 2010, the same 2,561 households were interviewed for each of the yearly surveys. Since the replacement process is random, the sampled households continue to be representative and this process do not introduce selection bias.

The monetary indicator of wellbeing is per capita consumption. The ENAHO defines the poverty line as "a minimum expenditure deemed necessary for an individual in order to obtain all the goods and services which satisfy his or her basic needs". The total poverty line is the sum of food expenditures (an extreme poverty line calculated on the basis of minimum daily caloric intake) and non-food expenditures. In Peru, separate poverty lines are calculated for urban and rural areas and for each region, such as the Costa (Coast), the Sierra (the Andes) and the Selva (Jungle). According to INEI, the national monthly poverty line was 263.8 nuevos soles in 2010, while the extreme poverty line was 148.6 nuevos soles. To standardize the monetary indicator of wellbeing, we use the 2010 national poverty line as the reference poverty line. 11

\subsubsection{Growth, poverty and inequality trends in Peru}

Peru experienced remarkable economic performance between 2005 and 2010, with an annual equivalent GDP growth rate of about $7.2 \%$. This increase enabled the population to raise their yearly per capita consumption by an average of $4.4 \%$ per year during this period. However, as we can see in table PER-1, the annual growth rate was not stable over time and was deeply disrupted by the economic crisis of 2008/09. We can also observe that the poverty headcount decreased by more than the third, from $48.7 \%$ in 2005 to $31.3 \%$ in 2010 . Inequality decreased substantially, with a fall in the Gini index from 0.379 to about 0.345 over this period of time. Of course, growth may have a limited impact on poverty depending on the nature of change in the distribution. Thus, we begin by decomposing the yearly change in poverty between growth and inequality components. The

\footnotetext{
${ }^{10}$ Strata are defined on the basis of the number of households in each town or locality. For instance, the first strata includes localities with more than 100,000 housings.

${ }^{11}$ The standardization consists of multiplying the monetary indicator of wellbeing in region $r$ in time $t$ by $z_{r_{r e f}, t_{r e f}} / z_{r, t}$.
} 
approach that we adopt is that of Datt and Ravallion (1992), which was later improved by Shorrocks (1999). As we can observe in figure PER-1, the combined contribution of growth and inequality has ensured a significant yearly decrease in poverty. For instance, the contribution of growth component in the first period of the economic crisis (2007/08), was low compared to that of inequality. The opposite case held in the two following years. For the change in the poverty gap, the contribution of growth and inequality are similar to those for the headcount (see figure PER-2). However, the size of the contribution of inequality may differ significantly from one poverty index to another. Based on these preliminary results, it seems that Peruvian social programs effectively faced the adverse impacts of the economic shocks on social welfare.

\subsubsection{The pro-poorness of growth in Peru}

In figure PER-3, we show the GIC curves and growth in average consumption. As we can observe, our estimates show that the yearly growths were first order absolutely pro-poor. This is because all GIC curves lie above the null horizontal line for most of the distribution of the poor. Our estimates also show that yearly growth for 2007/08 and 2009/10 were first order relatively pro-poor since the GIC curves were higher than observed growth in average consumption. These preliminary results provide a useful summary of the nature of pro-poorness in Peru during the study period. However, as mentioned above, it is more appropriate to verify that growth was pro-poor with the statistical robustness conditions.

Except for 2005/06 and 2008/09, figures PER-4 and PER-5 show that growth was robustly first order absolutely pro-poor in each year. We arrive at the same conclusion for the second order of dominance, as shown in figures PER-6 and PER-7. Figures PER-8 and PER-9 show that, with the statistical robustness condition, we cannot confirm for the first order relative pro-poor in Peru. However, when we focus on an interim period, such as from 2007 to 2010 , we find that growth was also first and second order relatively pro-poor, as shown in figures PER-12 and PER-13. This finding indicates also that the results with respect to pro-poorness can be sensitive to the length of the period being analyzed.

What can we conclude starting from these results? First, the absolutely propoor growth was sufficient to ensure a significant decrease in poverty in each year, as reported in table PER-1. For the 2007/08 period, the relatively pro-poor growth contributed significantly to reduced poverty. First, we can conclude that redistribution can be more effective at reducing poverty during periods of crisis and is less so during periods of expansion. Second, we can confirm that the poor in 
Peru have continued to benefit from growth after the economic recovery through the growth component.

As we have already explained, the impact of growth on poverty depends on the sensitivity of the selected poverty index to growth as well as on the extent of growth across the income distribution. Using the Kraay (2004) decomposition approach, we show how the Kraay's pro-poor components have contributed in the evolution of poverty gap, in table PER-2 and figure PER-14. From these results, we remark that:

- The observed low growth rate during the first period of the economic crisis $(2007 / 08)$ lowered the reduction in poverty gap;

- During the 2005/06 period, the redistributive component-the pattern of growth across the income distribution-has an adverse and significant effect on poverty reduction;

- The estimated values of the Kraay's pro-poor components are similar to those derived using the Datt and Ravallion (1992) approach, as we can observe by comparing the results of figure PER-2 with those reported in table PER-2,

Now, we will return to results of our proposed decomposition of changes in poverty into pro-poor components, as shown in equation 14 and as reported in table PER-3 and figure PER-15. In general, we find that growth among the poor is lower than among the entire population but is more stable over time. The absolute covariance between the sensitivity of poverty to growth and growth itself — shown in the last column of the table — has continued to be substantially high in 2008/09 and increased during the 2009/10 recovery period, which indicate an improvement in the distribution of the benefits of growth within the poor.

\subsubsection{The non-anonymous pro-poorness of growth and mobility in Peru}

As we discussed above, we are interested in pro-poor growth in order to study the connection between growth and poverty. Also, we can recognize that income growth in part reflects the dynamic of income. Looking at growth through use of the non-anonymous principle may add valuable information about income mobility and how it interacts with the poverty over time. In figure PER-16, we present the non-anonymous GIC curves when the period of reference to define the poor group is the initial. As we can see in this figure, we find that growth was first 
order non-anonymous pro-poor for all periods between 2007 and 2010. However, when the period of reference to define the poor group is the final period, growth does not appear to be pro-poor (see the figure PER-17). In general, this result is expected and it is more plausible that those who are more poor in the final period are those who are vulnerable to poverty but are not poor in the initial period (indicating downward mobility). To remove the arbitrariness of selecting the reference period to define the poor, we also present intertemporal pro-poor growth in order to focus on changes of incomes of the poor in general. As we can observe in figure PER-18, the poor experienced an increase in income over time. This is consistent with the ongoing decrease in poverty during the studied period.

Among the popular indices to quantify mobility is that of Shorrocks (1978), based on the information of the diagonal of the transition matrix. Formally, the index equals $M=[g-\operatorname{trace}(Z)] /(g-1)$, where $g$ is the number of partitions of the population and $Z$ is the transition matrix. Typically, the normalized index by $g /(g-1)$ indicates the percentage of movers by quintile or decile (see tables PER-4 and PER-5). In table PER-6, we present some mobility statistics from the transition matrix by decile. As we can observe, mobility increased during the 2008/09 crisis period, during which $26.1 \%$ stayed in the same decile. We also show that, for the $2007 / 10$ period as a whole, mobility was higher than when shorter periods are considered (yearly mobility). For those with incomes equal to or less than the median $(p<0.5)$ ), we observe that a greater percentage saw their income increase rather than decrease. This is consistent earlier results that showed significant improvements in the welfare of the poor over time.

\subsection{The Ecuadorian case}

\subsubsection{The Ecuadorian data}

The National Institute of Statistics and Census INEC produces quarterly data for the most important socioeconomic variables, such as employment, unemployment, underemployment and other demographic information relating to education, internal migration and household incomes. The Integrated Household SurveySIEH - is a basic strategic planning tool to produce demographic and economic statistics. Under the SIEH , there was also the National Surveys of Employment, Unemployment and Underemployment, (ENEDMU: Encuseta Nacional de Empleo, Desempleo y Subempleo). The ENEMDU urban geographic areas correspond to the five major cities (Quito, Guayaquil, Cuenca, Machala and Ambato), Rest of Urban Sierra, Rural Sierra, Other Urban Costa, Rural Costa, Urban Ama- 
zon, Rural Amazon. . The ENEMDU survey follows a stratified design with three stages (UPM, census zone and household) where the primary sampling unit is referred to as UPM (Unidades Primaria du Muestreo). In the second stage, one census zone is selected within each UPM, and in the third stage, a pre-determined number of dwellings are selected. The UPM's are chosen with a probability proportional to size sampling. The sampling unit is a dwelling or housing structure, and information regarding the household or households occupying each dwelling is collected. The survey covers a wide range of economic and socio-demographic information such as: the labour force, different sources of income, housing, migration, education and other social indicators. Between approximately 13,900 and 20,400 households were surveyed each December between 2000 and 2010. To be noted here that (expansion factor) provided by the INEC are used in order to take into account to optimize the national representativeness of the sample.

To study the pro-poorness of growth in Ecuador, we use the 2005-2010 ENEMDU surveys. Per capita income is considered as the monetary indicator of wellbeing for the Ecuadorian population. The poverty and extreme poverty lines are based on the official poverty line, updated using the CPI. This poverty line was calculated using the Living Conditions Survey of 2006 (ECV2, 5th round). The official poverty line was $\$ 57.29$ US per capita per month in 2006, and $\$ 69.05$ US per capita per month in 2010.

\subsubsection{Growth, poverty and inequality trends in Ecuador}

Between 2005 and 2010, Ecuador has registered an average GDP of about $3.2 \%$. During the same period, the average growth rate of per capita income, estimated using microdata, was about $2.1 \%$. The GDP and per capita income growth trends show the deep impact of the 2008 world economic crisis on the Ecuadorian economy. Indeed, GDP growth fell from $6.5 \%$ in 2008 to $0.4 \%$ in 2009 . Furthermore, the results show an abrupt decline in per capita income of about $5.8 \%$ during the 2007/08 period (see table ECU-1). In the 2009/10 period, the Ecuadorian economy recovered somewhat, to grow by about $3.2 \%$ in 2010 . Examining the poverty trend presented in table ECU-1, we can see that the headcount decreased by about $10 \%$ between 2005 and 2010 . This decline mostly occurred in the 2005/06 and 2009/10 periods, outside the time of the world economic crisis. However, the decrease in inequality as measured by the Gini index was more pronounced during the 2007/08 period. The trends of the impact of growth and changes in inequality on poverty are shown in figures ECU-1 and ECU-2. In general, these figures show the expected negative correlation between growth and 
poverty. This also explains the contribution of negative growth to greater poverty in 2007/08 and 2008/09. However, the inequality component lightened the impact of negative growth on poverty during these periods, allowing Ecuador to nevertheless have an appreciable decrease in poverty throughout the period, except in 2008/09.

\subsubsection{The pro-poorness of growth in Ecuador}

In figure ECU-3, we show the GIC curves and growth in per capita income. Without considering statistical robustness, growth was absolutely pro-poor in 2005/06, 2007/08 and 2009/10. Generally speaking, growth was also relatively pro-poor with the exceptions of 2006/07 and 2009/10. When considering the $2005 / 10$ period as a whole, growth was both absolutely and relatively pro-poor.

How can we reviewing our perception to the absolute and relative approaches starting from Ecuadorian experience? Let us focus on the outcomes in 2008/09 and 2009/10. In 2008/09, growth was relatively but not absolutely pro-poor, even though poverty increased during this period. This surprising finding may raise questions with regard to the relative approach. Indeed, during crisis periods, the relative approach simply focuses on the change in inequality rather than that of poverty. In 2009/10, economic growth in Ecuador was nearly inequality-neutral, a case where all incomes increase by the same proportion. This clearly helps reduce poverty but not inequality. This also renders the observed growth absolutely but not relatively pro-poor. Can we conclude that the growth of 2008/09 was better for the poor than that of $2009 / 10$ ? In general, it should not be difficult to agree that any distributive change that reduces poverty will be welcomed by the poor.

We will now review the types of pro-poor growth in Ecuador, considering statistical robustness. For the 2005/06 and 2009/10 periods, figures ECU-4 and ECU-5 show that growth was first order absolutely pro-poor. Furthermore, for 2005/10 as a whole, figure ECU-12 shows that growth was also first order absolutely pro-poor. For the second order of dominance, figures ECU-6 and ECU-7 show that growth was absolutely pro-poor in the 2005/06, 2007/8 and 2009/10

periods. For the relative approach, figures ECU-8 and ECU-9 show that growth was relatively first order pro-poor in 2007/08 and 2008/09. The same results were also found when considering the second order of dominance, as shown in figures ECU-10 and ECU-11. Additionally, we find that for 2005/10 as a whole, growth was first order relatively pro-poor (see figure ECU-13).

Next, we return to Kraay (2004)'s decomposition in order to understand how growth, and its pattern relative to income, has affected poverty (see the results 
of table ECU-2). First, we note that the sensitivity of poverty to growth remained stable during the period being studied. Thus, the main contribution of the product of average income growth and sensitivity to growth $(C 1 C 2)$ was driven by the level of growth in average income. Similar to what we found with the Datt and Ravallion (1992) decomposition, the results show again that the redistributive impact, captured by the patter of growth in relative income component, contributed to poverty reductions during the periods of negative economic growth.

Now, we turn to results of the proposed decomposition of changes in poverty into pro-poor components, as shown in table ECU-3. Mainly, we find that for the two periods where the decrease in poverty was substantial (2005/06 and 2009/10), the correlation between the sensitivity to growth $(\eta(p))$ and the growth $(g(p))$ was high and thus that relative changes in income contributed to reduced poverty.

What lessons can we draw from the Ecuadorian experience?

- During periods of crisis (negative growth), it is socially desirable to have positive income growth among the poor (an absolute view);

- If the condition of absolute pro-poorness is not satisfied during periods of crisis (negative growth), it is socially desirable for the poor to be affected less than the rich (a relative view);

- During periods of expansion (positive growth), it is socially desirable for the poor to benefit more from growth (a relative view);

- If the relative pro-poorness condition is not satisfied during periods of expansion, it is socially desirable for the poor to continue to register positive income growth (an absolute view);

However, we must recall the ambiguity surrounding comparisons between the results of the absolute and relative approaches. To untangle this ambiguity, let us return to the reason for considering the relative form of pro-poorness. In general, the idea pertains to the conditions required to avoid inequality trap. Especially in countries with greater poverty and inequality, relatively higher growth among the poor is required to substantially reduce poverty. For these countries, low absolute pro-poorness may keep the poor group in their situation for a long time. Unfortunately, this narrow view cannot be generalized across countries at different stages of development. Indeed, many emerging economies have succeeded in substantially reducing poverty but have seen inequality persist or even increase. The debate about the relevance of the different conditions of pro-poorness may 
continue. However, the pro-poorness of growth can evaluated in specific contexts, with the nature of growth and the level of the country's wealth potentially impacting our outlook on the pro-poorness of growth.

\subsection{The Bolivian case}

\subsubsection{The Bolivian data}

The National Institute of Statistics conducted several rounds of household surveys, and the first of these took place in 1978. These surveys include the Permanent Household Survey (EPH), the Integrated Household Survey (IHS) and the National Employment Survey.

In 1999, a World Bank initiative began in the region by implementing the Living Standards Measurement Surveys (LSMS) that aim to collect information on the living conditions of the Bolivian population in order to produce poverty indicators and to support policies and programs that improve the welfare of households. The first data collected in the country in the framework of the LSMS was gathered in November of 1999. From 1999-2002, Bolivia's National Institute of Statistics carried out a household survey as part of the Program for the Improvement of Surveys and the Measurement of Living Conditions in Latin America and the Caribbean (MECOVI). The Continuing Survey of Households, similar to a household budget survey, ran between 2003 and 2004. It preserves the traditional content of the survey, with an emphasis on household income and expenditures. Starting from 2005, the surveys returned to the form of specific homes with the implementation of the Household Survey, which continued to explore the living conditions of the Bolivian population through multi-thematic surveys that make it possible to investigate general household characteristics. The Encuesta de Hogares $(\mathrm{EH})$ allows multi-thematic research relating to: sociodemographic characteristics, health, education, employment, income and expenditures of household members, and the characteristics of housing and household utilities, in order to generate poverty indicators. This makes it possible to design, evaluate and monitor policies and to design social action programs with a view to improving the welfare of households. In this study, we use the 2005-2009 EH surveys. These samples are stratified and clustered with unequal probability weights and contain data on about 4000 surveyed household. Per capita income is the monetary indicator of wellbeing that is adopted. In Bolivia, the official poverty line varies by department and among urban and rural areas to account for price differences. For 2009, we estimate the weighted average monthly poverty line across the depart- 
ments of Bolivia to be about 549.51 Bolivianos (BOB). We use this as a reference poverty line to perform the temporal and spatial standardization.

\subsubsection{Growth, poverty and inequality trends in Bolivia}

Between 2005 and 2009, Bolivia registered an average annual GDP growth of about $4.6 \%$. This significant increase in GDP did not translate into a similar trend for per capita income, as estimated from microdata, which declined by an average of about $-1.5 \%$ during the same period. As shown in table BOL-1, the trend of per capita income shows the deep impact of world economic crisis of 2008 on the wellbeing of the Bolivian population, with an $8.5 \%$ fall in average per capita income between 2007 and 2008. An impressive recovery followed this negative result and average per capita income increased by about $5.1 \%$. Looking at poverty trends, we can see that the two significant decreases in the poverty headcount and poverty occurred during the 2007/08 and 2008/9 periods. Similarly, we note that inequality also decreased significantly during these two periods. The impacts of growth and inequality on poverty are shown in figures BOL-1 and BOL-2. These figures mainly show that inequality lightened the negative impact of growth during crisis periods. We can also note the low contribution of the redistribution (inequality) component during the 2008/09 period.

\subsubsection{The pro-poorness of growth in Bolivia}

In figure BOL-3, we show the GIC curves and growth in average per capita income. Without considering statistical robustness, growth was absolutely pro-poor for the extremely poor in 2005/06 and was absolutely pro-poor in 2007/08. We reach the same conclusion with respect to relative pro-poorness. For the entire study period of 2005-2009, growth was absolutely and relatively pro-poor. Note

that for the $2008 / 09$ period, the GIC curve beyond the $10^{\text {th }}$ percentile was significantly higher than zero. We can thus generally consider growth to have been pro-poor in this period if the function used to evaluate social welfare of poverty does not depend mainly on the wellbeing of the first decile. We now review the nature of pro-poor growth in Bolivia in consideration of statistical robustness. Figures BOL-4 and BOL-5 show that growth was only first order absolutely propoor when considering the entire study period (2005/09) as a whole. However, we can conclude that growth was second order absolutely pro-poor for the 2007/08, 2008/09 and 2005/09 periods (see figures BOL-6 and BOL-7). When considering relative pro-poorness, figures BOL-12 and BOL-14 show that the growth was 
both first and second order pro-poor in the 2007/08 and 2005/09 periods. Now, we return to Kraay (2004)'s decomposition in order to understand how growth and its pattern has affected the poverty gap. In 2005/06, the change in poverty and in the different components were insignificant (see table BOL-2). During 2006/07, the negative impact of average income growth $(C 1 C 2)$ was largely balanced by the pro-poor pattern of growth $(C 3)$. This was also the case for 2007/08. As reported earlier, the poverty reduction between 2008 and 2009 largely resulted from growth in average income $(C 1 C 2)$, where the contribution of the redistributive factor $(C 3)$ was practically nil. The results of the decomposition of changes in poverty into pro-poor components are also reported in table BOL-3. For 2005/06, the change in poverty would have been $2.3 \%(C 1 C 2)$ if the benefits of growth were equally distributed. Otherwise, we can conclude for the negative impact of the within poor-group inequality $(C 3)$. For the remaining periods, and especially for 2008/09, we find that both average growth $(C 1 C 2)$ and the distribution of growth among the poor $(C 3)$ have the effect of reducing poverty. In summary, for the Bolivian case, we can conclude that growth was both relatively and absolutely pro-poor during the $2005 / 09$ period. The world economic crisis deeply impacted the wellbeing of the Bolivian population in 2008. This effect was significantly lightened by the redistribution (inequality) factor and was followed by a remarkable period of recovery (2008/09).

\subsection{The venezuelan case}

\subsubsection{The venezuelan data}

The Encuesta de Hogares por Muestreo (EHM) is the national household survey in Venezuela, conducted by the National Statistics Institute (INE: El Instituto Nacional de Estadísticas). The survey is conducted since 1967, two times per year and the period of data collection is 6 months. The main objective of this survey is to provide general information on socioeconomic and sociodemographics characteristics of the labor force. The EHM survey is stratified with a multistage sampling design. The primary sampling units are the lots, which represents a geographical areas of about 15 houses. For the used data in our study (2005 to 2010), the sampling frame is composed of the Master Sample based on the National Population Census of 2001. The total number of lots in the sample of 2005 is 3036, equivalent to 45,000 homes, approximately. The surveys of the second semester for each of the yeas from 2005 to 2010 was used in our study. Further, we use the per capita income as the monetary indicator of wellbeing. The official poverty 
line varies spatially to account for price differences. The daily national poverty line was about 520 Bolivar fuerte (VEF) in 2010. We use this level as a reference poverty line to perform the temporal and spatial standardizations.

\subsubsection{The trend of growth, poverty and inequality in Venezuela}

Between 2005 and 2010, Venezuela has registered an annual equivalent GDP of about $3.5 \%$. During the same period, the average growth rate of per capita income, estimated using microdata, was about $1.9 \%$. The GDP and per capita income growth trends show the deep impact of the economic crisis on the period of 2008 until 2010. Indeed, the GDP growth was negative for the years of 2009 and 2010 with a levels of $-3.3 \%$ and $-1.9 \%$ respectively. As shown also in table VEN-1, there has been a significant decline in the per capita income for the years of 2009 and 2010. Examining the poverty trend presented, we can see that the headcount decreased sharply between the years of 2005 and 2007. The level of headcount has practically remained constant after this period. Thus, the main decline in the whole studied period mostly occurred outside the time of the world economic crisis. However, the decrease in inequality as measured by the Gini index was more pronounced during the 2005/06 and 2008/10 periods. The trends of the impact of growth and changes in inequality on poverty are shown in figures VEN-1 and VEN-2. Mainly, we conclude for the importance of the inequality component to lighten the impact of negative growth on poverty during the periods of crisis, as is the case for the years of 2009 and 2010.

\subsubsection{The pro-poorness of growth in Venezuela}

In figure VEN-3, we show the GIC curves and growth in per capita income. Without considering statistical robustness, growth was absolutely pro-poor in $2005 / 06$ and 2006/07. Generally speaking, growth was also relatively pro-poor with the exceptions of 2007/08. When considering the 2005/10 period as a whole, growth was both absolutely and relatively pro-poor. As was discussed for the case of other countries, like the Ecuador for instance, the relative pro-poorness is checked easily during the recession periods.

We will now review the types of pro-poor growth in Venezuela, considering statistical robustness. For the 2005/06 and 2006/07 periods, figures VEN-4 and VEN-5 show that growth was first order absolutely pro-poor. Furthermore, for 2005/10 as a whole, figure VEN-12 shows that growth was also first order absolutely pro-poor. For the second order of dominance, figures VEN-6 and VEN-7 
show that growth was absolutely pro-poor in the 2005/06, 2006/07 and 2008/09 periods. For the relative approach, figures VEN-8 and VEN-9 show that growth was relatively first order pro-poor in 2005/06, 2008/09 and 2009/10. For relative second order of dominance, as shown in figures VEN-10 and VEN-11 the dominance is checked for all periods, except for the period of 2007/08. Additionally, we find that for 2005/10 as a whole, growth was first order relatively pro-poor (see figure VEN-13).

In table VEN-2 we show the results of the Kraay (2004)'s decomposition in order to understand how growth, and its pattern relative to income, has affected poverty. First, we note that the sensitivity of poverty to growth was relatively higher in 2007/08. however, its level was practically stable for the rest of periods and the main contribution of the product of average income growth and sensitivity to growth $(C 1 C 2)$ was driven by the level of growth in average income. Similar to what we found with the Datt and Ravallion (1992) decomposition, the results show again that the redistributive impact, captured by the patter of growth in relative income component, have contributed to poverty reductions during the periods of negative economic growth.

Now, we turn to the results of the proposed decomposition of changes in poverty into pro-poor components (see the tableVEN-3). Mainly, we find a negative impact of the redistribution in 2008/09 and a positive effect for the following period. To understand, better why this was the case for the period of 2008/09, let us reviewing the GIC curve in figure VEN-3, As we can remark, for the period of $2008 / 09$, the growth was important among the poorest of poor group. Thus, this reduction in inequality that occur mainly within the poor will not help in reducing the poverty gap index.

\subsection{The Colombian case}

\subsubsection{The Colombian data}

The National Administrative Department of Statistics (DANE) implemented the (ENH) quarterly National Household Survey from 1976 to 1999. The main aim this survey was to assess the evolvement of employment, unemployment and to measure changes in levels of other variables related to the populations labor force. This survey was replaced in 2000 by the yearly Continuous Household Survey (ECH). To avoid the seasonality effect, this survey allows to estimate the average weekly indicators of the labor force for a given period. The ECH survey is stratified with multi-staged sampling and self-weighted for the 13 cities and their 
metropolitan areas (Bogota, Medellin, Cali, Barranquilla, Bucaramanga, Manizales, Pasto, Pereira, Cucuta, Ibague, Monteria, Cartagena y Villavicencio). The sampling frame consists of the cartographic inventory and listings of dwellings by city from the Population and Housing National Census of 1993. For the year of 2004, the sample size in each quarter corresponds to 50,850 households in the thirteen cities and 12,510 households in other domains of study. In our study, we use the validated data for the years of 2004, 2005, 2008, 2009 and 2010. The per capita income is the monetary indicator of wellbeing that is adopted. The official poverty line varies spatially to account for price differences. The estimated weighted yearly average poverty line in 2010 was about 187048.42 pesos colombians. We use this level as a reference poverty line to perform the temporal and spatial standardization.

\subsubsection{The trend of growth, poverty and inequality in Colombia}

Between 2004 and 2010, Colombia has registered an average annual GDP of about $5.5 \%$. During the same period, the average growth rate of per capita income, estimated using microdata, was about $4.1 \%$. The trend of GDP shows the deep impact of the economic crisis on the period of 2008 until 2010. Mainly the GDP has decreased from $8.2 \%$ in 2007 to $2.5 \%$ in 2008 , then to $0.8 \%$ in 2009 . The increase in GDP to $4.3 \% 2010$ marks the start of recovery period. As shown also in table COL-1, the variation in average per capita has grown during all the studied periods. However, the yearly variation has decreased in 2008/2009. As we can observe also, the headcount has decreased by about 10\% between 2004 and 2010, while the poverty gap has decreased by the quarter. The inequality as measured by the Gini index was remained practically with a level of about 0.53 . The trends of the impact of growth and changes in inequality on poverty are shown in figures COL-1 and COL-2, In general, we observe that inequality increases slightly the poverty indices during the expansion periods. Further, we find that growth was enough to ensure the significant and continues reduction in poverty, except during the crisis period of $2008 / 09$.

\subsubsection{The pro-poorness of growth in Colombia}

In figure COL-3, we show the GIC curves and growth in average per capita income. Without considering statistical robustness, growth was absolutely propoor in 2004/05, 2008/09 and 2009/10. Further, growth was also relatively propoor in $2008 / 09$. When considering the $2004 / 10$ period as a whole, growth was 
both absolutely and relatively pro-poor.

By considering the statistical robustness condition, we find that growth was first order absolutely pro-poor for the 2004/05, 2008/09 and 2009/10 periods (see figures COL-4 and COL-5). Furthermore, for 2005/10 as a whole, figure COL-12 shows that growth was also first order absolutely pro-poor. For the second order of absolute pro-poorness, we find similar results to those of the first order, shown in figures COL-6 and COL-7, For the relative approach, figures COL-8 and COL-9 show that growth was relatively first order pro-poor only for the period of 2008/09. This was also the case for the second order of dominance, as shown in figures COL-10 and COL-11. Also, we find that for 2005/10 as a whole, growth was first order relatively pro-poor (see figure COL-13).

Now, we return to Kraay (2004)'s decomposition in order to show how growth, and its pattern relative to income, has affected poverty (see the results of table COL-2). First, we note that the component pattern of growth in relative income increases in general the poverty except during the period of 2008/09. We remark also that the sensitivity of poverty to growth is low for the period of 2005/08. Thus, the main contribution of the product of average income growth and sensitivity to growth $(C 1 C 2)$ was driven by the level of growth in average income. Similar to what we found with the Datt and Ravallion (1992) decomposition, the redistributive impact, captured by the pattern of growth in relative income component, have contributed to poverty reductions during the periods of negative economic growth.

Now, we turn to results of the proposed decomposition of changes in poverty into pro-poor components, as shown in table ECU-3. Mainly, we find that, for the two periods where the decrease in poverty was substantial (2005/06 and 2009/10), the correlation between the sensitivity to growth $(\eta(p))$ and the growth $(g(p))$ was high, and thus, that the relative changes in income contributed in reducing poverty.

\section{A comparative analysis of pro-poorness of growth in the L.A. Andean countries}

In this section, we try to draw a general picture on the nature of pro-poorness of growth in the L.A. Andean countries between 2005 and 2010. As already discussed, during this period, an appreciable economic performance was observed at the beginning of the studied period. However, this period was followed by the 2008 economic crisis. Our aim is to synthesize the results of pro-poorness 
of growths in order to show the similarities and dissimilarities across the studied countries, and then we try to explain them.

\subsection{The trend of growth, poverty and inequality}

As we can observe in figures LAA-1 and LAA-2, the studied period can be subdivided into three phases. The first phase, between 2005 and 2007, was featured by a remarkable economic growth in the L.A. Andean countries, except for Bolivia. This phase was followed by 2008 world economic crisis. To be noted here that the impact of this crisis did not occur at the same time in all countries. For instance, while Ecuador registered the economic downturn in 2007/08, Venezuela experienced the crisis in 2008/09. Of course, the nature and level of dependance of the economy of each country with that of the rest of world will determine the duration and amplitude of the impact. After the second phase of the economic crisis, a third phase characterized by some economic recovery has followed. However, the exception was Venezuela, and where the domestic product and the average per capita continue to register negative growth rates, and this, even in 2009/10 period.

Now we turn to review the trend of poverty, measured by the headcount (see the figure LAA-3). In general, we observe that poverty in L.A. Andean countries follows a decreasing trend. However, the speed of this decrease varies across countries and periods. It is clear that the 2008 world economic crisis has slowed down the decrease of poverty. Further, we observe that the speeds of decrease in Peru and Ecuador were high compared to the rest of the countries. This has enabled them to reach the lowest levels of poverty observed in Venezuela. Further, we note that Bolivia and Colombia continue to display the highest levels of poverty.

Inequality is high in most of the L.A. Andean countries (see the figure LAA-4). Inversely to poverty, the speed of decrease in inequality is relatively low. This may be explained by the nature of increase in the disparities during the boom economic periods, and where some sectors perform better than others. Inversely, these disparities have the tendency of decrease during the recession periods. This finding can be explained mainly by two facts. The first is the high decrease in returns of those with high physical and human capital. The second is the generous social packages that can target well the poor and, consequently, lighten the reduction in their income. 


\subsection{The absolute and relative pro-poorness of growth in LA countries}

Tables LAA-1 and LAA-2 summarize the results found for the first and second order of dominance of absolute and relative pro-poorness of growth in the L.A. Andean countries. In these two tables, the cell is marked only if the dominance condition is checked with the statistical robustness. Except for Ecuador, we generally find that growth was relatively pro-poor during the economic crisis period (2007/08 and 2008/09). Inversely, growth was in general absolutely pro-poor during the boom and recovery economic periods. Based on this, it seems that the relative pro-poor measurements are the good indicator during the crisis periods in order to check whether the impact is relatively low for the poor. This may be the case where the governmental programs are intense and target well the poor during the economic crisis period. However, the absolute pro-poor measurements can be useful to check whether the poor benefits sufficiently during the boom economic periods to escape poverty.

\section{Lessons and conclusions}

This paper is devoted to study the pro-poorness of growth in the Latino American Andean countries for the $2005 / 10$ period. It is worth noting that this period was marked by different events, which have largely affected the distribution of wealth in this region. Indeed, at the beginning of the studied period, these countries have registered in general an appreciable economic performance. However, this performance was followed by the 2008 world economic crisis, followed in its turn by a period of economic recovery. Our main aim was to check whether growth during the pre and post-shock periods was pro-poor as well as to highlight the distribution of the burden of the economic crisis.

Of course, fighting against poverty, helping the inclusion of the poor group into the economic activity sphere and improving the social wellbeing in general, continue to be the primordial objectives of social planners and policymakers. Two main factors can help the improvement of wellbeing of deprived group: the economic growth and the equitable distribution of wealth. Even if economists can agree for the potential impact of each of the two factors on poverty, they have not a consensus about the importance of each of them. Mainly, the pro-poor realization can be seen from different angles. The first focuses on the importance of absolute impact of growth without considering the distribution of benefits. This 
view is in concordance with the Pareto optimum principle; in such case poor and non-poor groups may benefit largely in absolute terms. The second focuses on the importance of the relative impact of growth on poverty without considering the absolute level of change. This view is defended by the possibility of low impact of growth on poverty in the case of high inequality. Unfortunately, each of the two approaches emerging from these views may contain some weakness, and this, depending on the studied case. Beside the debate surrounding the importance of each of these two fundamental factors, which are growth and inequality, that reshape the distribution of wellbeing, other preoccupations emerge when the dynamic nature of pro-poor analysis is considered. Among these aspects, we find the importance of considering the non-anonymity principle in order to focus on assessing the wellbeing of the same unit of analysis -the individual for instance-. The other aspect concerns the choice of period of the definition of poor group. To be noted here that this work contains a developed theoretical framework in order to analyze pro-poor growth in a dynamic manner, and where we consider the poor in the initial and final periods.

The results of pro-poorness of growth for the peruvian case show that growth was in general yearly absolutely pro-poor and was relatively pro-poor when we consider the 2007/10 period. The peruvian experience shows also that even if growth was not yearly relatively pro-poor, this country shows the highest decrease in poverty within this short period, with about a third of decrease. This fact raises the question about the importance of considering the relative criteria of pro-poorness. It is worth noting that the Peru has been affected by the 2008 world economic crisis. However, the impact on poor was largely lightened by the redistribution component. This indicates the effectiveness of the social packages to support the poor during this period of crisis. In this paper, some theoretical developments and a set of results were carried out for the peruvian case in order to show the linkage between the income mobility, the pro-poor growth as well as the inter-temporal wellbeing of the poor group. The statistics summarized starting from transition matrices show that Peru has registered a net yearly upward income mobility, and this, especially for those with incomes below the median. This finding is confirmed also by the inter-temporal pro-poor growth results and where the situation of poor group, defined in initial and final periods, has registered a significant improvement.

For the Ecuadorian case, poverty has decreased in general significantly during the studied period (the headcount has decreased by about $10 \%$ ). Further, we find that growth was yearly absolutely pro-poor for the 2005/06 and 2009/10 periods, and yearly relatively pro-poor for the $2005 / 06,2007 / 8$ and $2009 / 10$ periods. How- 
ever, even if growth was relatively pro-poor in $2007 / 08$, the country registered a significant increase in poverty within the same period. This raises again the question about the pertinence of using the relative approach. Mainly, during the crisis periods, this approach seems to focus only on the nature of change in inequality rather than that in poverty.

Now we focus on the Bolivian experience, which is covered for the period between 2005 and 2009. This country continues to register the highest poverty rates and where about $60 \%$ of the population are stated to be poor in 2005 . The important decrease in poverty in this country occurred within the recovery period in 2008/09, and where the headcount decreased by about $6 \%$. Growth was second order absolutely pro-poor for the 2007/08 and 2008/09 periods and relatively pro-poor growth in the 2007/08 period. Further, growth was absolutely and relatively pro-poor when considering the entire study period as a whole. Starting from the Bolivian experience, we discover how the statistical robustness conditions may induce to some doubt with regards to the empirical results found in other works on the pro-poorness of growth. Indeed, in many cases, we remark that the pro-poorness conditions are checked, but when we add the statistical robustness condition, the results of pro-poorness begin non significant. The world economic crisis deeply impacted the wellbeing of the Bolivian population in 2008. This effect was significantly lightened by the redistribution (inequality) factor, and further by a remarkable period of recovery (2008/09).

From the Venezuelan case, covered for the $2005 / 10$ period, we learned that the timing and duration of the impact of the 2008 world economic crisis differ from one country to another. Especially, for Venezuela, the impact of the crisis started in 2009 and continued in 2010, with GDP of $-3.3 \%$ in 2009 and $-1.9 \%$ in 2010 . The headcount has decreased sharply between 2005 and 2007, but remaind constant after this period. For this country, we find also that growth was yearly absolutely pro-poor for the 2005/06 and 2006/07 periods, and yearly relatively pro-poor for the 2005/06, 2008/09 and 2009/10 periods. As we can remark, we have again a case where growth was relatively pro-poor in 2009/10 without decrease in poverty.

Results found for the Columbian country have some similarities with the others. This country has registered a remarkable decrease in headcount by about $10 \%$. This significant decrease in poverty occurred even if the inequality remained high (0.53 in 2010). In this country, we find also that growth was yearly absolutely for the 2004/05, 2008/09 and 2009/10 periods and was relatively first order pro-poor only for the period of 2008/09. Also, we find that for $2005 / 10$ as a whole, growth was absolutely and relatively pro-poor.

By comparing the different results of the studied L.A. Andean countries, we 
find that growth was relatively pro-poor during the crisis periods $(2007 / 08$ and 2008/09). Inversely, growth was is in general absolutely pro-poor during the boom and recovery economic periods. Starting from this, we can conclude that the relative pro-poor measurements can be good indicators during the crisis periods. This can help to check whether the economic crises affect relatively more the non-poor. This can be the case when the social governmental programs are intense and target well the poor group. In an another part, we can consider that the absolute pro-poor measurements are useful indicators in order to check whether the poor benefit sufficiently from growth during the boom economic periods to escape poverty. The salient fact was about the dynamic of inequality in the Andean L.A. countries. Mainly, we find that the 2008 world economic crisis has contributed in the sharp and significant decrease in inequality. Obviously, this is the case when the impact of the economic crisis is relatively more supported by the non-poor group. In such case, we observe also a relative pro-poor growth. More important, our results show that this decrease in inequality has remained even during the recovery period.

Finally, note that the lessons drawn from the study of pro-poorness of growth in the different L.A. andean countries as well as the discussion about the intertemporal pro-poor growth will contribute to aliment the discussion about the concept of pro-poor of growth. This can in its turn inspire future works in order to investigate better on the concept of pro-poor growth and how the latter is linked with other issues of the distributive analysis. 


\section{The Peruvian results}


Table PER-1: Trend of average per capita consumption, poverty and inequality: Peru 2005/10

\begin{tabular}{|c|c|c|c|c|c|c|c|c|c|}
\hline Year & $\begin{array}{r}\text { Average } \\
\text { consumption }\end{array}$ & $\begin{array}{l}\text { Yearly } \\
\text { variation }\end{array}$ & Variation & Headcount & $\begin{array}{l}\text { Yearly } \\
\text { variation }\end{array}$ & $\begin{array}{r}\text { Poverty } \\
\text { gap }\end{array}$ & $\begin{array}{l}\text { Yearly } \\
\text { variation }\end{array}$ & $\begin{array}{r}\text { Gini } \\
\text { index }\end{array}$ & $\begin{array}{l}\text { Yearly } \\
\text { variation }\end{array}$ \\
\hline 2005 & 351.5 & - & & 48.7 & - & 16.6 & - & 0.3789 & \\
\hline 2006 & 377.0 & 25.6 & $(2005 / 07)$ & 44.5 & $-4.18 * *$ & 15.1 & $-1.52 *$ & 0.3852 & 0.0063 \\
\hline 2007 & 403.9 & 26.9 & $52.5 * * *$ & 39.3 & $-5.23 * * *$ & 12.8 & $-2.30 * * *$ & 0.3786 & -0.0066 \\
\hline 2008 & 406.4 & 2.5 & & 36.2 & $-3.10 * *$ & 11.1 & $-1.68 * *$ & 0.3533 & $-0.0253^{*}$ \\
\hline 2009 & 422.9 & 16.5 & $(2007 / 10)$ & 34.8 & -1.42 & 10.1 & -0.95 & 0.3582 & 0.0049 \\
\hline 2010 & 436.1 & 13.1 & $32.1 * *$ & 31.3 & $-3.45 * *$ & 8.8 & $-1.38 * *$ & 0.3448 & -0.0133 \\
\hline
\end{tabular}

Sampling design is fully taken into account in computing the standard errors.

$w_{\infty}$

${ }^{*} p \leq 0.10,{ }^{* *} p \leq 0.05,{ }^{* * *} p \leq 0.01$. 
Table PER-2: Decomposition of change in poverty gap into pro-poor growth components

Kraay (2004) approach - Peru 2005/10

\begin{tabular}{|c|c|c|c|c|c|c|c|}
\hline \multirow[b]{2}{*}{ Period } & \multirow{2}{*}{$\begin{array}{r}\text { Poverty } \\
\text { Change } \\
(\Delta P(\alpha=1))\end{array}$} & \multirow{2}{*}{$\begin{array}{r}\text { C1: Average } \\
\text { growth } \\
(g)\end{array}$} & \multirow{2}{*}{$\begin{array}{r}\text { C2: Sensitivity } \\
\text { to growth } \\
\left(\int \eta(p)\right)\end{array}$} & \multicolumn{2}{|c|}{$\mathrm{C} 1 \mathrm{C} 2$} & \multicolumn{2}{|c|}{ C3: Pattern of growth in relative incomes } \\
\hline & & & & $\begin{array}{r}\text { Absolute } \\
\text { Contribution }\end{array}$ & $\begin{array}{r}\text { Relative } \\
\text { Contribution }\end{array}$ & $\begin{array}{r}\text { Absolute } \\
\text { Contribution }\end{array}$ & $\begin{array}{r}\text { Relative } \\
\text { Contribution }\end{array}$ \\
\hline 2005/06 & -0.0152 & 0.0728 & -0.2692 & -0.0213 & $140 \%$ & 0.0061 & $-40 \%$ \\
\hline 2006/07 & -0.0230 & 0.0714 & -0.2692 & -0.0192 & $84 \%$ & -0.0038 & $17 \%$ \\
\hline 2007/08 & -0.0168 & 0.0061 & -0.2535 & -0.0016 & $9 \%$ & -0.0153 & $91 \%$ \\
\hline 2008/09 & -0.0095 & 0.0406 & -0.2467 & -0.0100 & $106 \%$ & 0.0005 & $-6 \%$ \\
\hline 2009/10 & -0.0138 & 0.0311 & -0.2287 & -0.0071 & $51 \%$ & -0.0067 & $49 \%$ \\
\hline
\end{tabular}

Table PER-3: Decomposition of change in poverty gap into pro-poor growth components New approach - Peru 2005/10

\begin{tabular}{|c|c|c|c|c|c|c|c|c|}
\hline \multirow[b]{2}{*}{ Period } & \multirow{2}{*}{$\begin{array}{r}\text { Poverty } \\
\text { Change } \\
(\Delta P(\alpha=1))\end{array}$} & \multirow{2}{*}{$\begin{array}{r}\mathrm{C} 1: \text { Average } \\
\text { growth rates } \\
(\bar{g})\end{array}$} & \multirow{2}{*}{$\begin{array}{r}\text { C2: Sensitivity } \\
\text { to growth } \\
\left(\bar{\eta}_{+}\right)\end{array}$} & \multirow{2}{*}{$\begin{array}{r}\text { Correlation } \\
\operatorname{Corr}(\eta(p), g(p))\end{array}$} & \multicolumn{2}{|c|}{$\mathrm{C} 1 \mathrm{C} 2$} & \multicolumn{2}{|c|}{$\mathrm{C} 3$} \\
\hline & & & & & $\begin{array}{r}\text { Absolute } \\
\text { Contribution }\end{array}$ & $\begin{array}{r}\text { Relative } \\
\text { Contribution }\end{array}$ & $\begin{array}{l}\text { Absolute } \\
\text { Contribution }\end{array}$ & $\begin{array}{r}\text { Relative } \\
\text { Contribution }\end{array}$ \\
\hline $2005 / 06$ & -0.0152 & 0.0221 & -0.2692 & -0.9593 & -0.0065 & $43 \%$ & -0.0087 & $57 \%$ \\
\hline $2006 / 07$ & -0.0230 & 0.0376 & -0.2692 & -0.9088 & -0.0101 & $44 \%$ & -0.0129 & $56 \%$ \\
\hline $2007 / 08$ & -0.0168 & 0.0273 & -0.2535 & -0.8286 & -0.0069 & $41 \%$ & -0.0099 & $59 \%$ \\
\hline $2008 / 09$ & -0.0095 & 0.0156 & -0.2467 & -0.6707 & -0.0039 & $41 \%$ & -0.0056 & $59 \%$ \\
\hline $2009 / 10$ & -0.0138 & 0.0219 & -0.2287 & -0.8279 & -0.0050 & $36 \%$ & -0.0088 & $64 \%$ \\
\hline
\end{tabular}


Table PER-4: Social transition matrices by deciles: Peru 2007-10

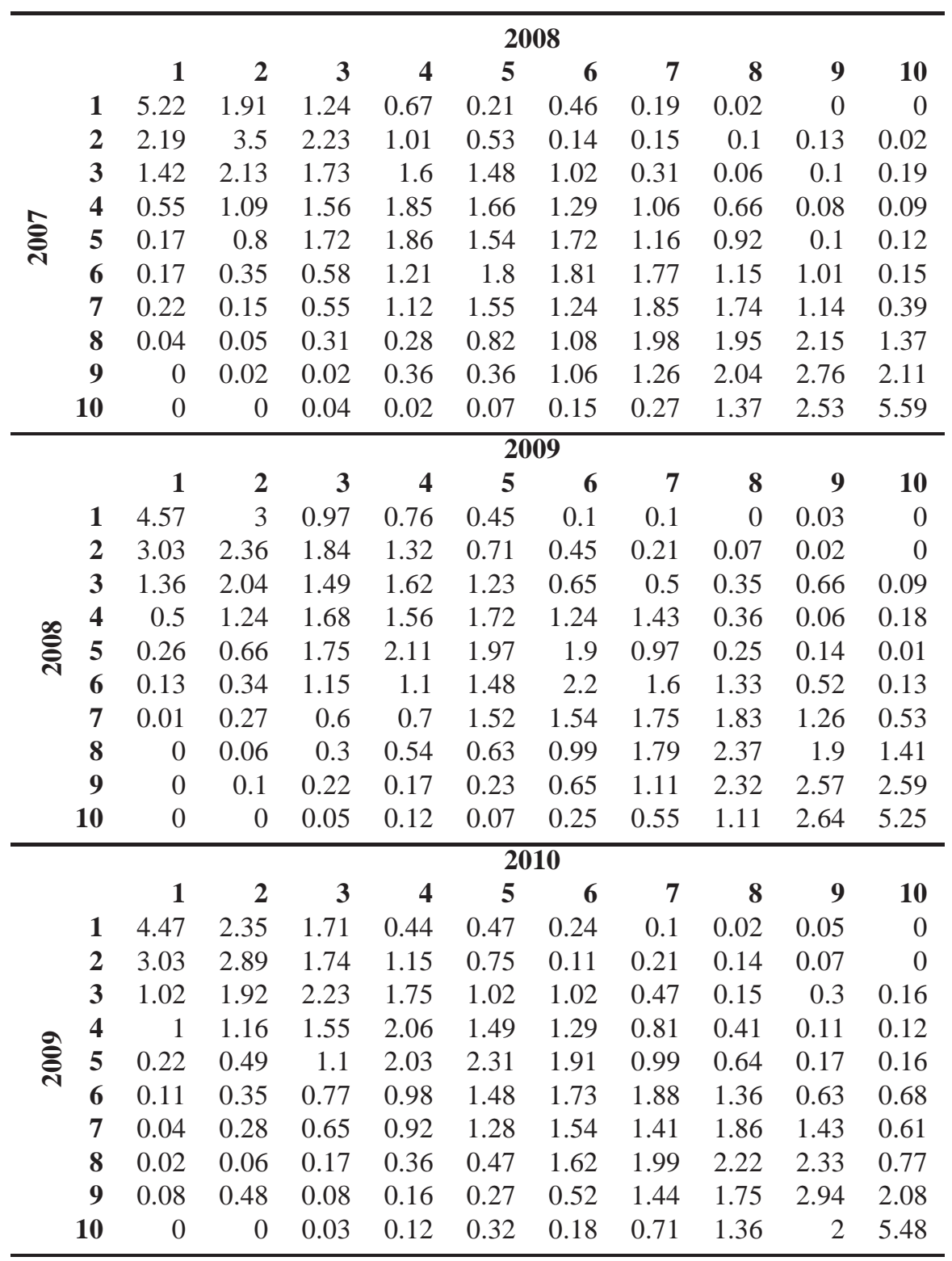


Table PER-5: Social transition matrices by deciles: Peru 2007-10

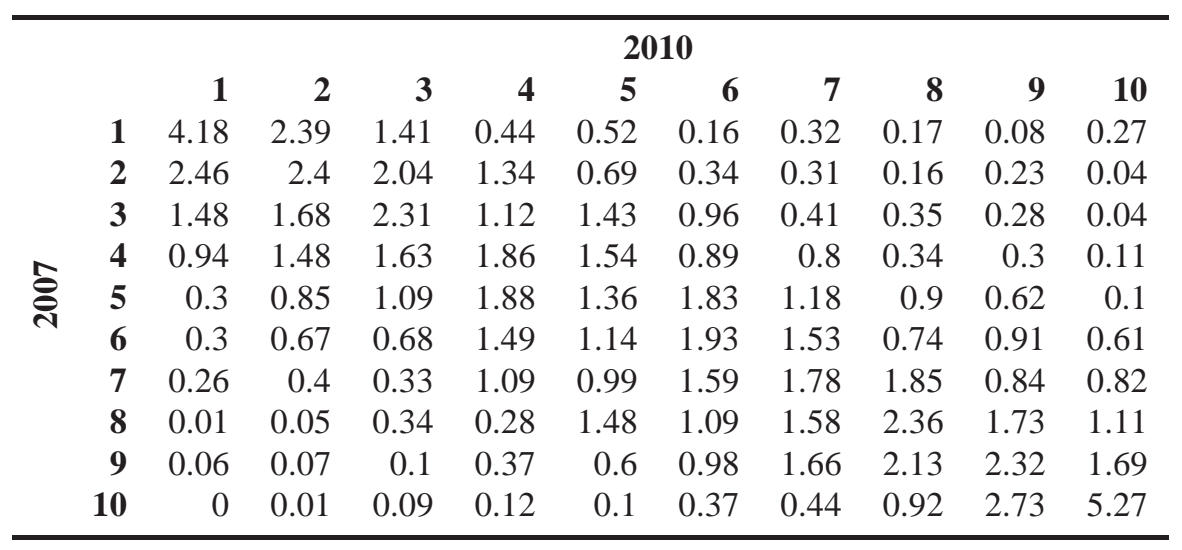


Table PER-6: Mobility statistics

\begin{tabular}{l|lrr|rrr|rrr}
\hline & \multicolumn{3}{|c|}{ Stayers } & \multicolumn{3}{c|}{ Downwards } & \multicolumn{3}{c}{ Upwards } \\
& All & $(p<=0.5)$ & $(p>0.5)$ & All & $(p<=0.5)$ & $(p>0.5)$ & All & $(p<=0.5)$ & $(p>0.5)$ \\
\hline $2007 / 08$ & $27.8 \%$ & $13.8 \%$ & $14.0 \%$ & $36.6 \%$ & $13.5 \%$ & $23.1 \%$ & $35.6 \%$ & $22.6 \%$ & $13.0 \%$ \\
$2008 / 09$ & $26.1 \%$ & $12.0 \%$ & $14.1 \%$ & $37.4 \%$ & $14.6 \%$ & $22.8 \%$ & $36.5 \%$ & $23.4 \%$ & $13.1 \%$ \\
$2009 / 10$ & $27.7 \%$ & $14.0 \%$ & $13.8 \%$ & $36.1 \%$ & $13.5 \%$ & $22.6 \%$ & $36.1 \%$ & $22.5 \%$ & $13.6 \%$ \\
$2007 / 10$ & $25.8 \%$ & $12.1 \%$ & $13.7 \%$ & $38.3 \%$ & $13.8 \%$ & $24.5 \%$ & $35.9 \%$ & $24.1 \%$ & $11.8 \%$ \\
\hline
\end{tabular}


Figure PER-1: Change in Headcount, growth and redistribution: Peru 2005/10

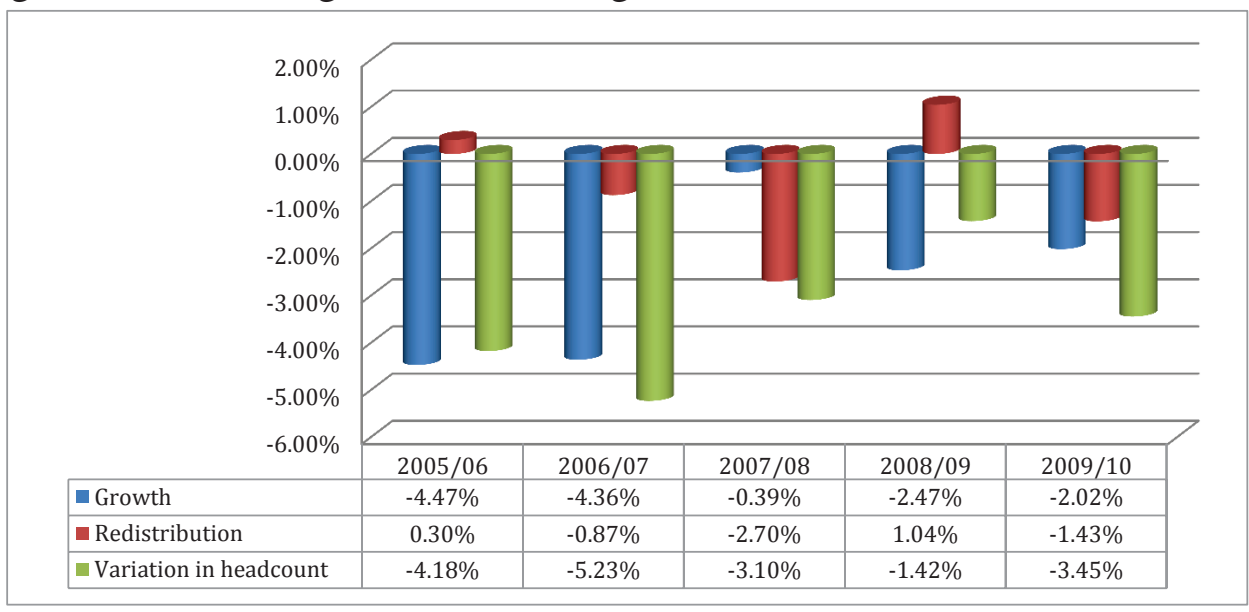

Figure PER-2: Change in poverty gap, growth and redistribution: Peru 2005/10

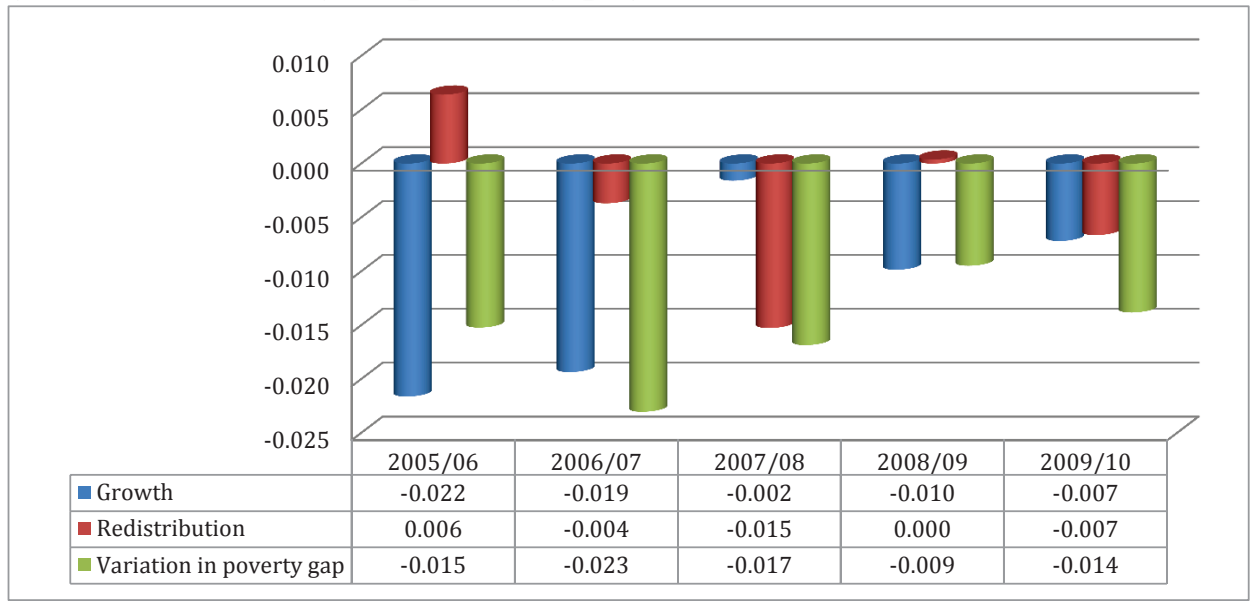


Figure PER-3: Growth incidence curves in Peru : $\left(Q_{2}(p)-Q_{1}(p)\right) / Q_{1}\left({ }_{p}\right)$
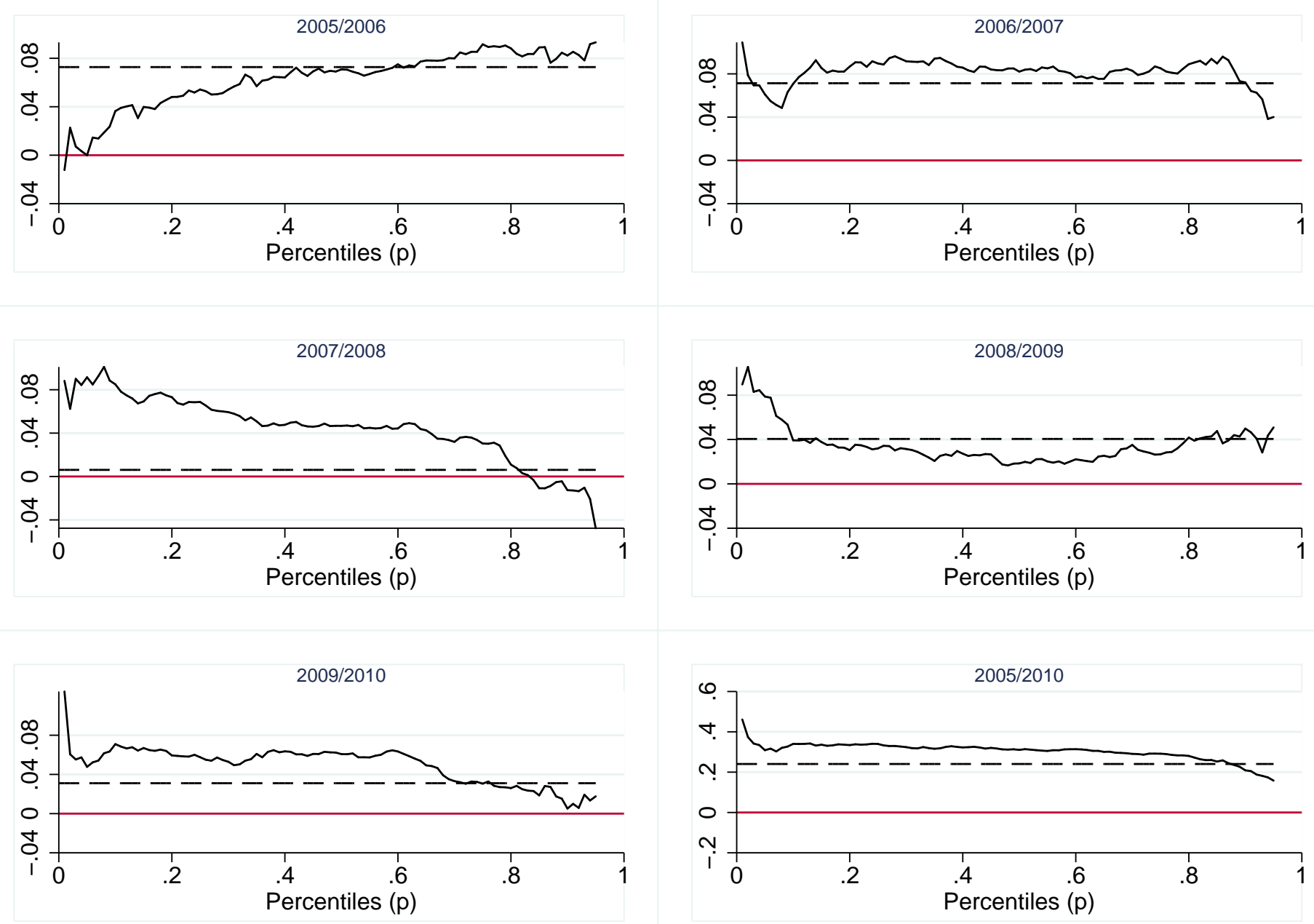
Figure PER-4: First order absolutely pro-poor : Peru 2005/10

Primal approach: $\left(\left(P_{2}(z, \alpha=0)-P_{1}(z, \alpha=0)\right)\right.$
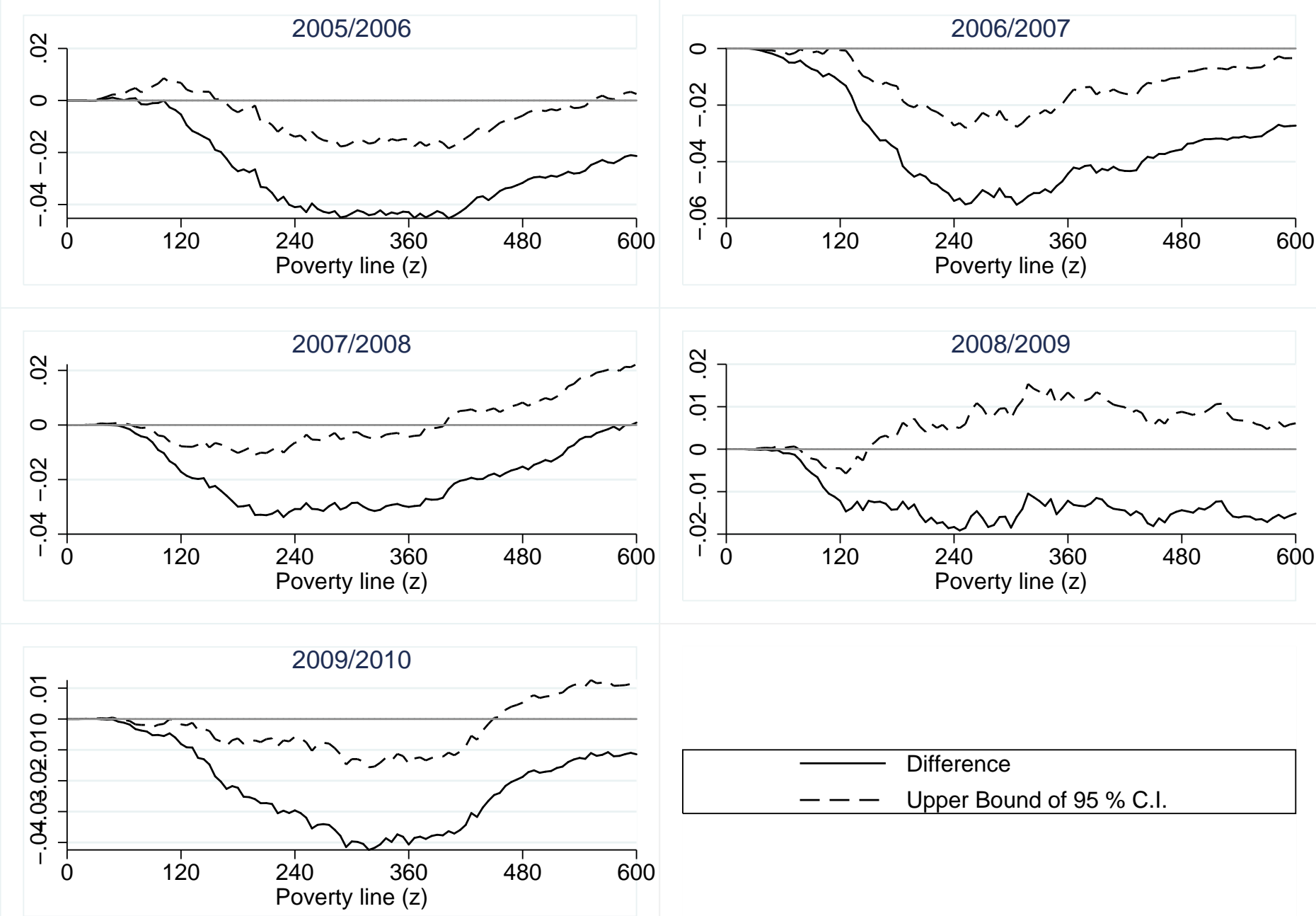
Figure PER-5: First order absolutely pro-poor : Peru 2005/10

Dual approach: $\left(\left(Q_{2}(p)-Q_{1}(p)\right)\right)$
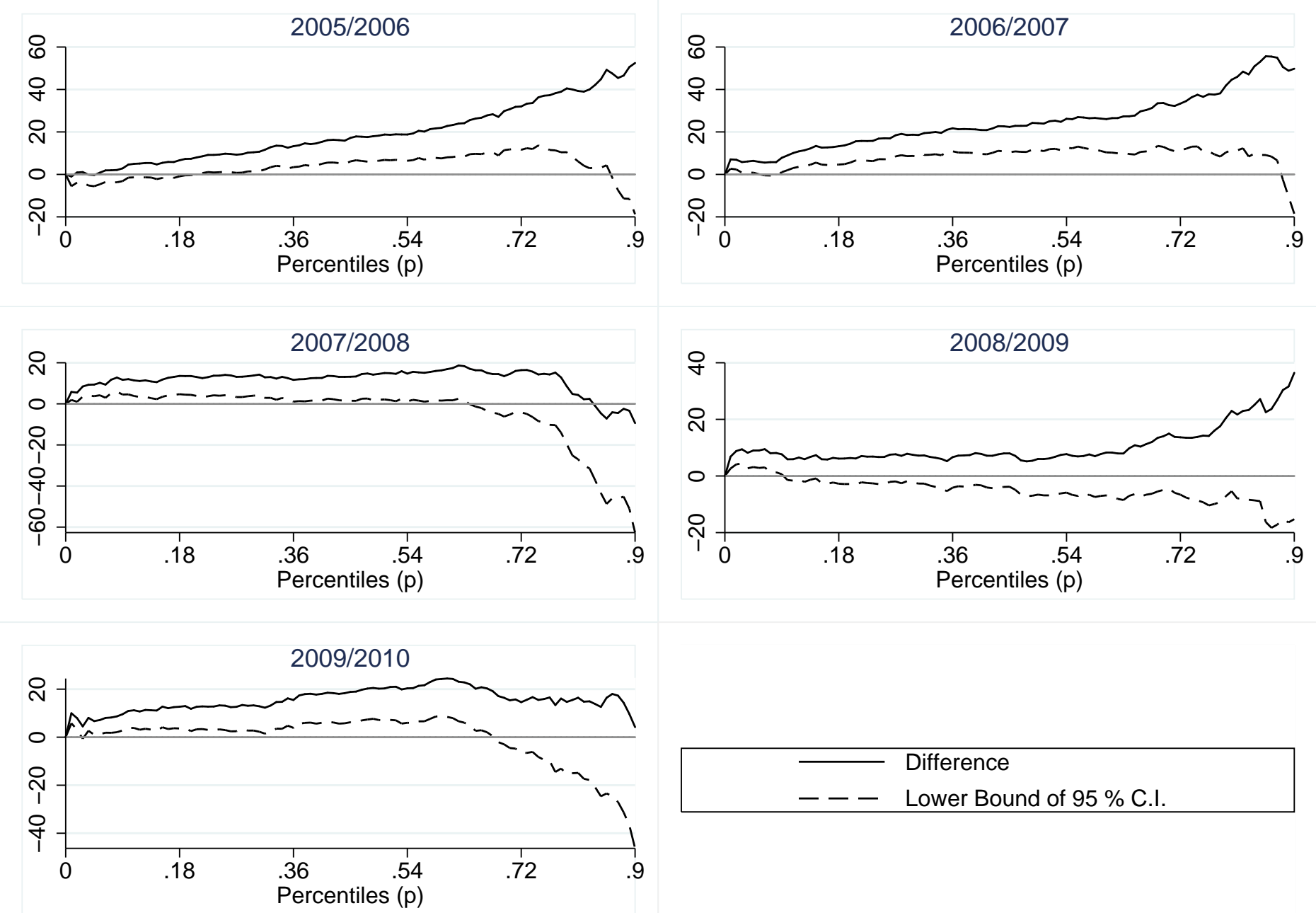
Figure PER-6: Second order absolutely pro-poor : Peru 2005/10

Primal approach: $\left(\left(z P_{2}(z, \alpha=1)-z P_{1}(z, \alpha=1)\right)\right.$
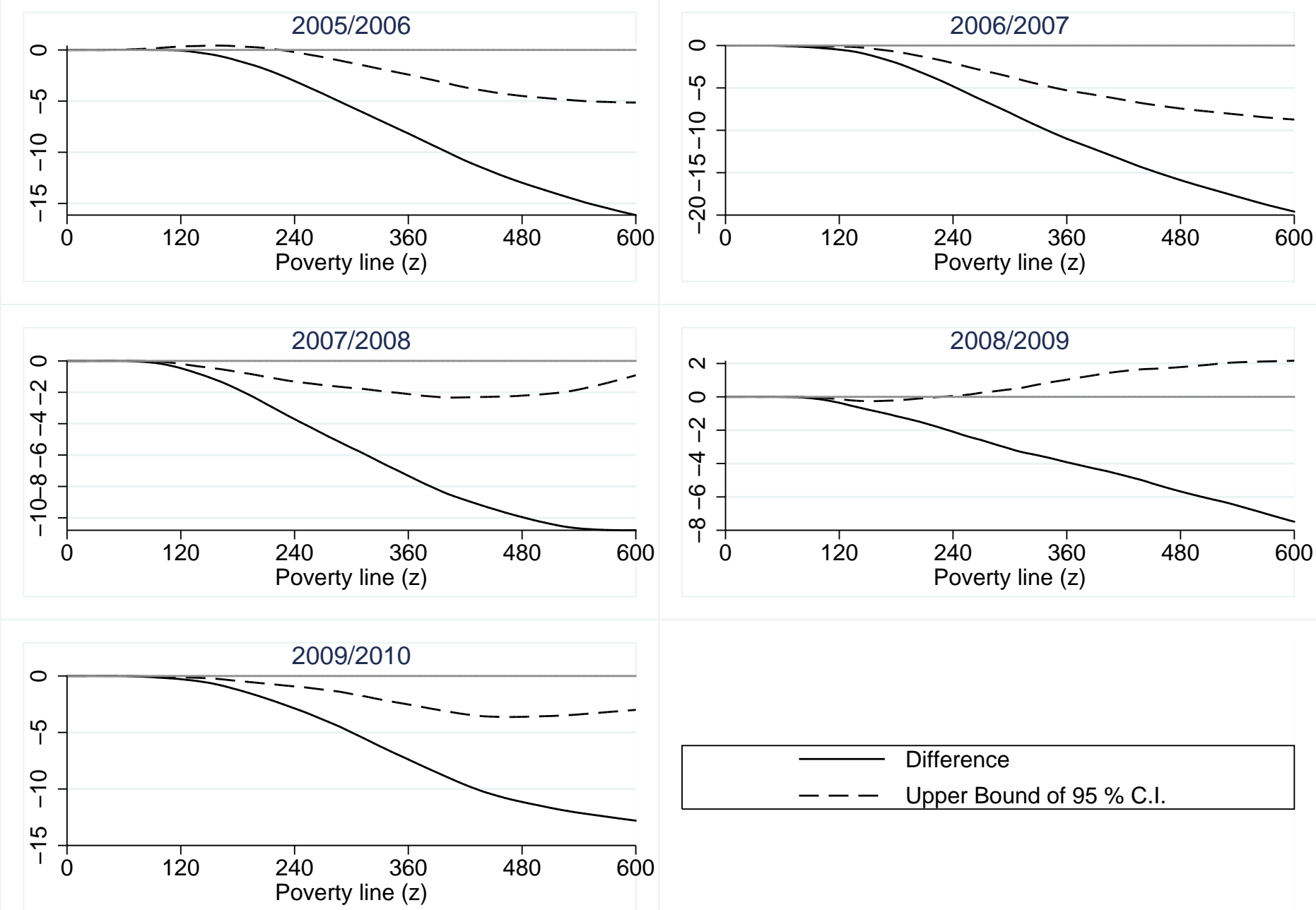
Figure PER-7: Second order absolutely pro-poor : Peru 2005/10

Dual approach: $\left(\left(G L_{2}(p)-G L_{1}(p)\right)\right)$
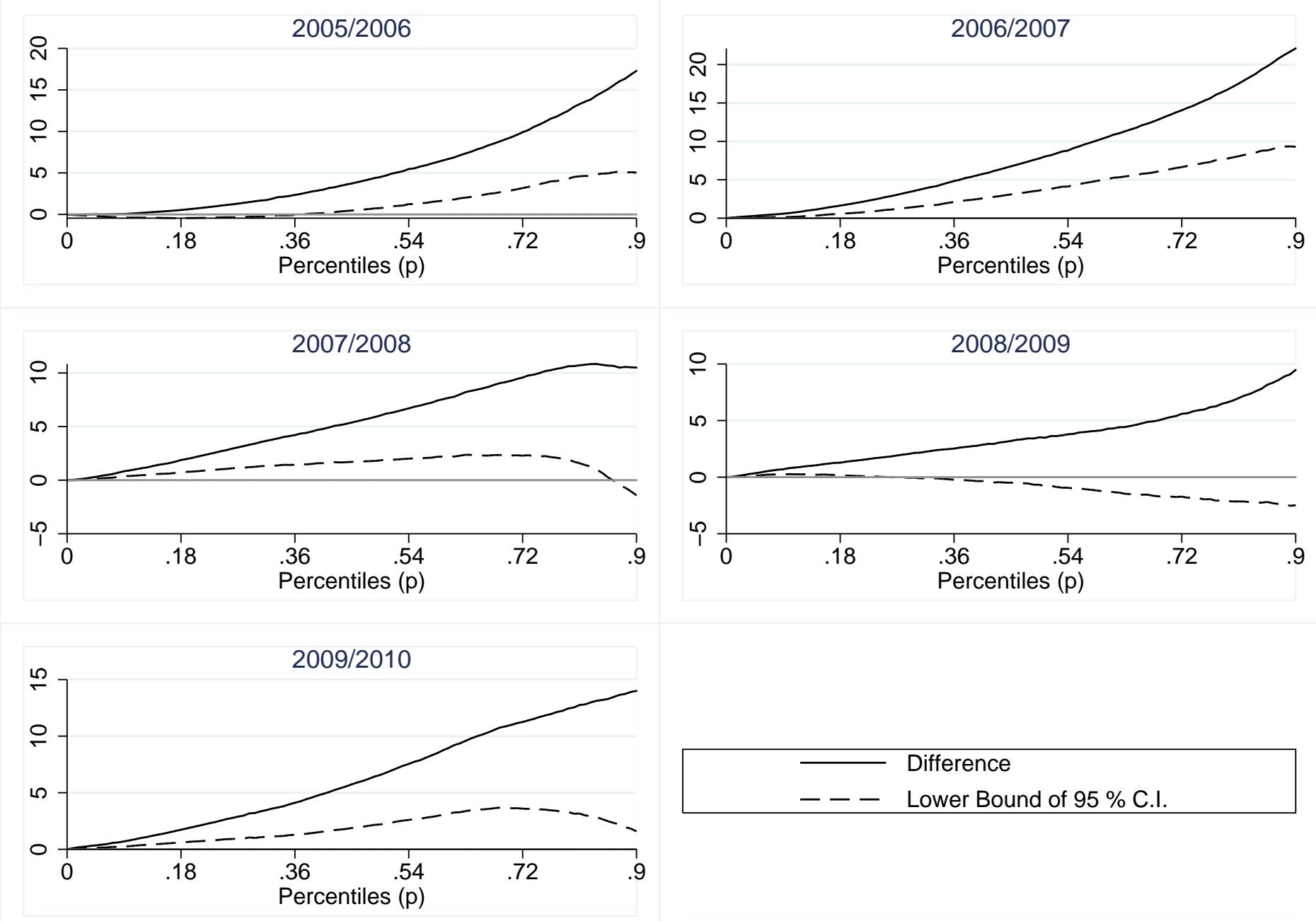
Figure PER-8: First order relatively pro-poor : Peru 2005/10

Primal approach: $\left(\left(P_{2}((1+g) z, \alpha=0)-P_{1}(z, \alpha=0)\right)\right.$
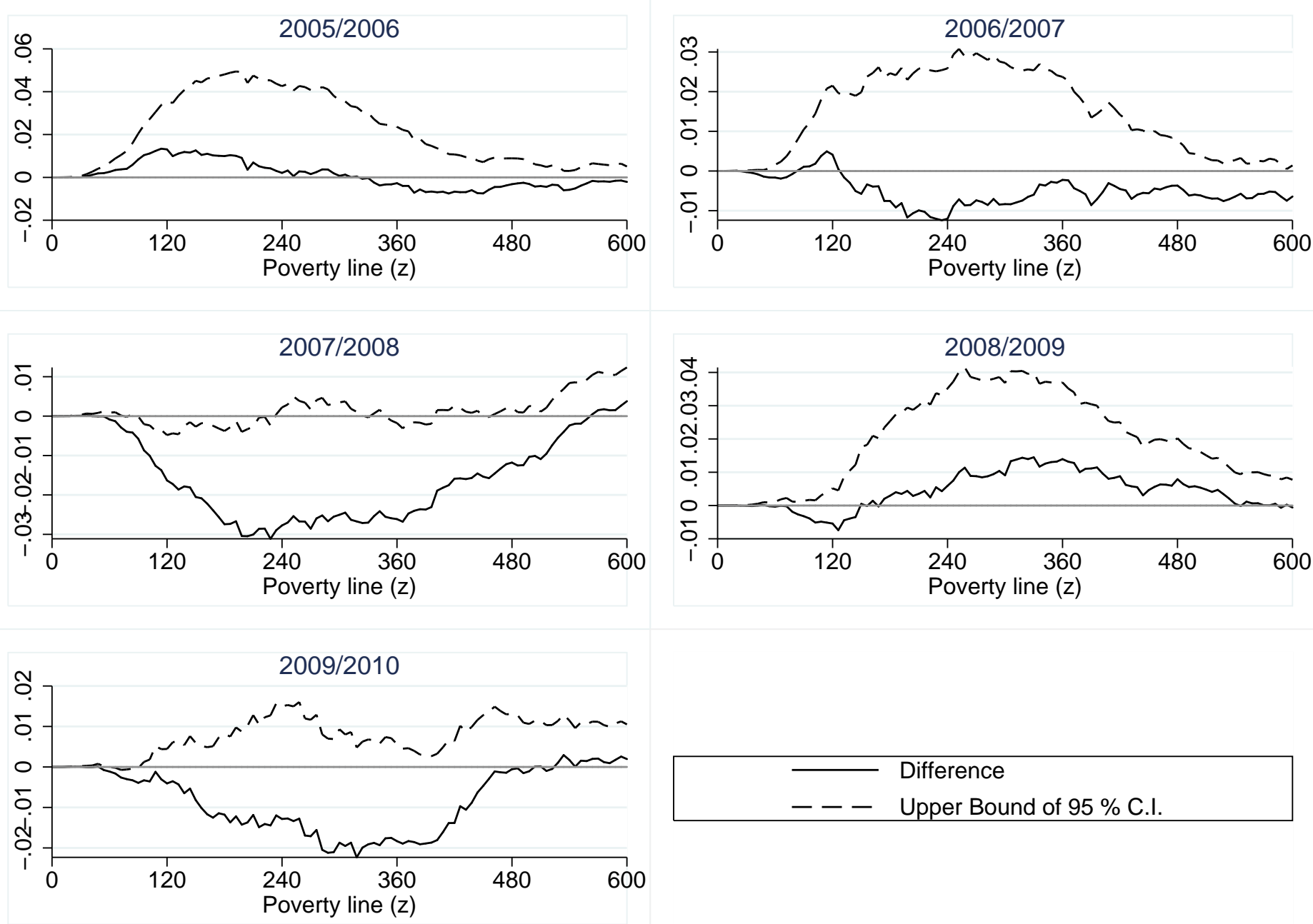
Figure PER-9: First order relatively pro-poor : Peru 2005/10

Dual approach: $\left(\left(Q_{2}(p) / Q_{1}(p)-\mu_{2} / \mu_{1}\right)\right)$
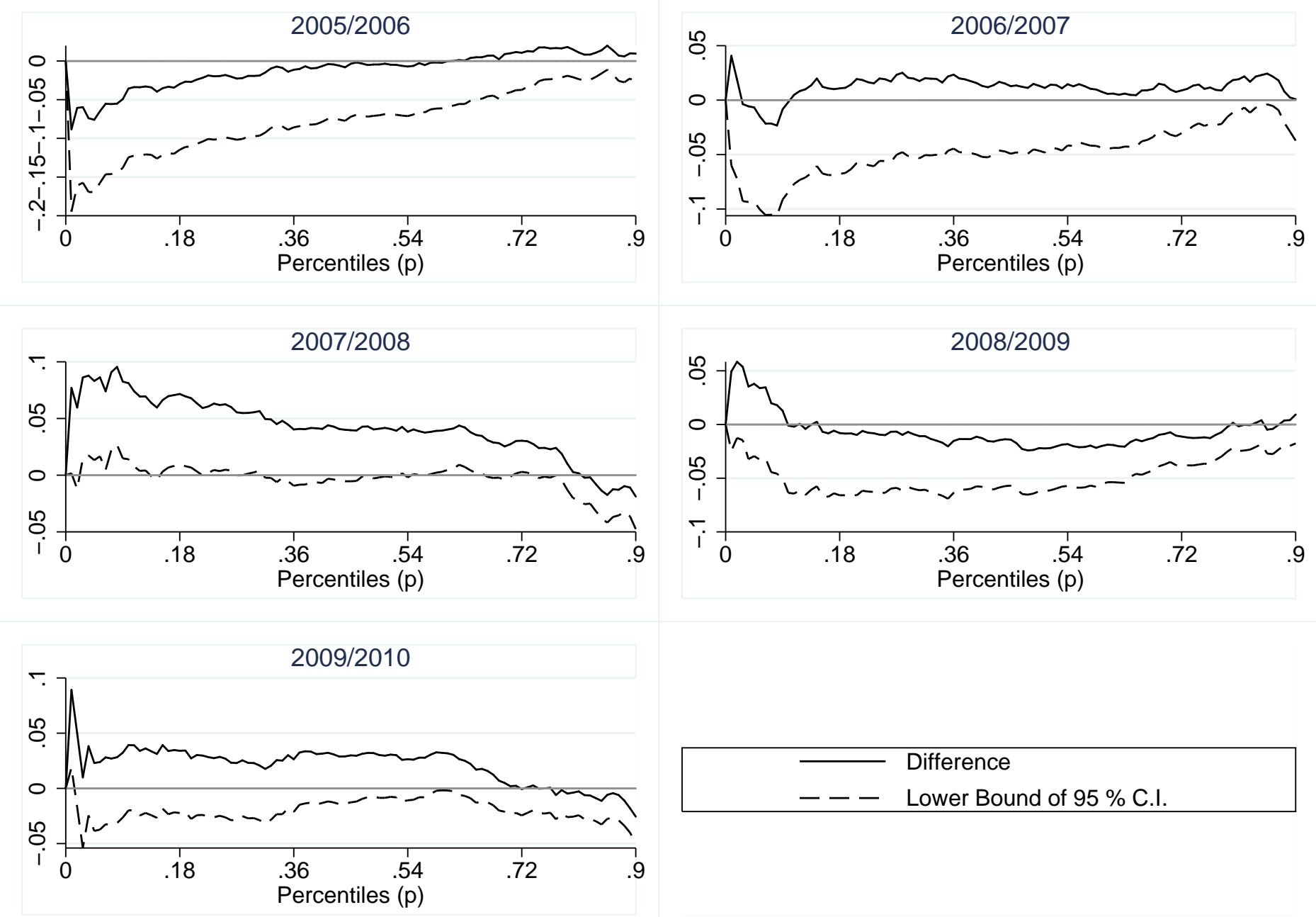
Figure PER-10: Second order relatively pro-poor : Peru 2005/10

Primal approach: $\left(\left(P_{2}((1+g) z, \alpha=1)-P_{1}(z, \alpha=1)\right)\right.$
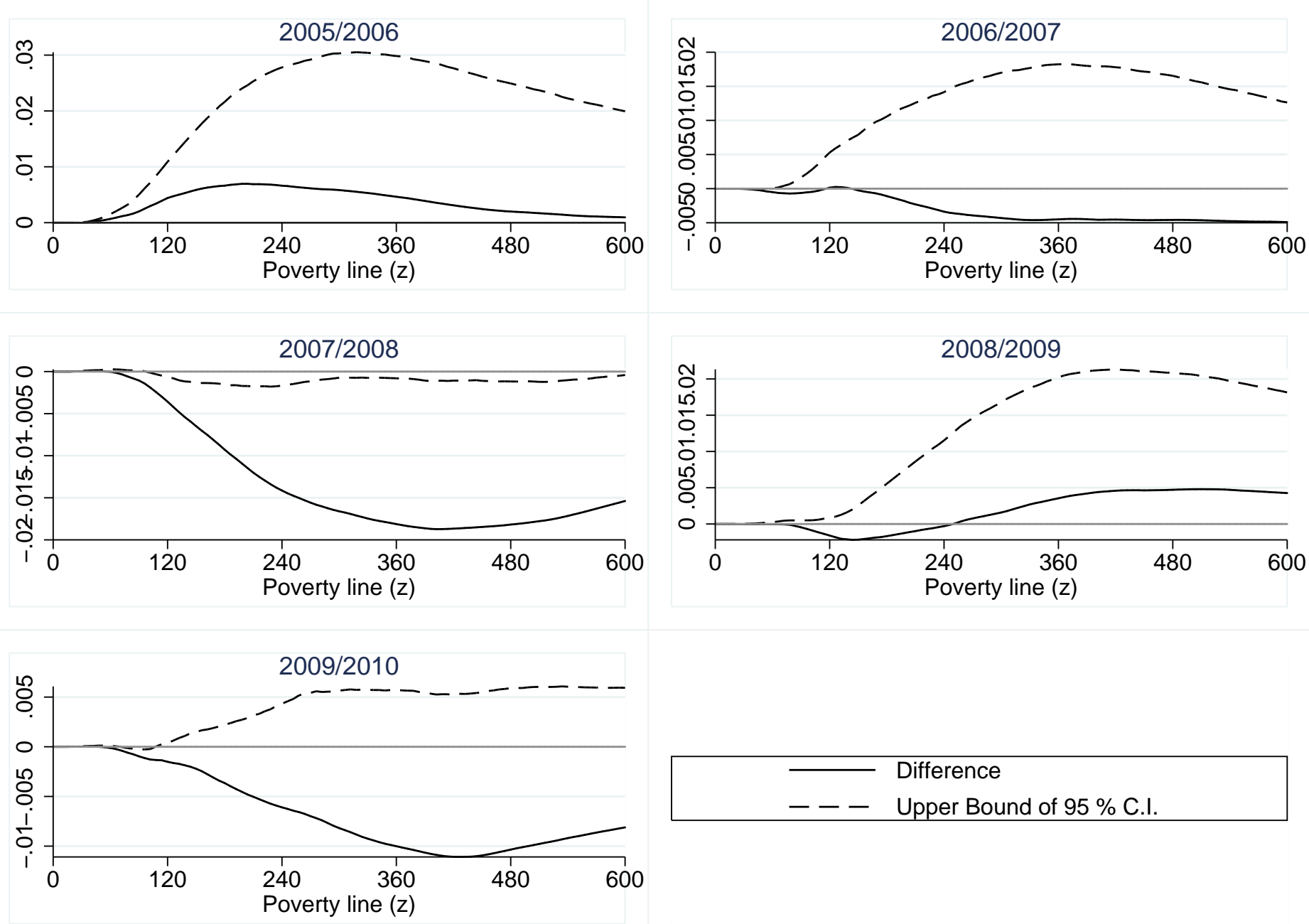
Figure PER-11: Second order relatively pro-poor : Peru 2005/10

Dual approach: $\left(\left(G L_{2}(p) / G L_{1}(p)-\mu_{2} / \mu_{1}\right)\right)$
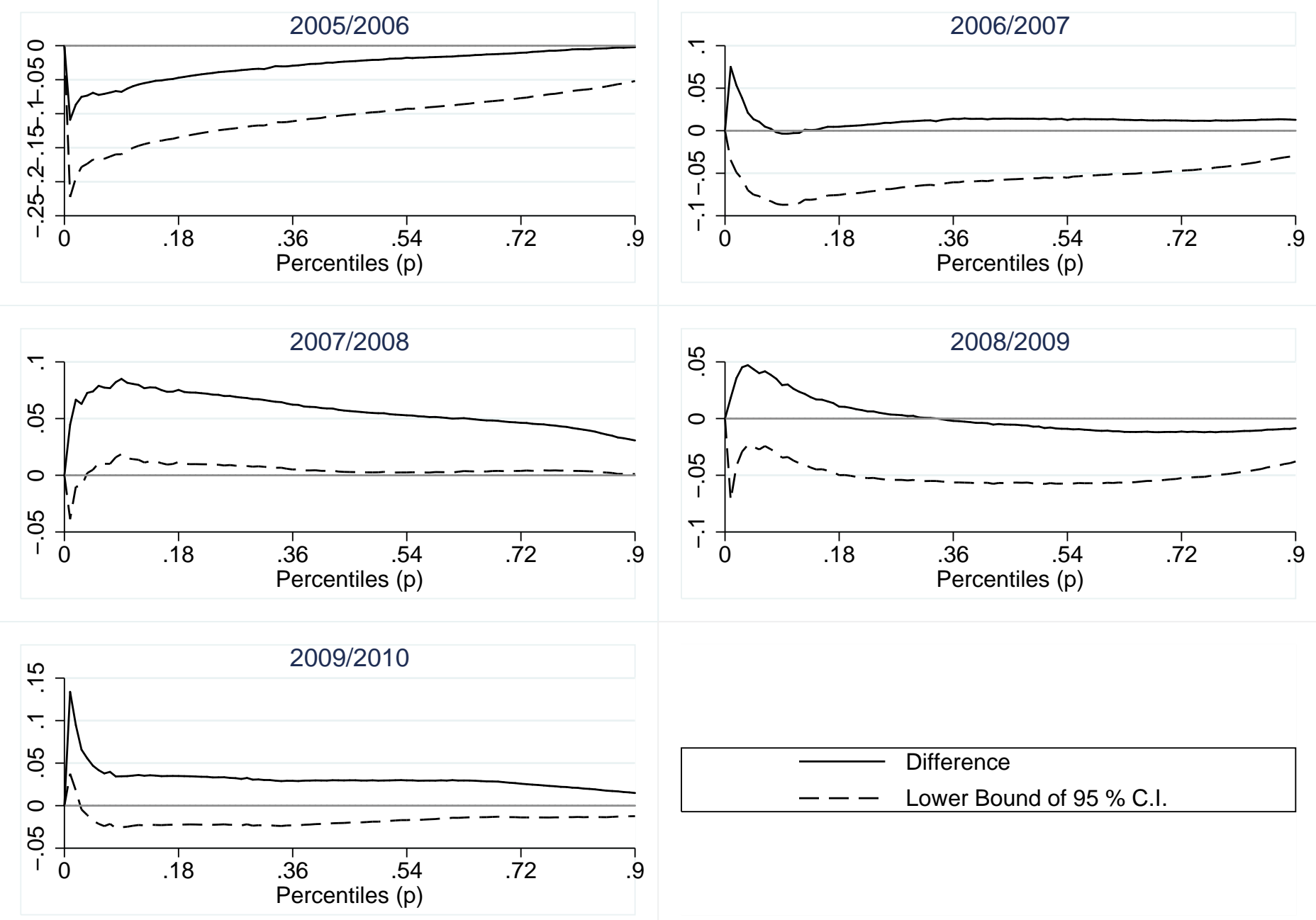
Figure PER-12: First order relatively pro-poor: Peru 2007-2010

Primal approach: $\left(\left(P_{2}((1+g) z, \alpha=0)-P_{1}(z, \alpha=0)\right)\right.$

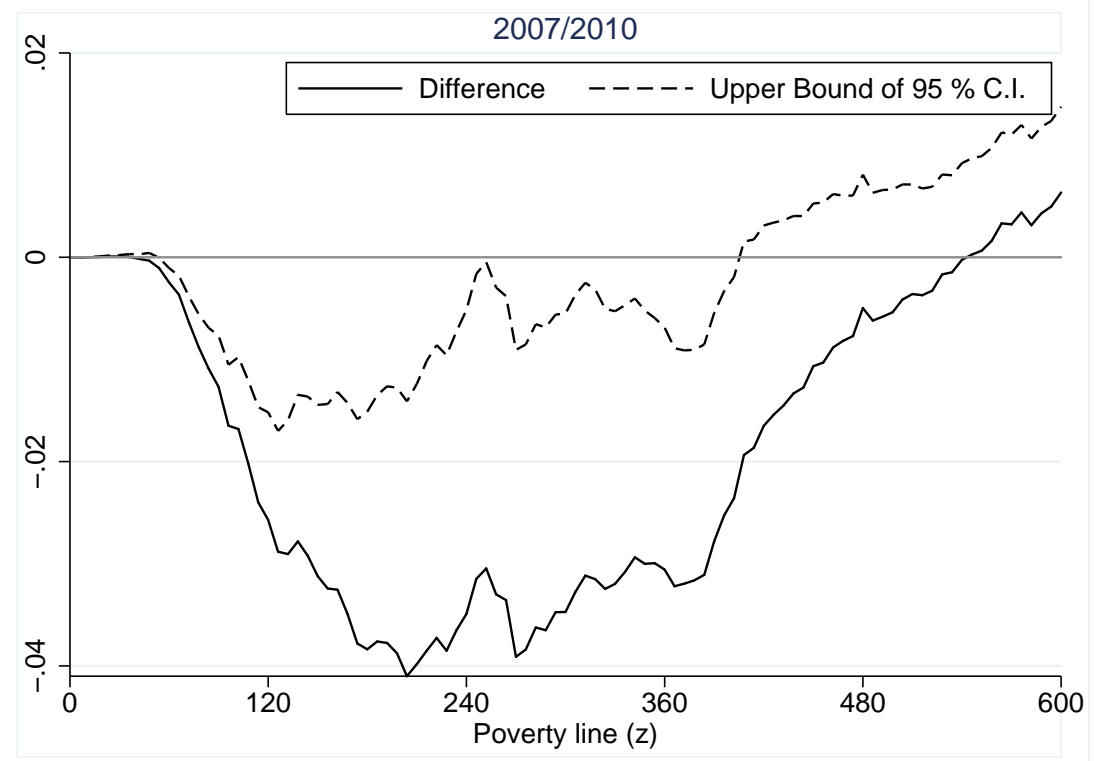

Figure PER-13: Second order relatively pro-poor: Peru 2007-2010

Primal approach: $\left(\left(P_{2}((1+g) z, \alpha=1)-P_{1}(z, \alpha=0)\right)\right.$

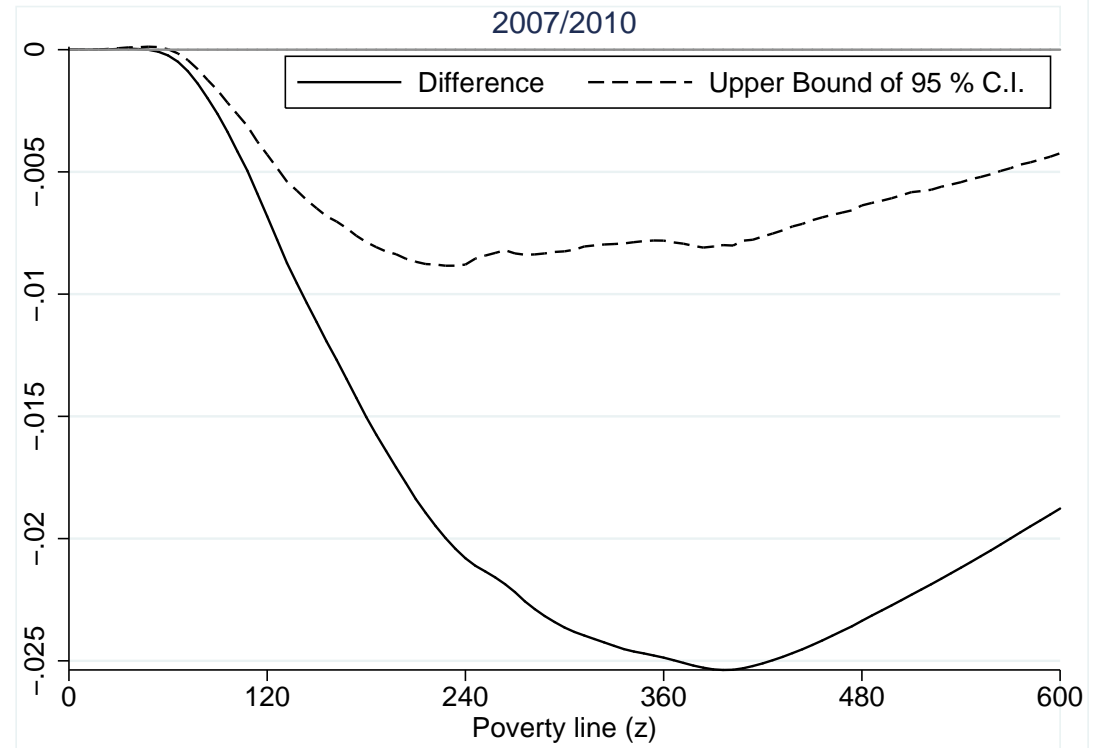


Figure PER-14: Decomposition of change in poverty gap into pro-poor growth components - Kraay 2004 approach -

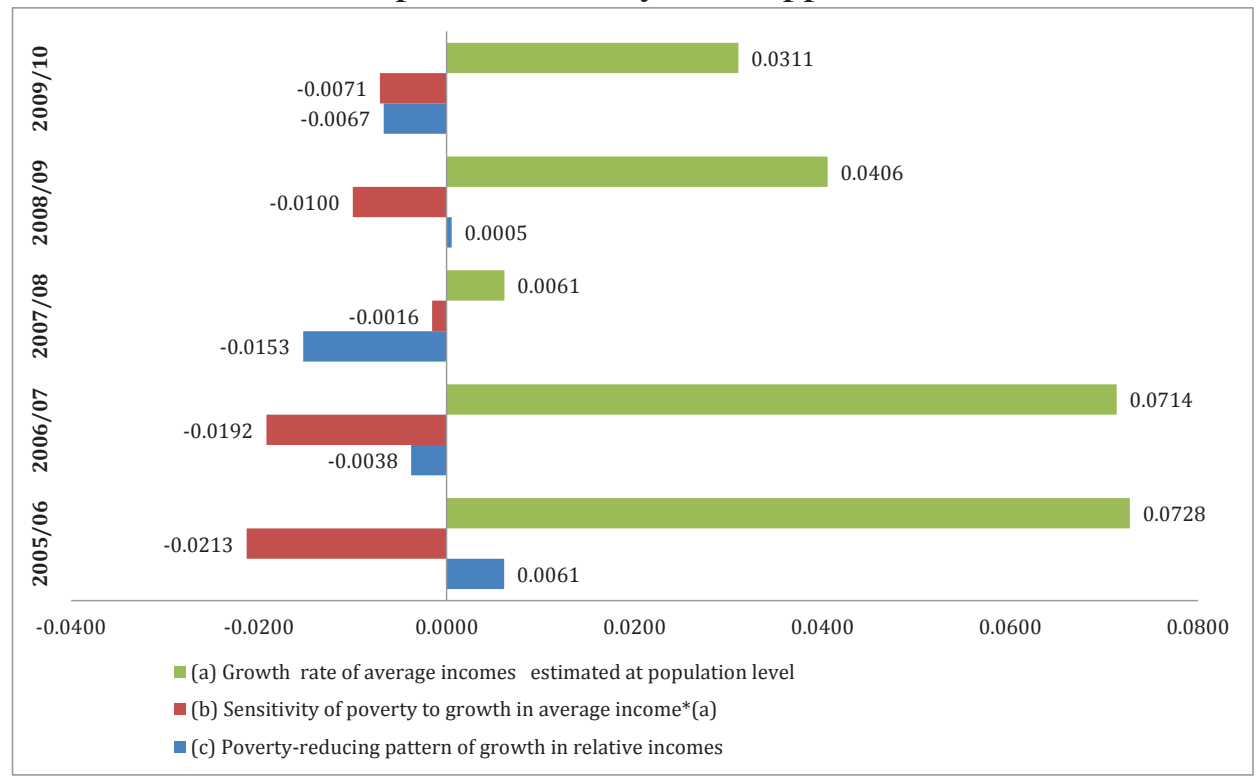

Figure PER-15: Decomposition of change in poverty gap into pro-poor growth components - New approach -

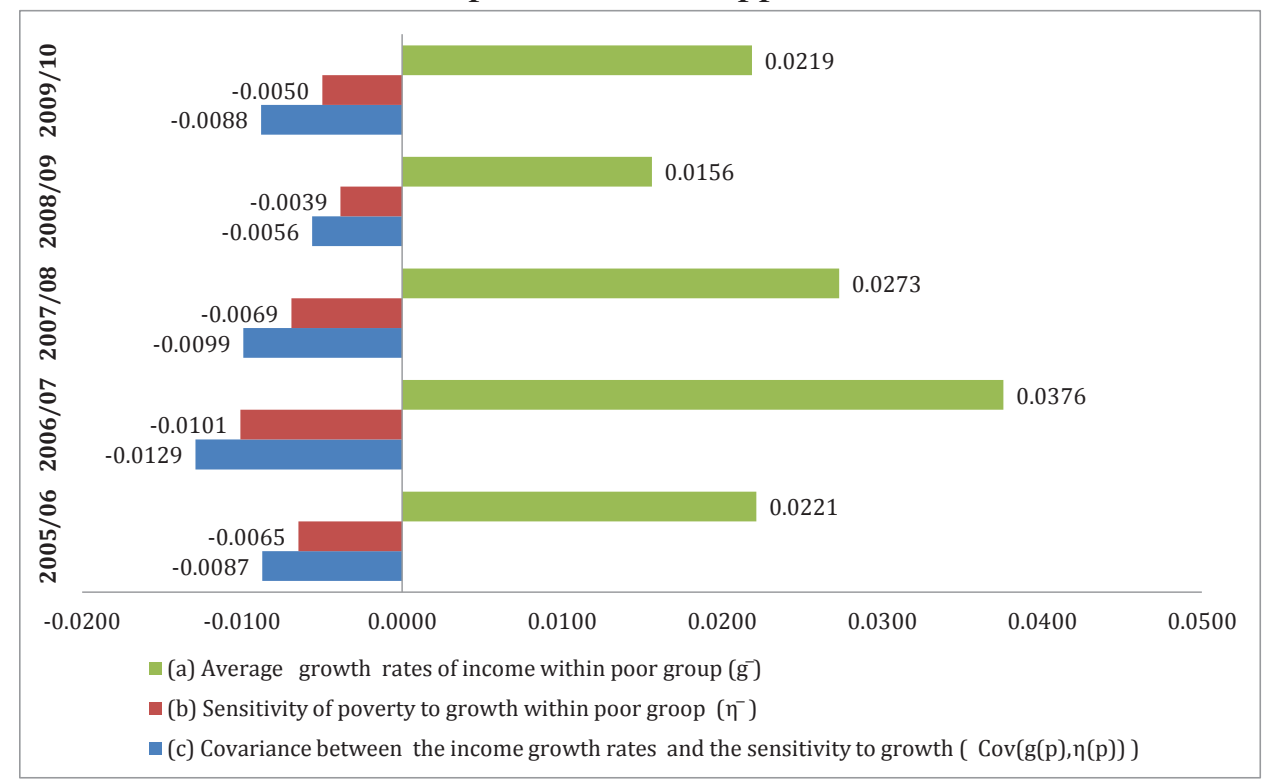


Figure PER-16: Non-anonymous first order absolutely pro-poor : Peru 2007/10 (Initial period of reference: $\left(E\left[y_{2} \mid y 1=Q_{1}(p)\right] / Q_{1}(p)-1\right)$
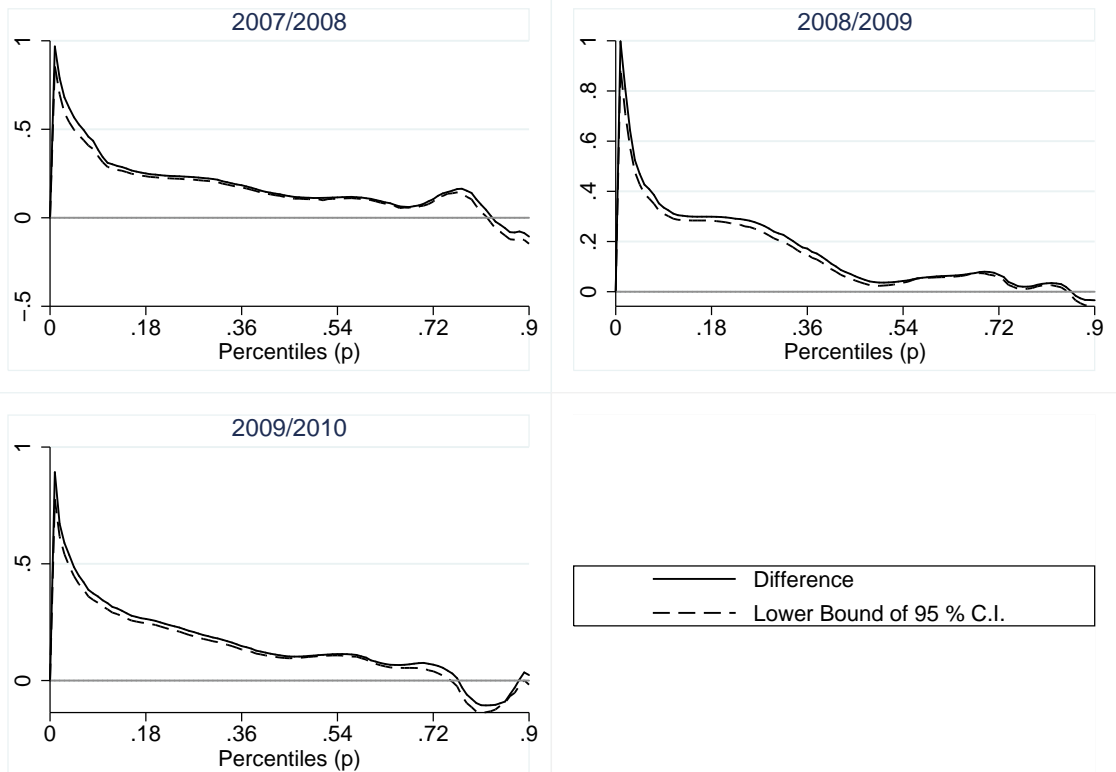

Figure PER-17: Non-anonymous first order absolutely pro-poor : Peru 2007/10 (Final period of reference: $\left(Q_{2}(p) / E\left[y_{1} \mid y 2=Q_{2}(p)\right]-1\right)$
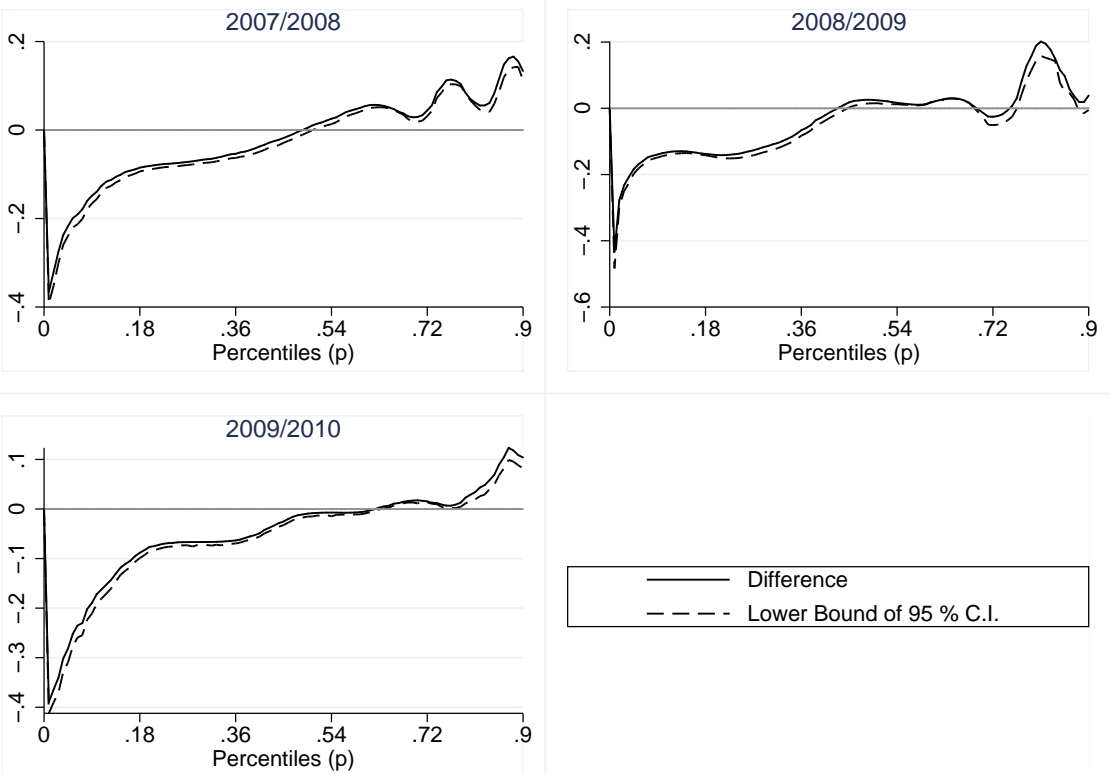
Figure PER-18: The inter temporal pro-poor growth: Peru 2007/10 $\left(0.5\left[\int y_{2} d \Phi\left(y_{2} \mid Q^{*}(p)\right)-\int y_{1} d \Phi\left(y_{1} \mid Q^{*}(p)\right)\right] / Q^{*}(p)\right)$
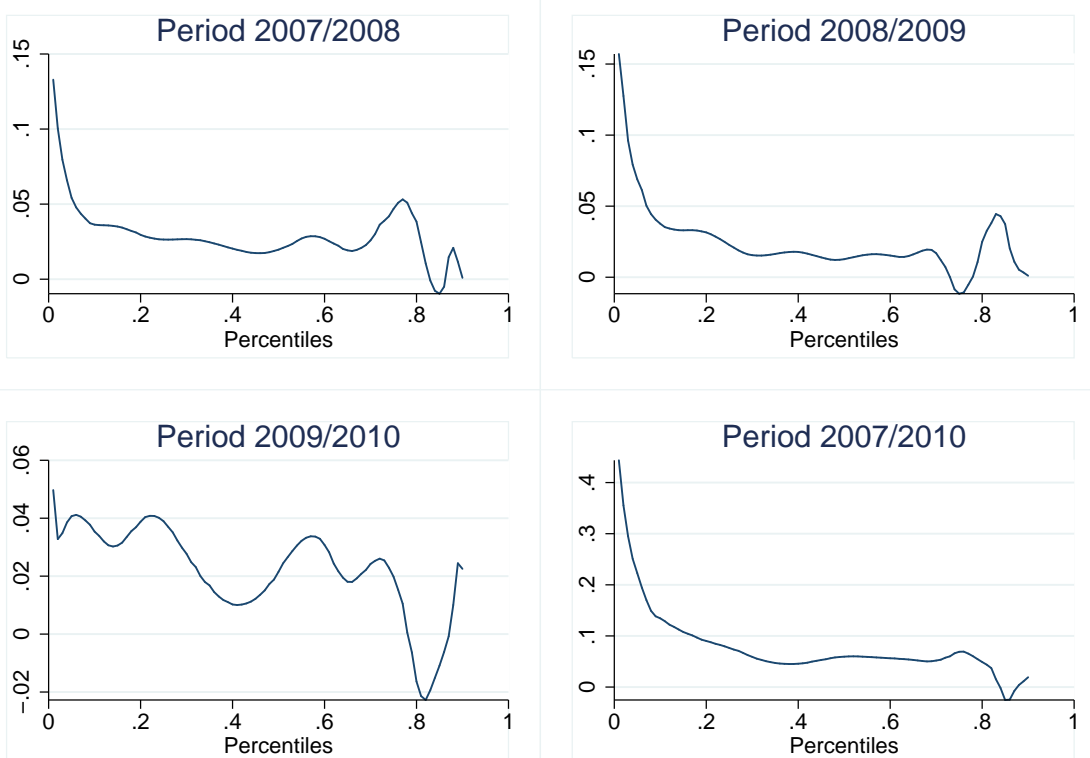


\section{The Ecuadorian results}


Table ECU-1: Trend of average per capita income, poverty and inequality: Ecuador 2005/10

\begin{tabular}{l|rl|rl|rl|rl}
\hline Year & $\begin{array}{r}\text { Average } \\
\text { income }\end{array}$ & $\begin{array}{l}\text { Yearly } \\
\text { variation }\end{array}$ & Headcount & $\begin{array}{l}\text { Yearly } \\
\text { variation }\end{array}$ & $\begin{array}{r}\text { Poverty } \\
\text { gap }\end{array}$ & $\begin{array}{l}\text { Yearly } \\
\text { variation }\end{array}$ & $\begin{array}{r}\text { Gini } \\
\text { index }\end{array}$ & $\begin{array}{l}\text { Yearly } \\
\text { variation }\end{array}$ \\
\hline 2005 & 146.3 & & 42.2 & & 18.8 & & 0.548 & \\
2006 & 159.8 & $13.50^{*}$ & 37.6 & $-4.56^{* * *}$ & 15.5 & $-3.37 * * *$ & 0.540 & -0.0090 \\
2007 & 167.1 & 7.3 & 36.7 & -0.87 & 15.3 & -0.13 & 0.551 & 0.0110 \\
2008 & 157.4 & -9.7 & 35.1 & $-1.65^{*}$ & 14.5 & $-0.85^{*}$ & 0.515 & $-0.036^{* * *}$ \\
2009 & 148.9 & $-8.52^{*}$ & 36.0 & 0.94 & 14.4 & -0.04 & 0.504 & -0.0110 \\
2010 & 162.3 & $13.42^{* * *}$ & 32.8 & $-3.27^{* * *}$ & 12.6 & $-1.80^{* * *}$ & 0.505 & 0.0010 \\
\hline
\end{tabular}

Sampling design is fully taken into account in computing the standard errors.

${ }^{*} p \leq 0.10,{ }^{* *} p \leq 0.05,{ }^{* * *} p \leq 0.01$. 
Table ECU-2: Decomposition of change in poverty gap into pro-poor growth components

Kraay (2004) approach - Ecuador 2005/10

\begin{tabular}{r|rrr|rr|rr}
\hline \multirow{2}{*}{ Period } & $\begin{array}{r}\text { Poverty } \\
\text { Change }\end{array}$ & $\begin{array}{r}\mathrm{C} \text { : Average } \\
\text { growth } \\
(\Delta P(\alpha)=1))\end{array}$ & $\begin{array}{r}\mathrm{C} 2 \text { : Sensitivity } \\
\text { to growth } \\
\left(\int \eta(p)\right)\end{array}$ & $\begin{array}{r}\text { C1C2 } \\
\text { Absolute } \\
\text { Contribution }\end{array}$ & $\begin{array}{r}\text { Relative } \\
\text { Contribution }\end{array}$ & $\begin{array}{r}\text { Pattern of growth in relative incomes } \\
\text { Absolute } \\
\text { Contribution }\end{array}$ \\
\hline $2005 / 06$ & -0.0337 & 0.0923 & -0.2172 & -0.0201 & 59 & -0.0137 \\
Relative \\
$2006 / 07$
\end{tabular}

Table ECU-3: Decomposition of change in poverty gap into pro-poor growth components New approach - Ecuador 2005/10

\begin{tabular}{|c|c|c|c|c|c|c|c|c|}
\hline \multirow[b]{2}{*}{ Period } & \multirow{2}{*}{$\begin{array}{r}\text { Poverty } \\
\text { Change } \\
(\Delta P(\alpha=1))\end{array}$} & \multirow{2}{*}{$\begin{array}{l}\text { C1: Average } \\
\text { growth rates } \\
(\bar{g})\end{array}$} & \multirow{2}{*}{$\begin{array}{r}\text { C2: Sensitivity } \\
\text { to growth } \\
\left(\int \eta(p)\right)\end{array}$} & \multirow{2}{*}{$\begin{array}{r}\text { Correlation } \\
\operatorname{Corr}(\eta(p), g(p))\end{array}$} & \multicolumn{2}{|c|}{$\mathrm{C} 1 \mathrm{C} 2$} & \multicolumn{2}{|c|}{ C3 } \\
\hline & & & & & $\begin{array}{r}\text { Absolute } \\
\text { Contribution }\end{array}$ & $\begin{array}{r}\text { Relative } \\
\text { Contribution }\end{array}$ & $\begin{array}{r}\text { Absolute } \\
\text { Contribution }\end{array}$ & $\begin{array}{r}\text { Relative } \\
\text { Contribution }\end{array}$ \\
\hline $2005 / 06$ & -0.0337 & 0.0772 & -0.2172 & -0.5630 & -0.0168 & 50 & -0.0170 & 50 \\
\hline $2006 / 07$ & -0.0013 & -0.0026 & -0.2022 & -0.2374 & 0.0005 & -41 & -0.0018 & 141 \\
\hline $2007 / 08$ & -0.0085 & 0.0161 & -0.2052 & -0.5421 & -0.0033 & 39 & -0.0052 & 61 \\
\hline $2008 / 09$ & -0.0004 & 0.0043 & -0.2041 & 0.0469 & -0.0009 & 199 & 0.0004 & -99 \\
\hline $2009 / 10$ & -0.0180 & 0.0380 & -0.2000 & -0.5855 & -0.0076 & 42 & -0.0104 & 58 \\
\hline
\end{tabular}


Figure ECU-1: Change in Headcount, growth and redistribution: Ecuador $2005 / 10$

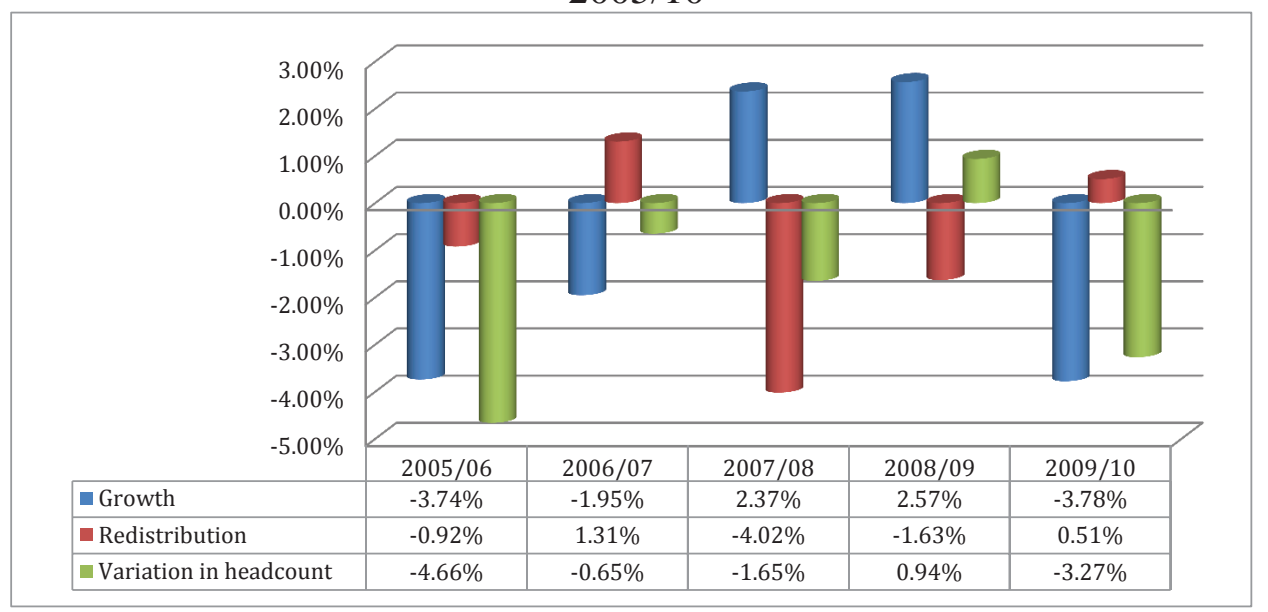

Figure ECU-2: Change in poverty gap, growth and redistribution: Ecuador

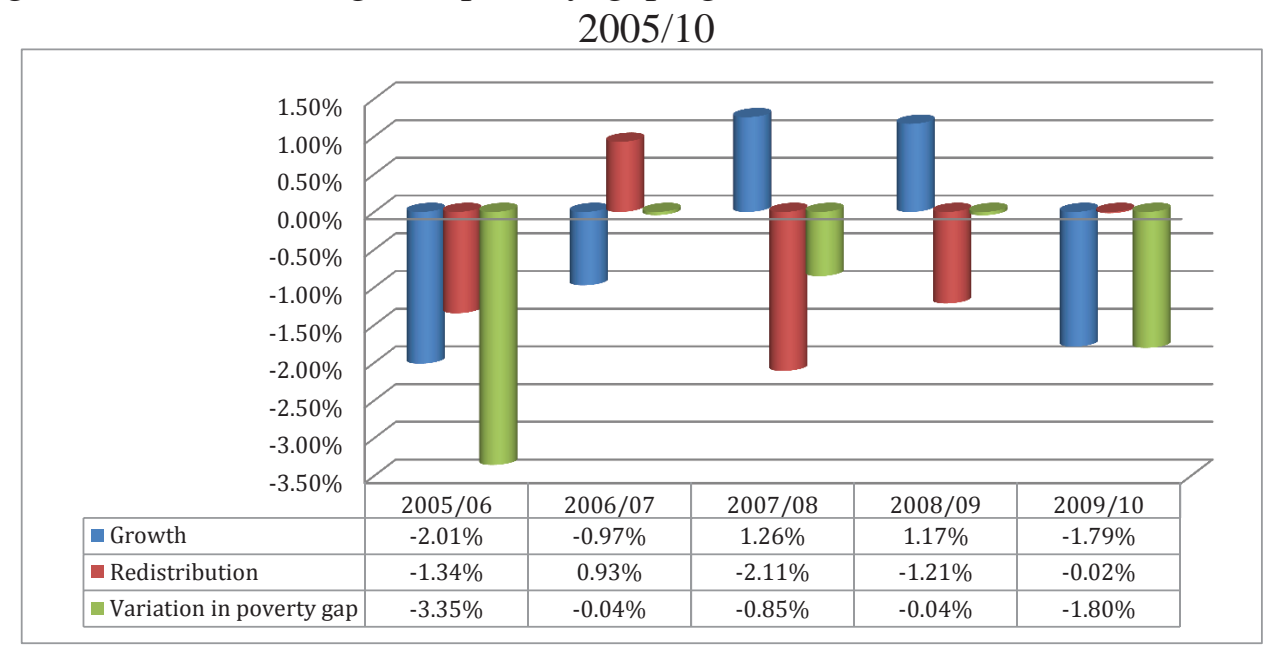


Figure ECU-3: Growth incidence curves in Ecuador : $\left(Q_{2}(p)-Q_{1}(p)\right) / Q_{1}(p)$
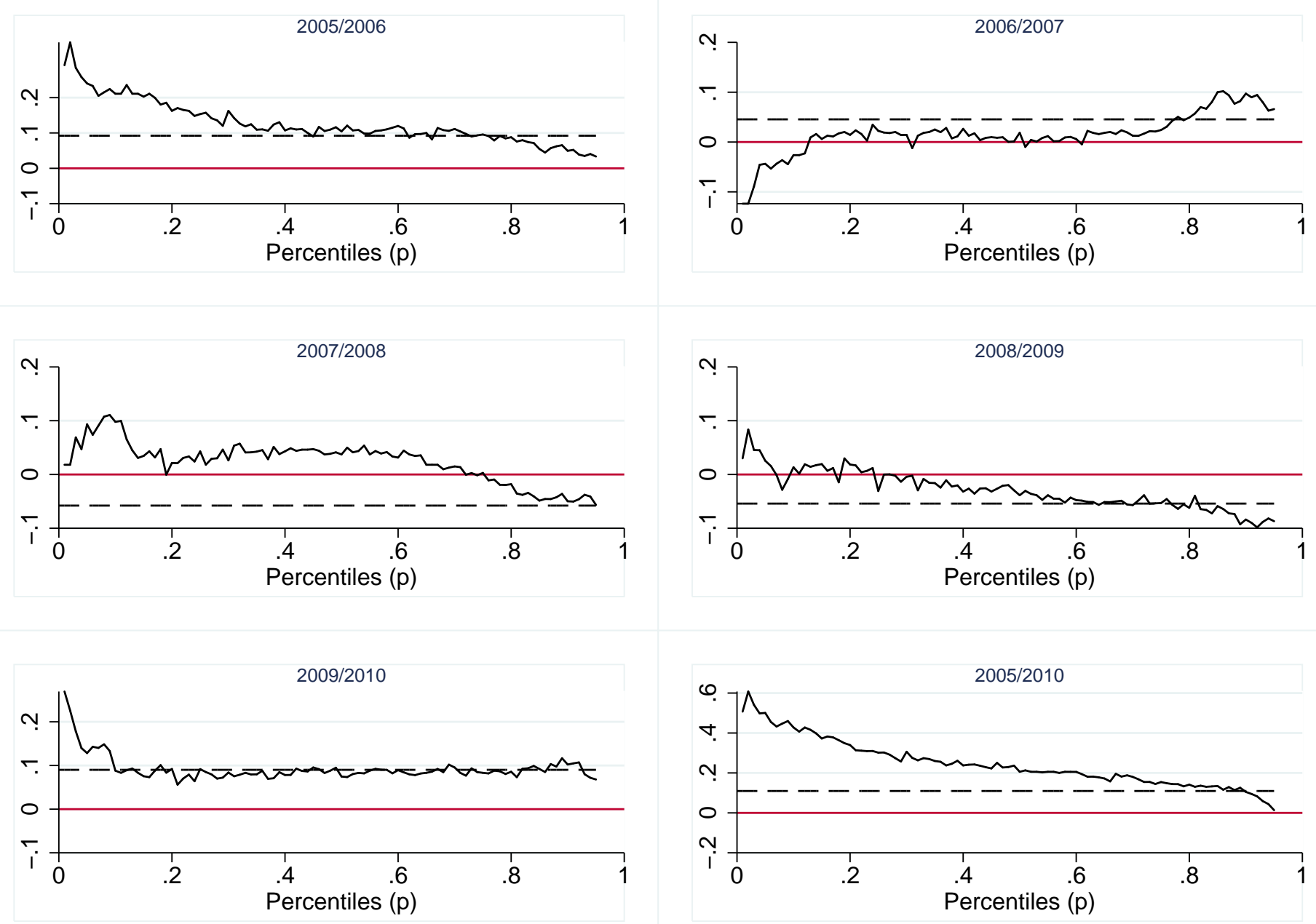
Figure ECU-4: First order absolutely pro-poor : Ecuador 2005/10

Primal approach: $\left(\left(P_{2}(z, \alpha=0)-P_{1}(z, \alpha=0)\right)\right.$
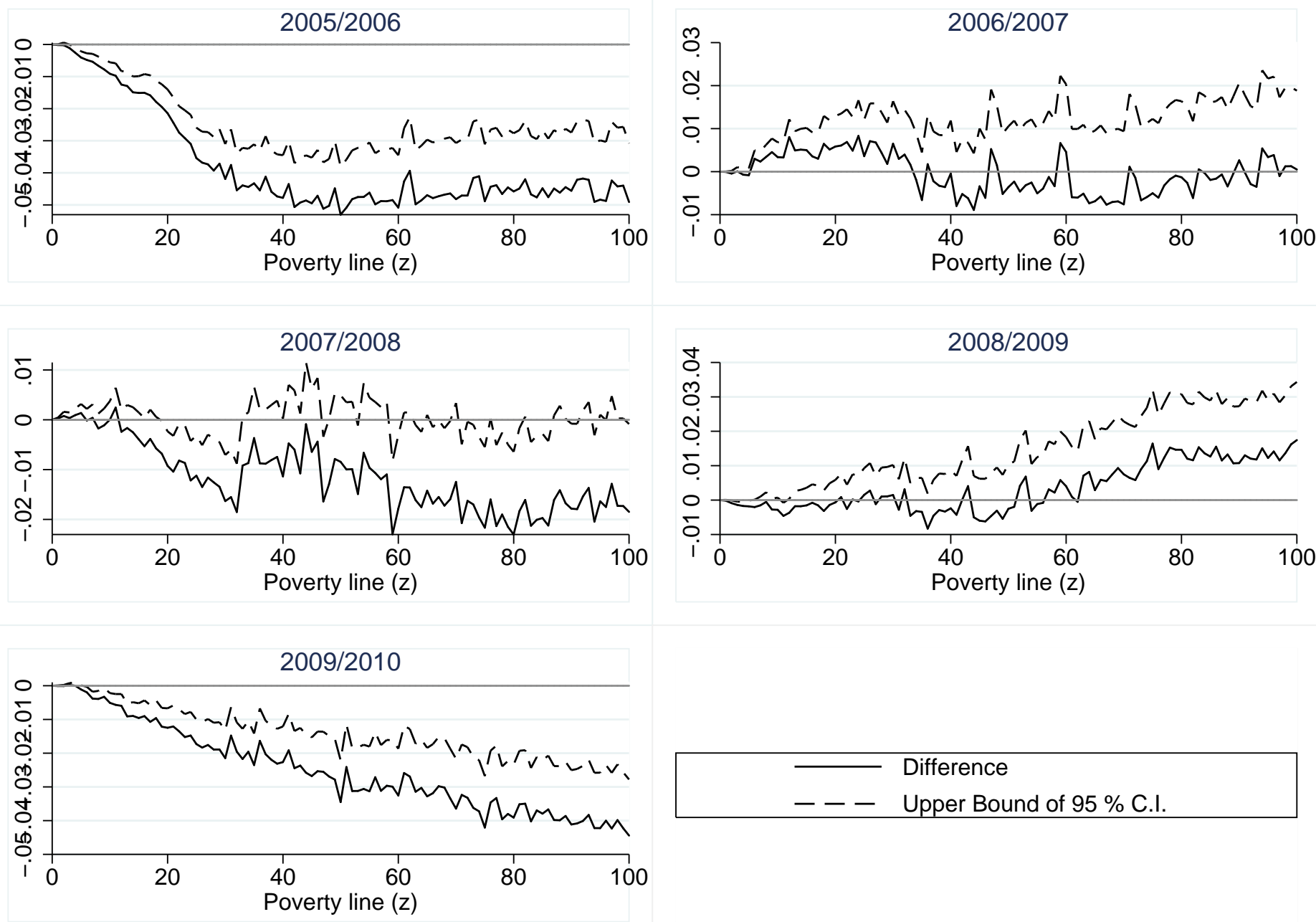
Figure ECU-5: First order absolutely pro-poor : Ecuador 2005/10 Dual approach: $\left(\left(Q_{2}(p)-Q_{1}(p)\right)\right)$
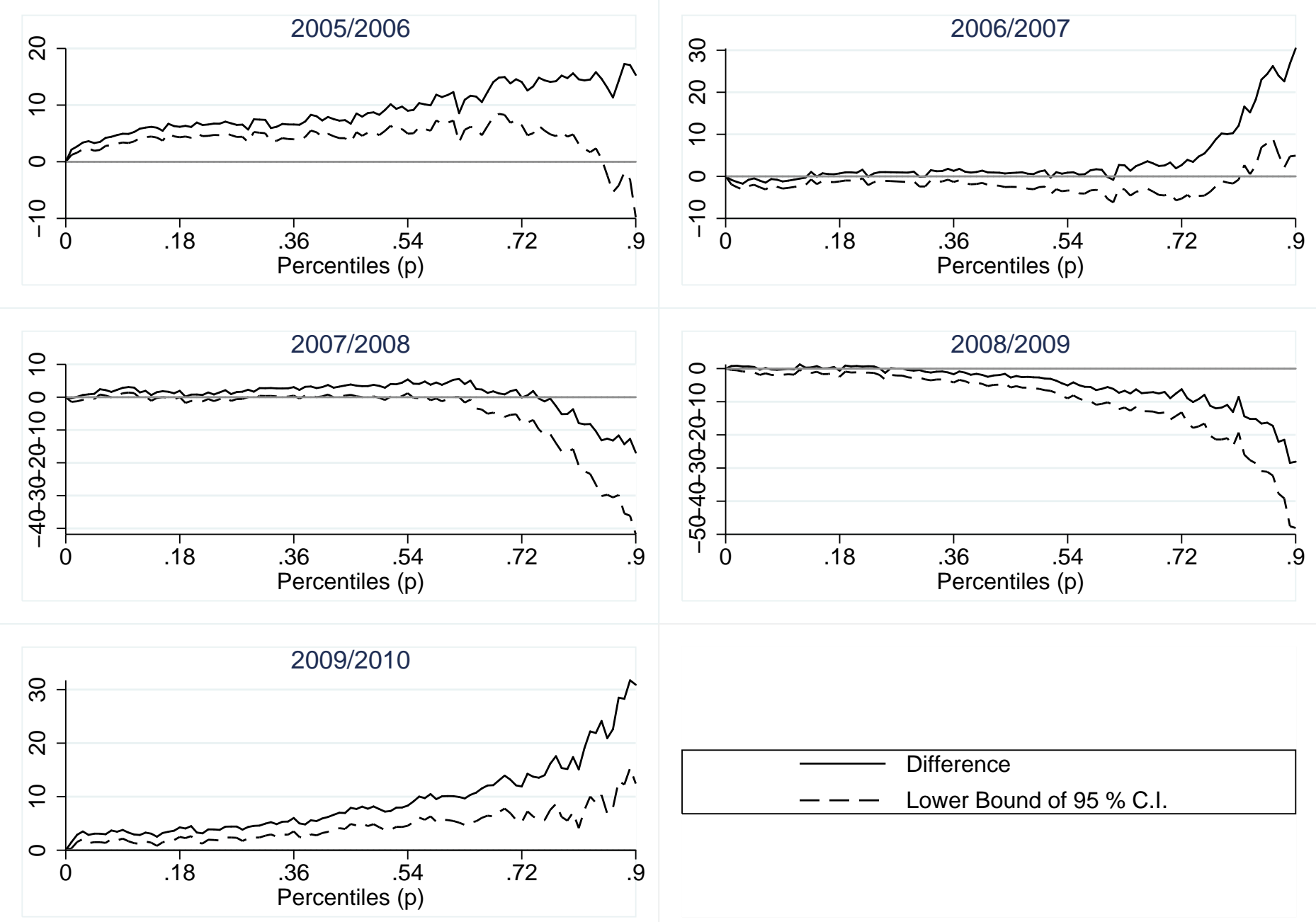
Figure ECU-6: Second order absolutely pro-poor : Ecuador 2005/10

Primal approach: $\left(\left(z P_{2}(z, \alpha=1)-z P_{1}(z, \alpha=1)\right)\right.$
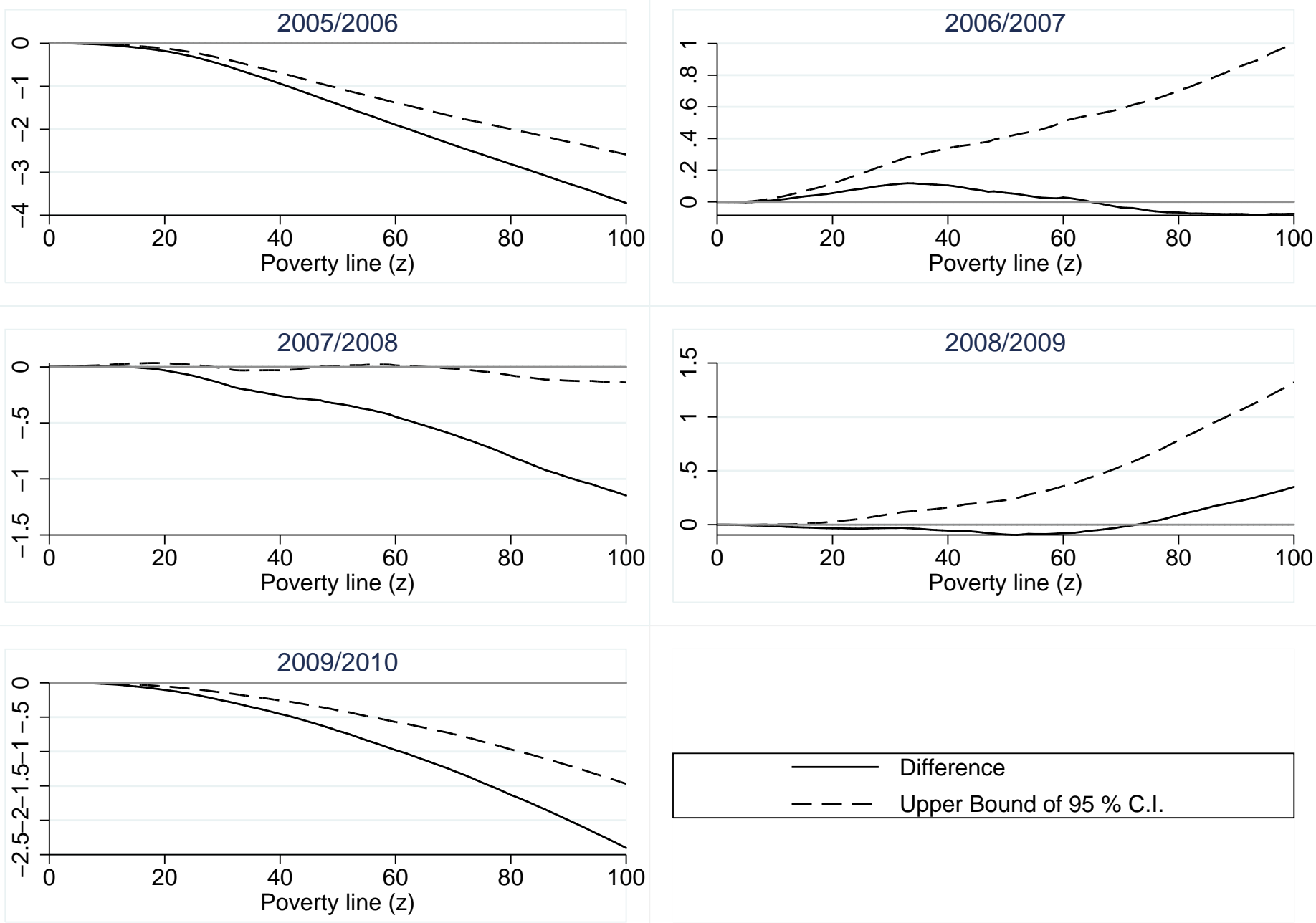
Figure ECU-7: Second order absolutely pro-poor : Ecuador 2005/10 Dual approach: $\left(\left(G L_{2}(p)-G L_{1}(p)\right)\right)$
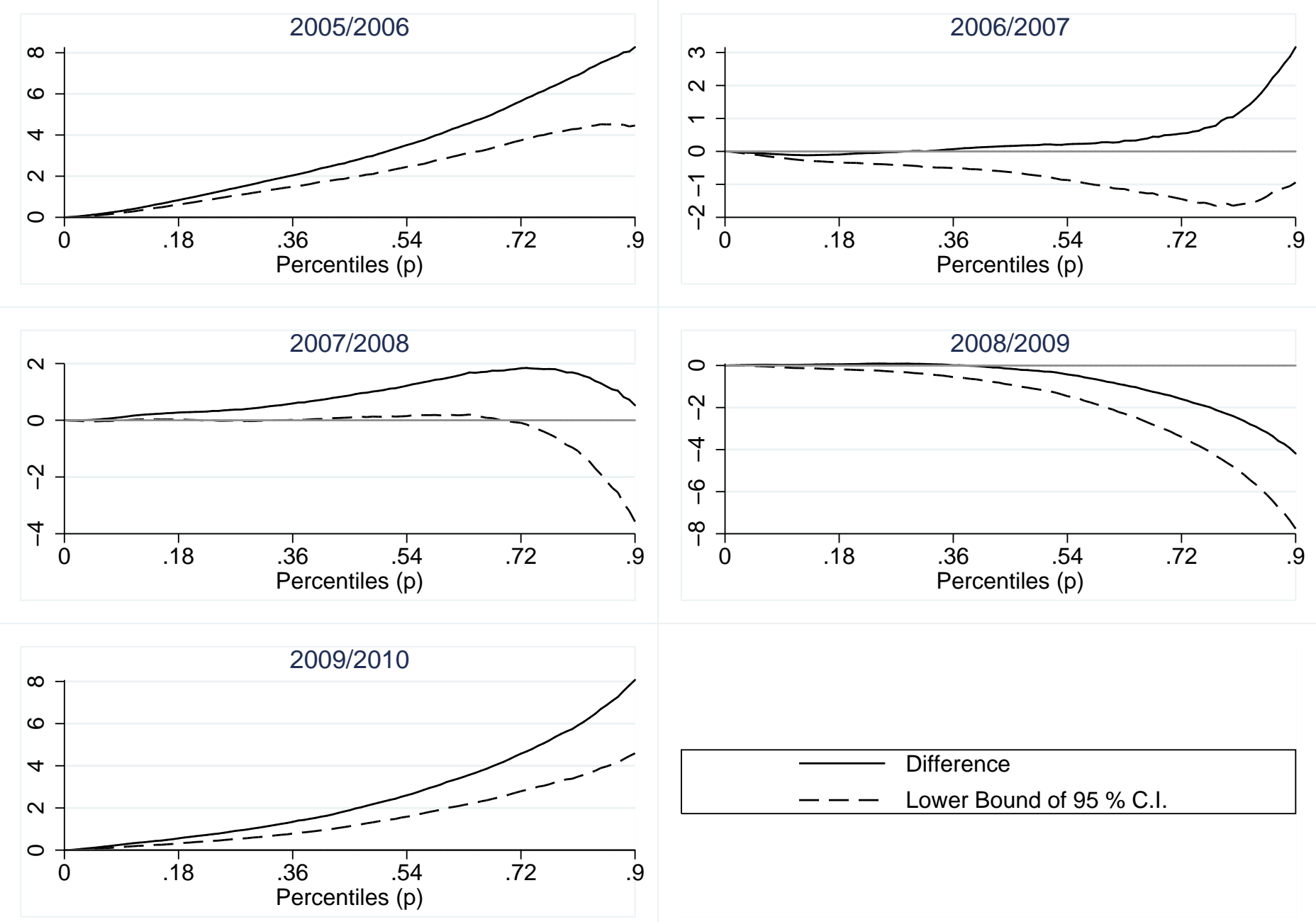
Figure ECU-8: First order relatively pro-poor : Ecuador 2005/10

Primal approach: $\left(\left(P_{2}((1+g) z, \alpha=0)-P_{1}(z, \alpha=0)\right)\right.$
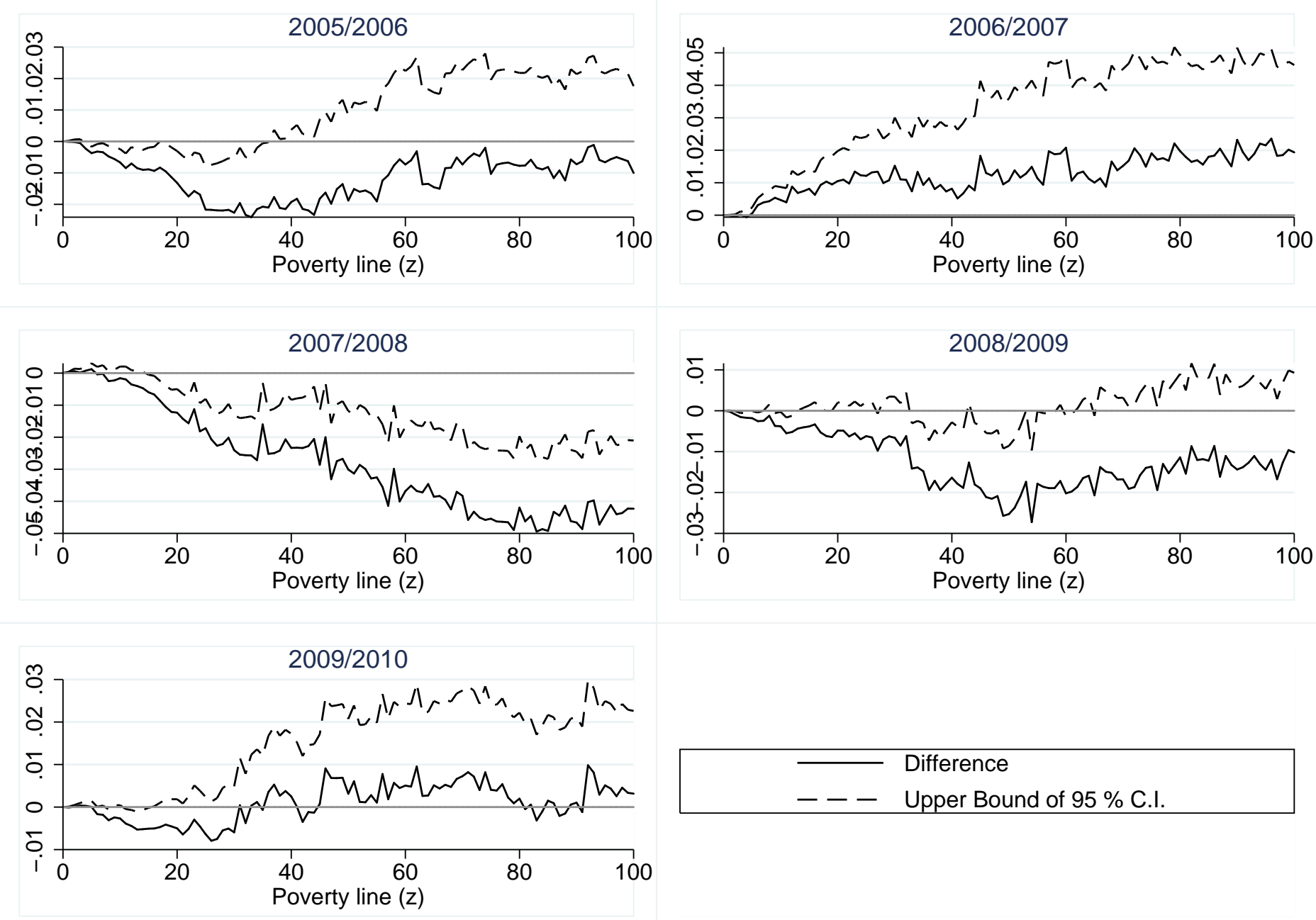
Figure ECU-9: First order relatively pro-poor : Ecuador 2005/10

Dual approach: $\left(\left(Q_{2}(p) / Q_{1}(p)-\mu_{2} / \mu_{1}\right)\right)$
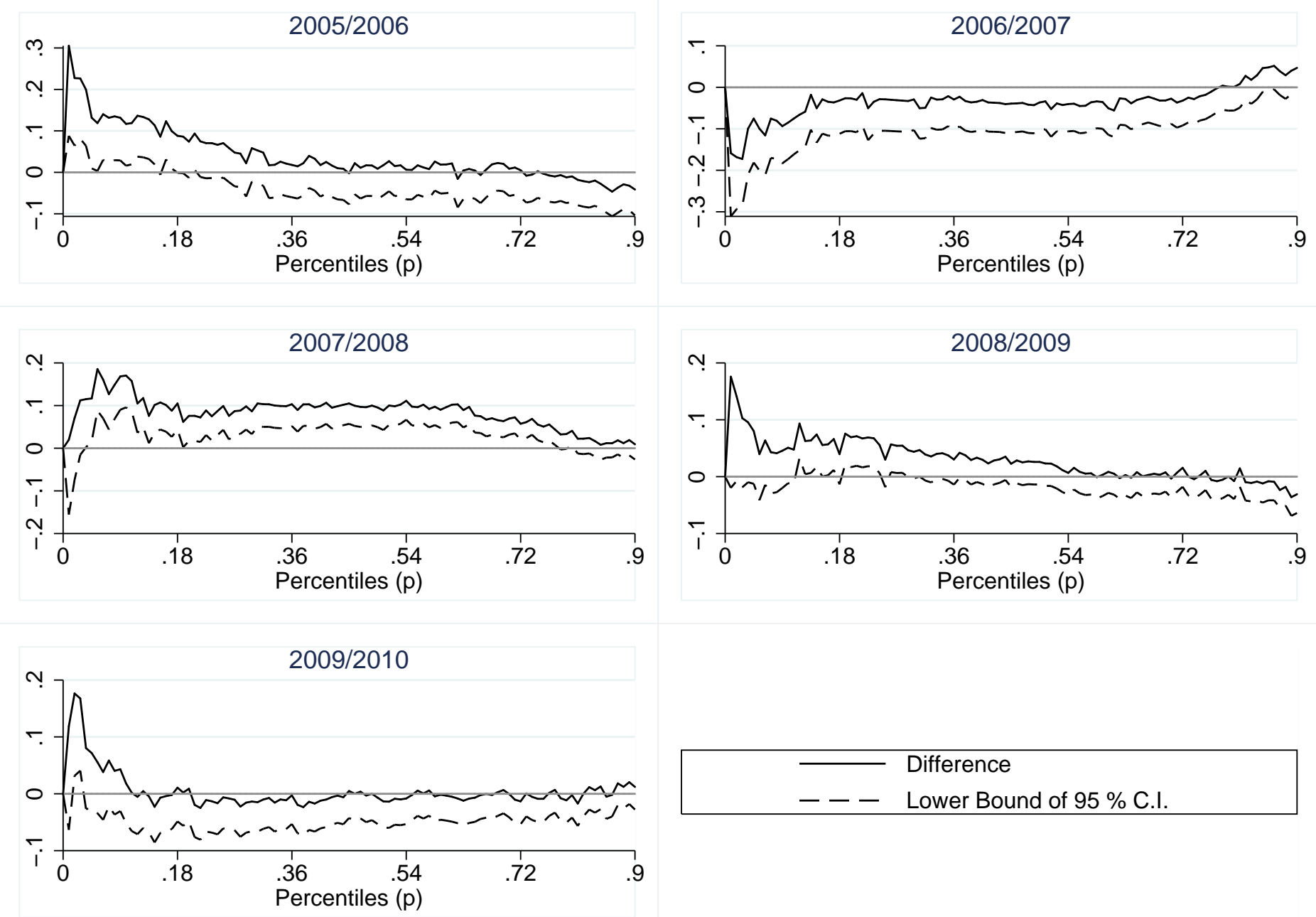
Figure ECU-10: Second order relatively pro-poor : Ecuador 2005/10

Primal approach: $\left(\left(P_{2}((1+g) z, \alpha=1)-P_{1}(z, \alpha=1)\right)\right.$
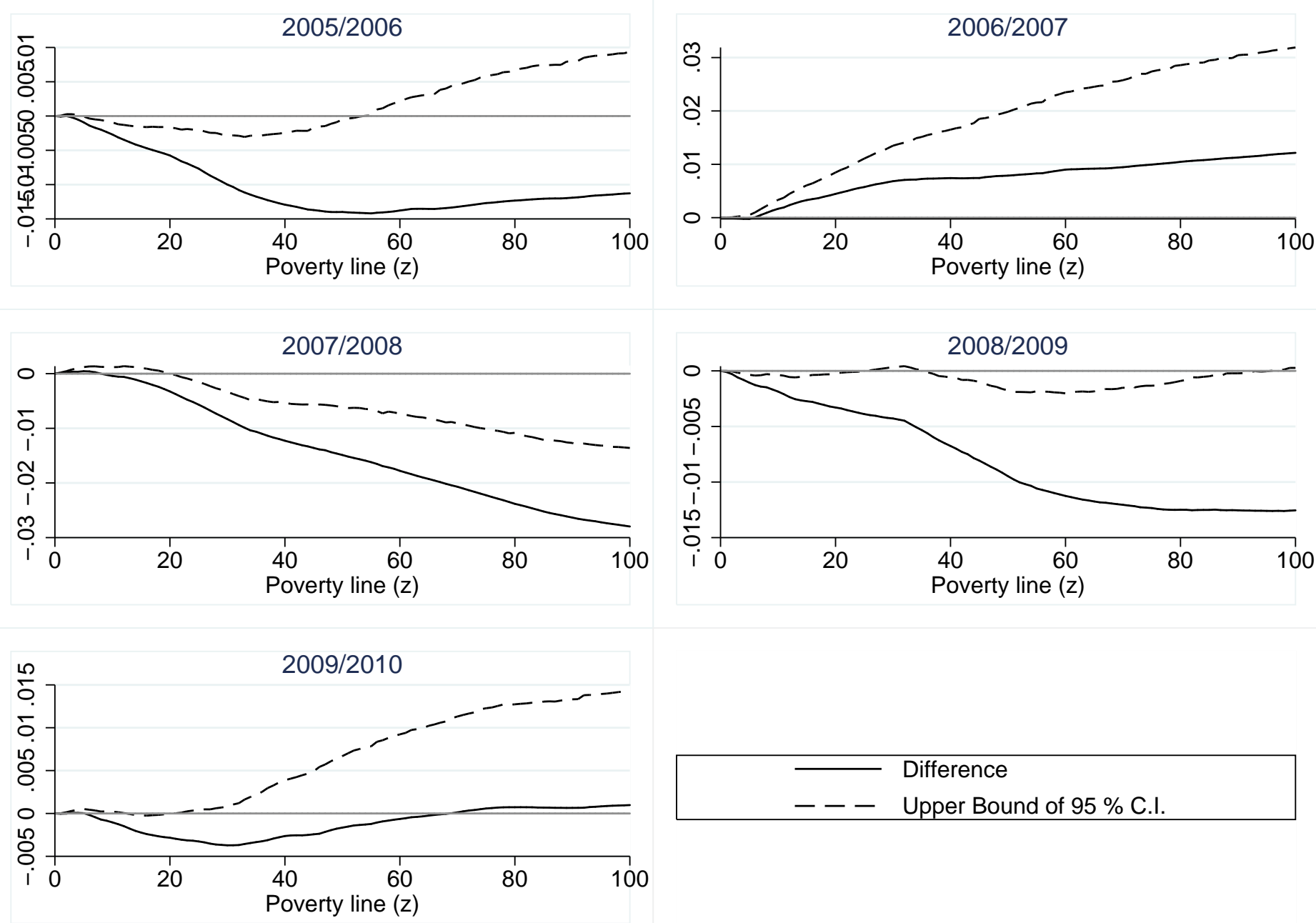
Figure ECU-11: Second order relatively pro-poor : Ecuador 2005/10

Dual approach: $\left(\left(G L_{2}(p) / G L_{1}(p)-\mu_{2} / \mu_{1}\right)\right)$
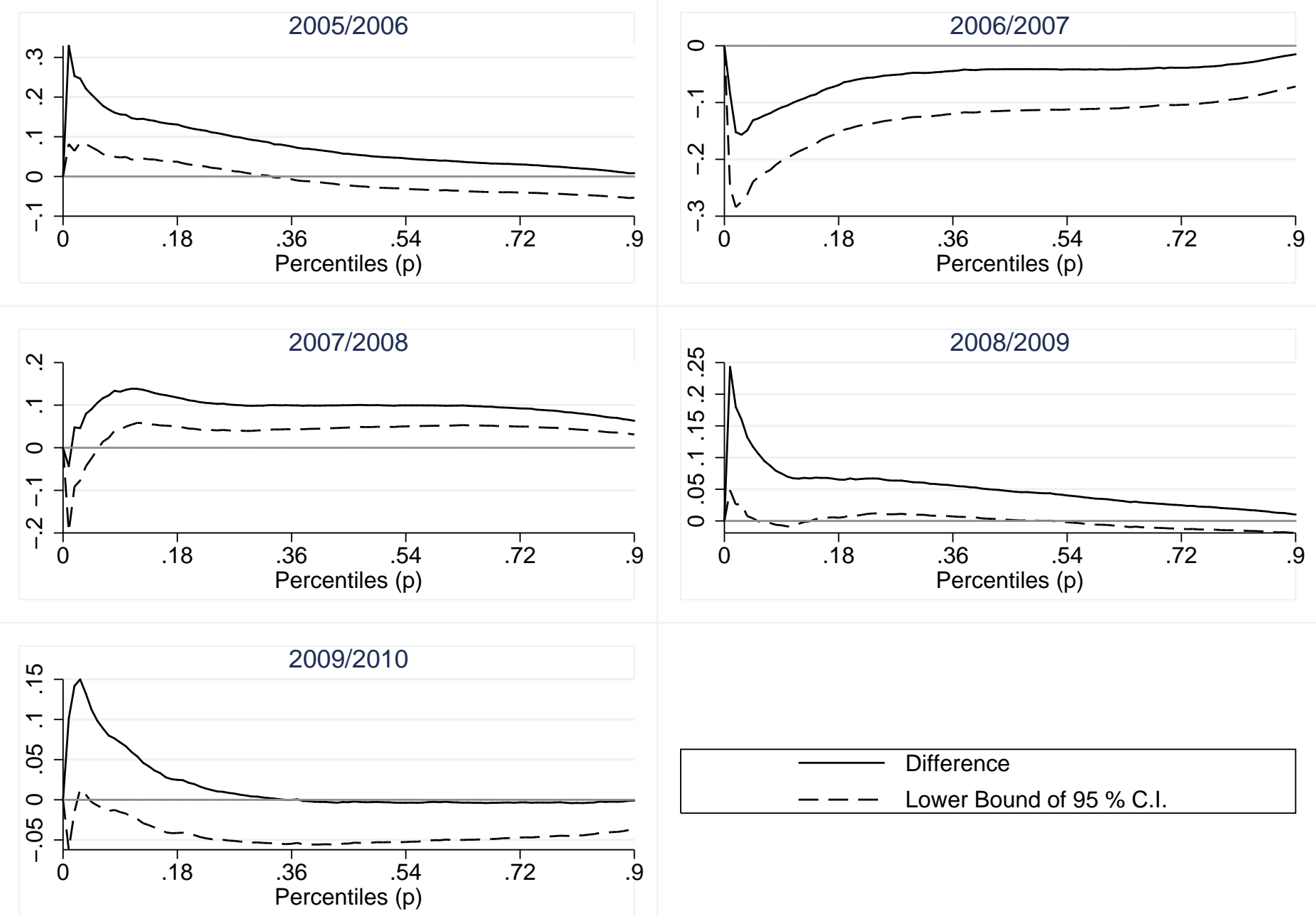
Figure ECU-12: First order absolute pro-poor: Ecuador 2005-2010 Primal approach: $\left(\left(P_{2}(z, \alpha=0)-P_{1}(z, \alpha=0)\right)\right.$

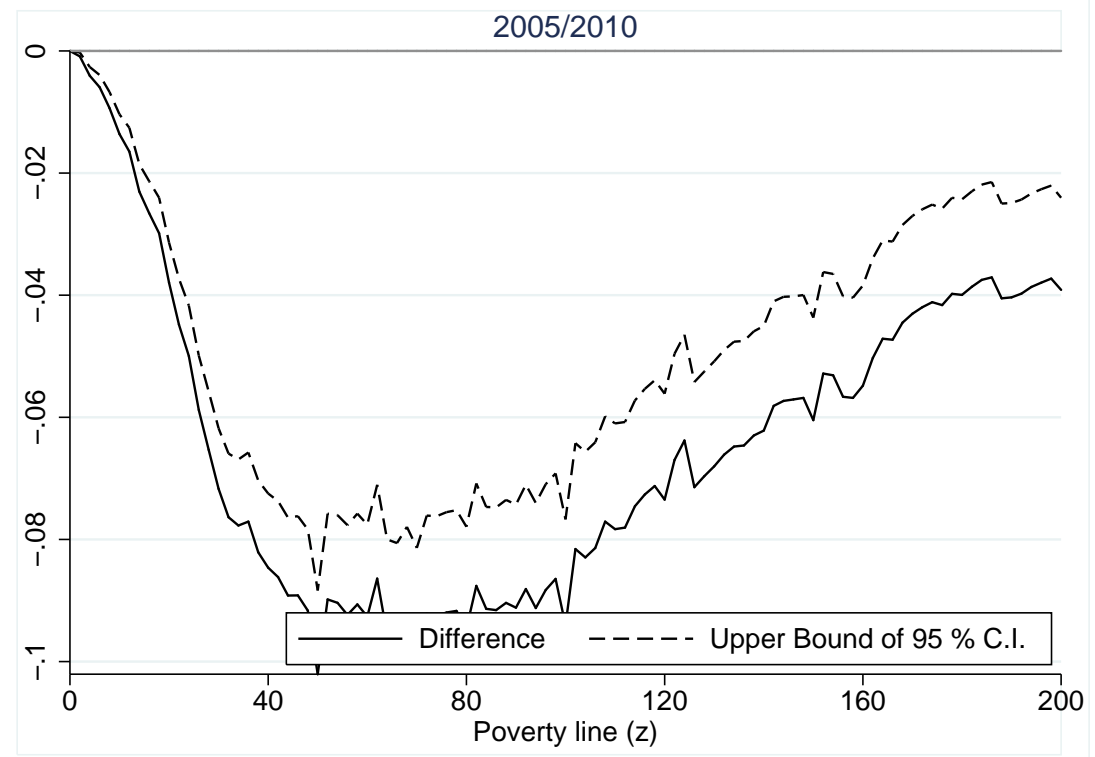

Figure ECU-13: First order relatively pro-poor: Ecuador 2005-2010 Primal approach: $\left(\left(P_{2}((1+g) z, \alpha=0)-P_{1}(z, \alpha=0)\right)\right.$

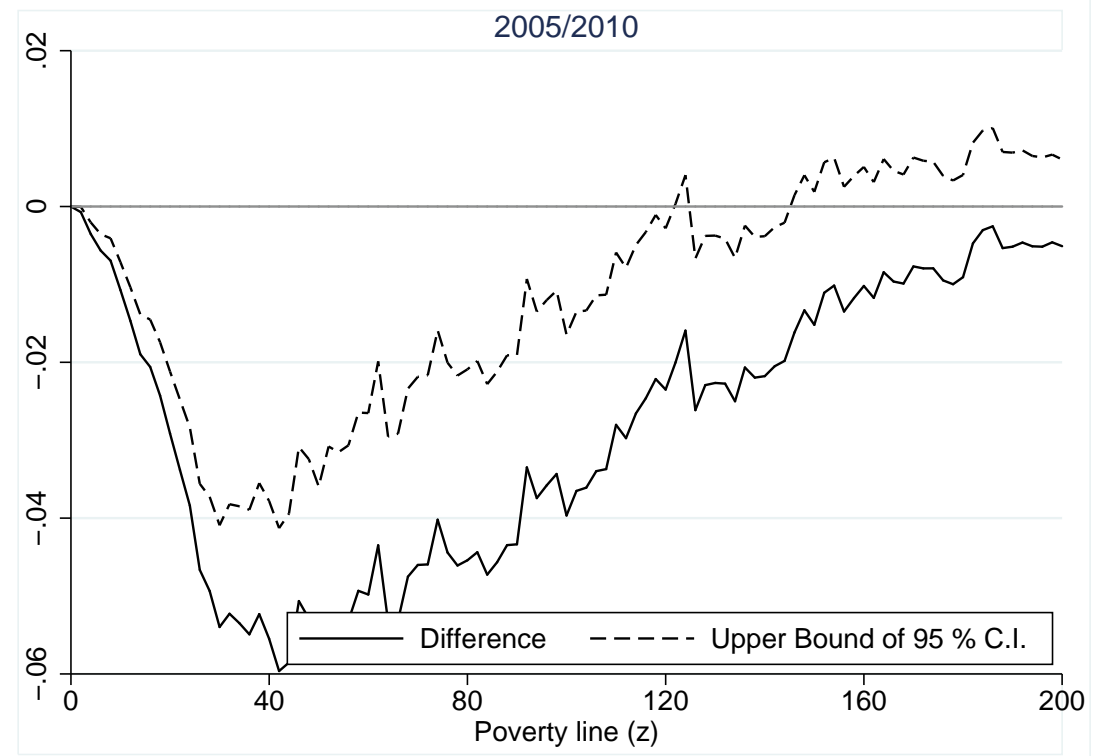




\section{The Bolivian results}


Table BOL-1: Trend of average per capita income, poverty and inequality: Bolivia 2005/09

\begin{tabular}{l|rl|rl|rl|rl}
\hline Year & $\begin{array}{r}\text { Average } \\
\text { income }\end{array}$ & $\begin{array}{l}\text { Yearly } \\
\text { variation }\end{array}$ & Headcount & $\begin{array}{l}\text { Yearly } \\
\text { variation }\end{array}$ & $\begin{array}{r}\text { Poverty } \\
\text { gap }\end{array}$ & $\begin{array}{l}\text { Yearly } \\
\text { variation }\end{array}$ & $\begin{array}{r}\text { Gini } \\
\text { index }\end{array}$ & $\begin{array}{l}\text { Yearly } \\
\text { variation }\end{array}$ \\
\hline 2005 & 800.8 & & 59.38 & & 33.16 & & 0.593 & \\
2006 & 800.2 & -0.6 & 59.76 & 0.39 & 32.31 & -0.85 & 0.582 & -0.0100 \\
2007 & 783.9 & -16.3 & 59.80 & 0.03 & 30.37 & -1.94 & 0.560 & -0.0220 \\
2008 & 716.9 & $-66.96^{*}$ & 57.26 & $-2.54 *$ & 27.79 & $-2.58^{* *}$ & 0.504 & $-0.056^{* * *}$ \\
2009 & 753.3 & 36.4 & 51.33 & $-5.93^{* * *}$ & 24.61 & $-3.18^{* * *}$ & 0.482 & $-0.021^{*}$ \\
\hline
\end{tabular}

Sampling design is fully taken into account in computing the standard errors.

${ }^{*} p \leq 0.10,{ }^{* *} p \leq 0.05,{ }^{* * *} p \leq 0.01$. 
Table BOL-2: Decomposition of change in poverty gap into pro-poor growth components Kraay (2004) approach - Bolivia 2005/09

\begin{tabular}{r|rrr|rr|rr}
\hline \multirow{2}{*}{ Period } & $\begin{array}{r}\text { Poverty } \\
\text { Change } \\
(\Delta P(\alpha=1))\end{array}$ & $\begin{array}{r}\mathrm{C} \text { : Average } \\
\text { growth } \\
(g)\end{array}$ & $\begin{array}{r}\text { C2: Sensitivity } \\
\text { to growth } \\
\left(\int \eta(p)\right)\end{array}$ & $\begin{array}{r}\text { C1C2 } \\
\text { Absolute } \\
\text { Contribution }\end{array}$ & $\begin{array}{r}\text { C3: Pattern of growth in relative incomes } \\
\text { Contribution } \\
\text { Absolute }\end{array}$ & $\begin{array}{r}\begin{array}{r}\text { Relative } \\
\text { Contribution }\end{array} \\
\text { Contribution }\end{array}$ \\
\hline $2005 / 06$ & -0.0085 & -0.0007 & -0.2616 & 0.0002 & -2 & -0.0087 & 102 \\
$2006 / 07$ & -0.0194 & -0.0204 & -0.2734 & 0.0056 & -29 & -0.0250 & 129 \\
$2007 / 08$ & -0.0258 & -0.0854 & -0.2830 & 0.0242 & -94 & -0.0500 & 194 \\
$2008 / 09$ & -0.0318 & 0.0508 & -0.2642 & -0.0134 & 42 & -0.0183 & 58 \\
\hline
\end{tabular}

Table BOL-3: Decomposition of change in poverty gap into pro-poor growth components New approach - Bolivia 2005/09

\begin{tabular}{|c|c|c|c|c|c|c|c|c|}
\hline \multirow[b]{2}{*}{ Period } & \multirow{2}{*}{$\begin{array}{r}\text { Poverty } \\
\text { Change } \\
(\Delta P(\alpha=1)) \\
\end{array}$} & \multirow{2}{*}{$\begin{array}{l}\text { C1: Average } \\
\text { growth rates } \\
(\bar{g})\end{array}$} & \multirow{2}{*}{$\begin{array}{r}\text { C2: Sensitivity } \\
\text { to growth } \\
\left(\int \eta(p)\right)\end{array}$} & \multirow{2}{*}{$\begin{array}{r}\text { Correlation } \\
\operatorname{Corr}(\eta(p), g(p))\end{array}$} & \multicolumn{2}{|c|}{$\mathrm{C} 1 \mathrm{C} 2$} & \multicolumn{2}{|c|}{$\mathrm{C} 3$} \\
\hline & & & & & $\begin{array}{l}\text { Absolute } \\
\text { Contribution }\end{array}$ & $\begin{array}{r}\text { Relative } \\
\text { Contribution }\end{array}$ & $\begin{array}{r}\text { Absolute } \\
\text { Contribution }\end{array}$ & $\begin{array}{r}\text { Relative } \\
\text { Contribution }\end{array}$ \\
\hline $2005 / 06$ & -0.0085 & 0.0882 & -0.2651 & 0.2384 & -0.0234 & 274 & 0.0149 & -174 \\
\hline $2006 / 07$ & -0.0194 & 0.0498 & -0.2735 & -0.2683 & -0.0136 & 70 & -0.0058 & 30 \\
\hline $2007 / 08$ & -0.0258 & 0.0737 & -0.2836 & -0.1077 & -0.0209 & 81 & -0.0049 & 19 \\
\hline 2008/09 & -0.0318 & 0.0530 & -0.2637 & -0.6536 & -0.0140 & 44 & -0.0178 & 56 \\
\hline
\end{tabular}


Figure BOL-1: Change in Headcount, growth and redistribution: Bolivia 2005/09

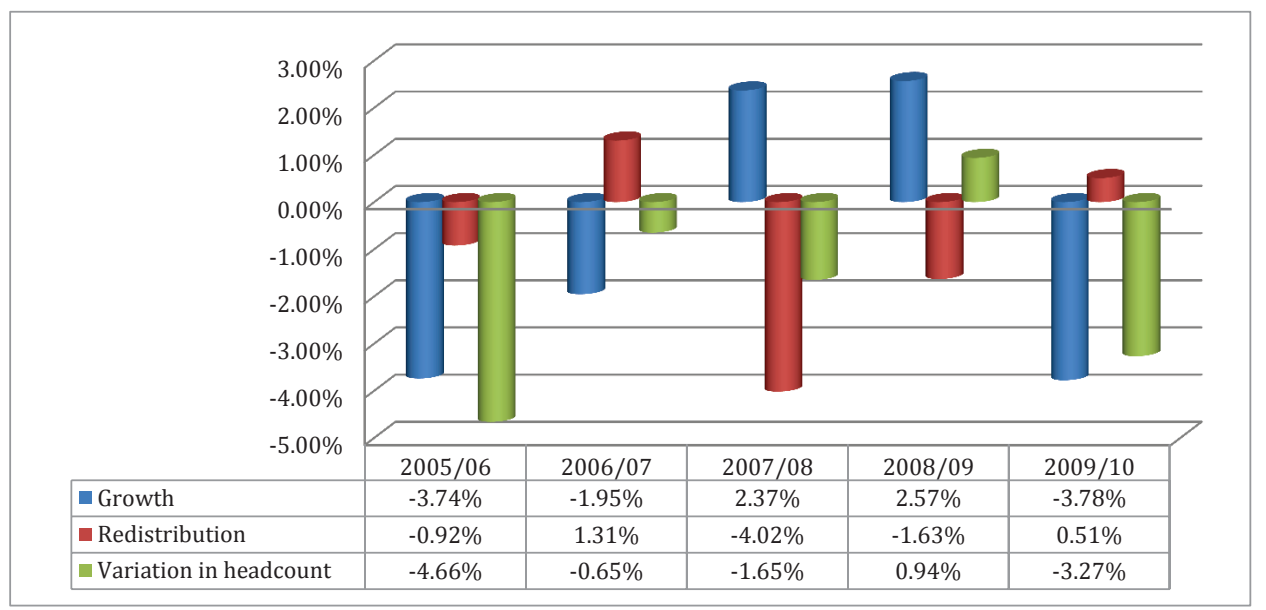

Figure BOL-2: Change in poverty gap, growth and redistribution: Bolivia 2005/09

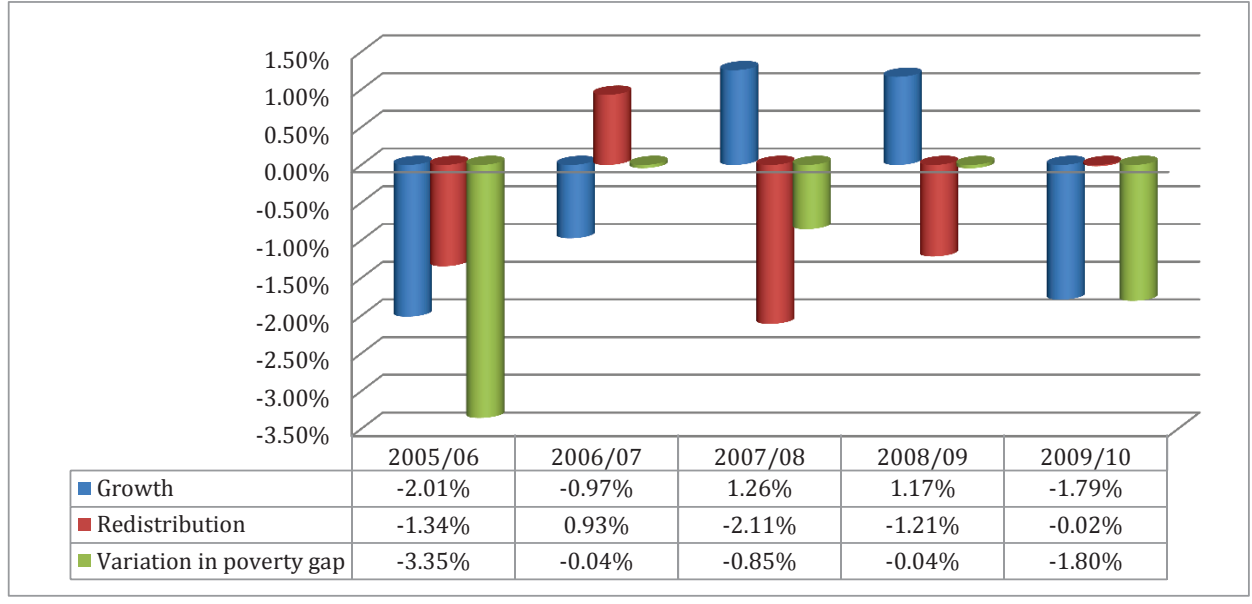


Figure BOL-3: Growth incidence curves in Bolivia : $\left(Q_{2}(p)-Q_{1}(p)\right) / Q_{1}(p)$
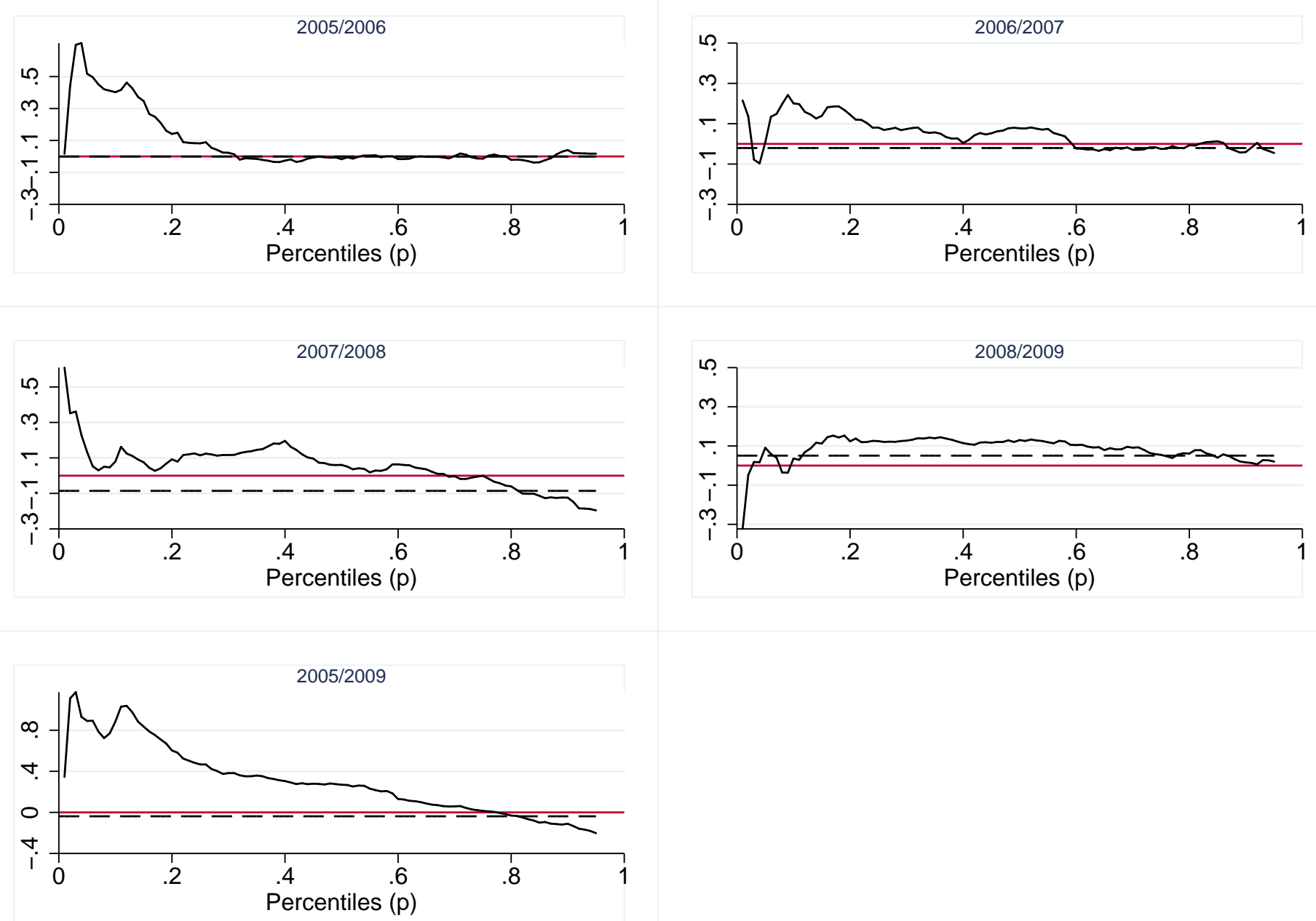
Figure BOL-4: First order absolutely pro-poor : Bolivia 2005/09

Primal approach: $\left(\left(P_{2}(z, \alpha=0)-P_{1}(z, \alpha=0)\right)\right.$
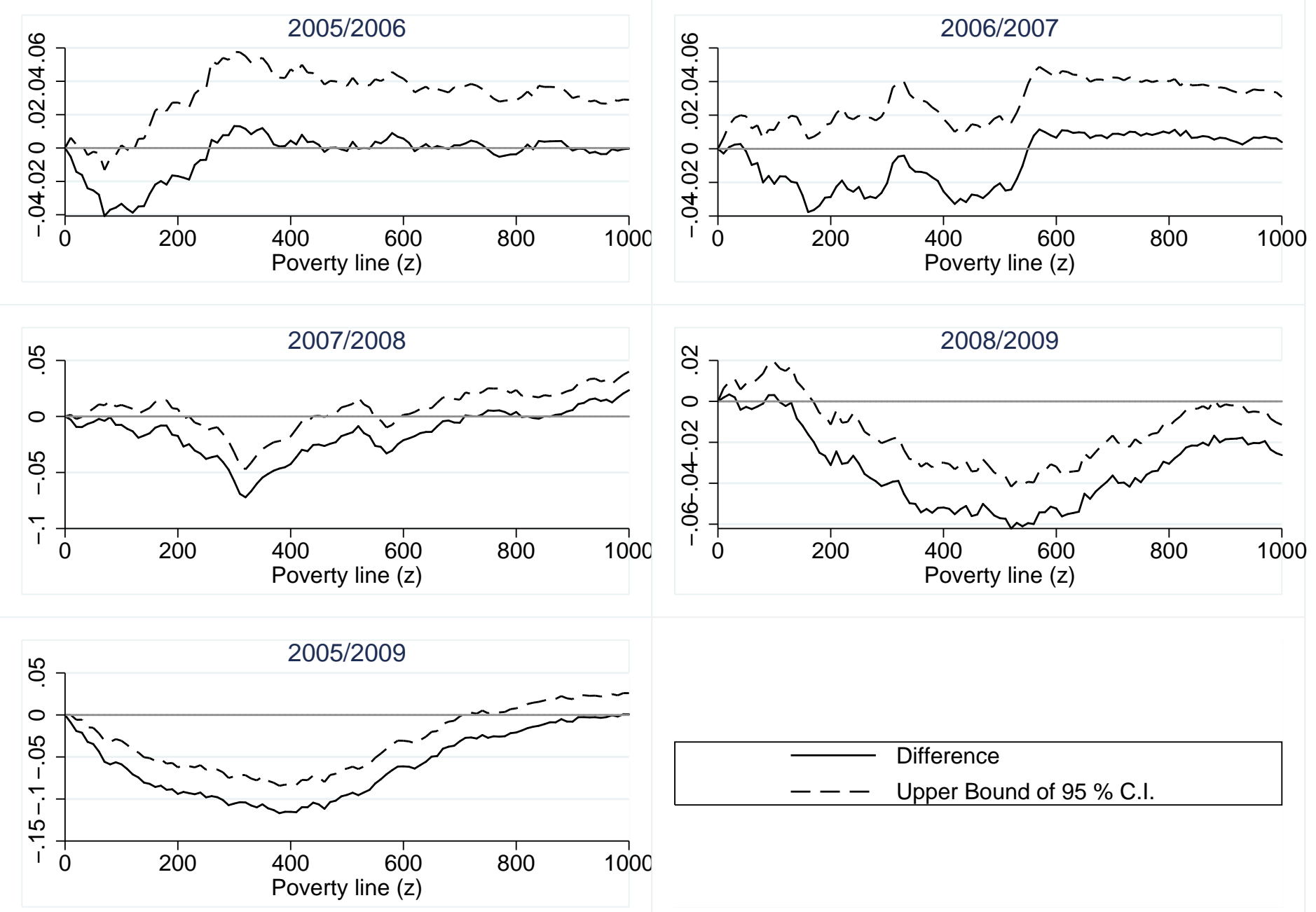
Figure BOL-5: First order absolutely pro-poor : Bolivia 2005/09

Dual approach: $\left(\left(Q_{2}(p)-Q_{1}(p)\right)\right)$
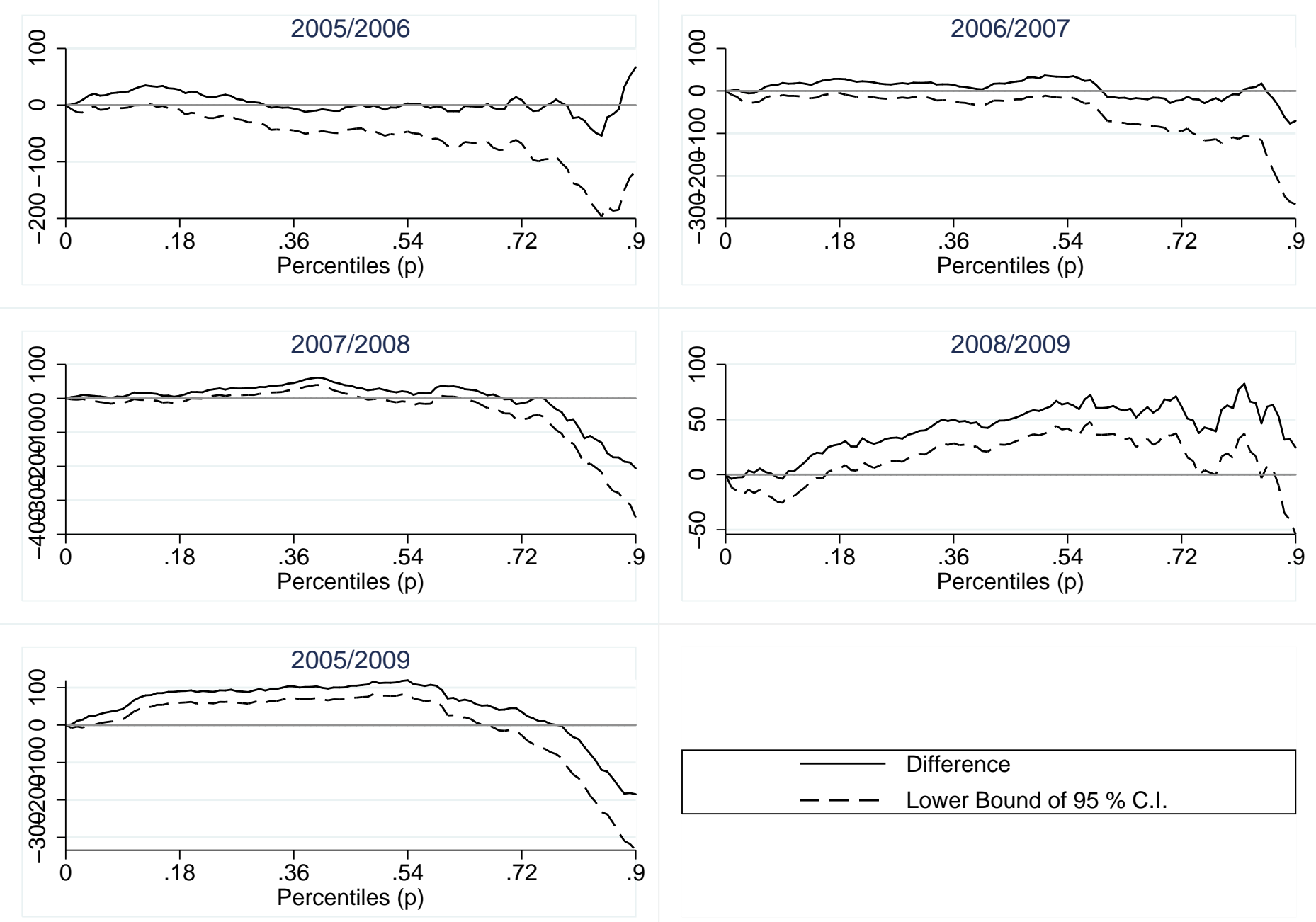
Figure BOL-6: Second order absolutely pro-poor : Bolivia 2005/09

Primal approach: $\left(z\left(P_{2}(z, \alpha=1)-P_{1}(z, \alpha=1)\right)\right.$
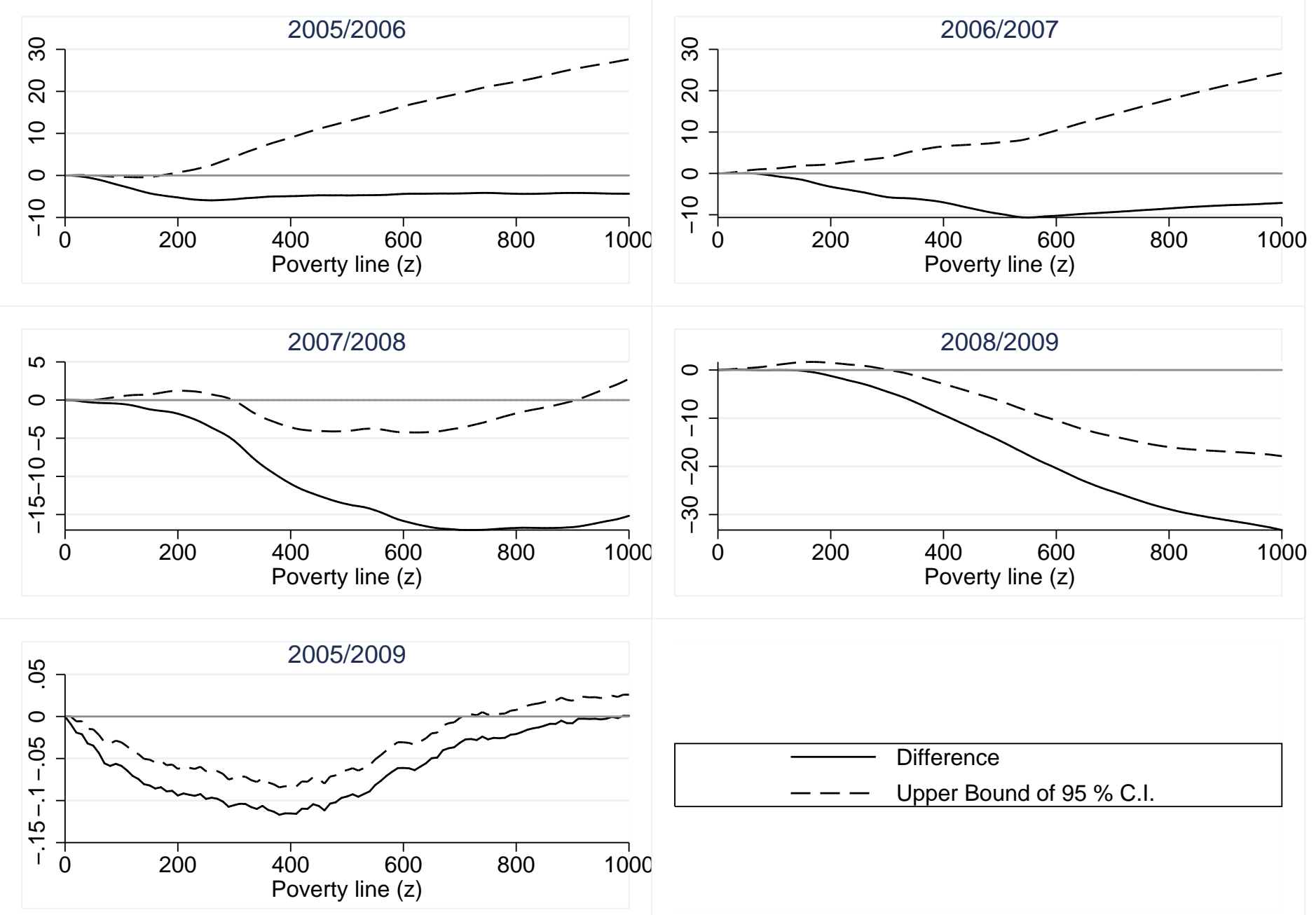
Figure BOL-7: Second order absolutely pro-poor : Bolivia 2005/09

Dual approach: $\left(\left(G L_{2}(p)-G L_{1}(p)\right)\right)$
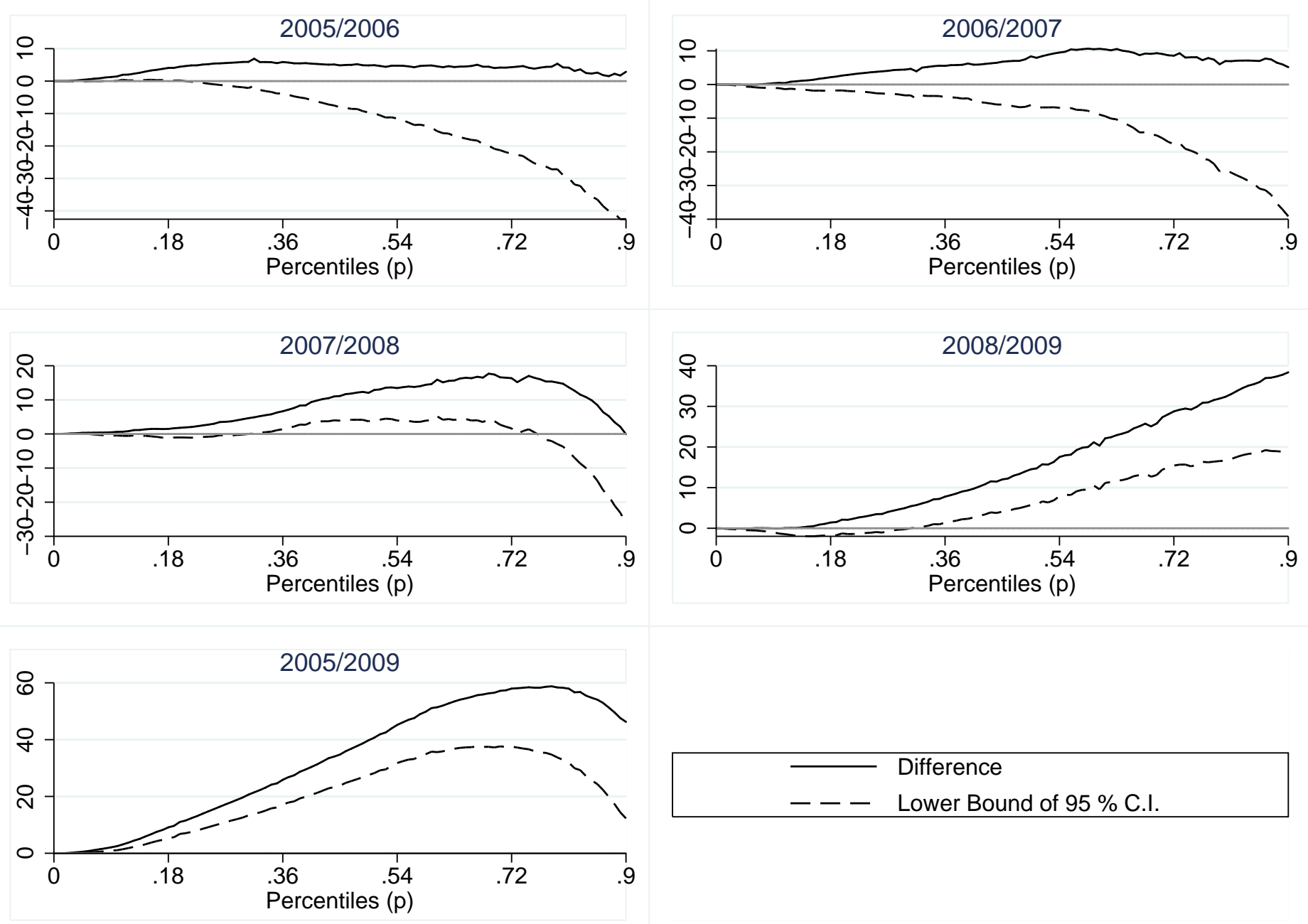
Figure BOL-8: First order relatively pro-poor : Bolivia 2005/09

Primal approach: $\left(\left(P_{2}((1+g) z, \alpha=0)-P_{1}(z, \alpha=0)\right)\right.$
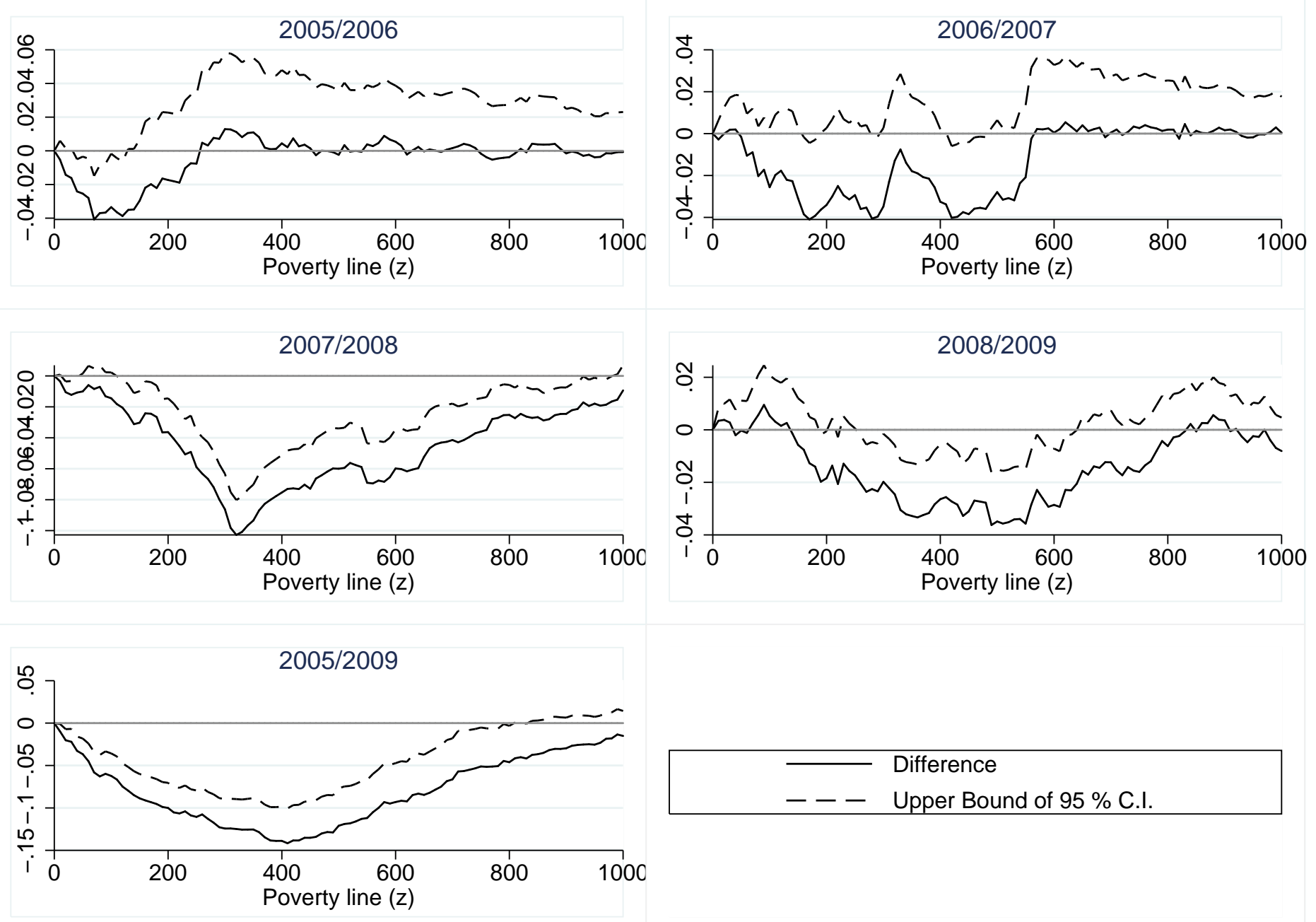
Figure BOL-9: First order relatively pro-poor : Bolivia 2005/09

Dual approach: $\left(\left(Q_{2}(p) / Q_{1}(p)-\mu_{2} / \mu_{1}\right)\right)$
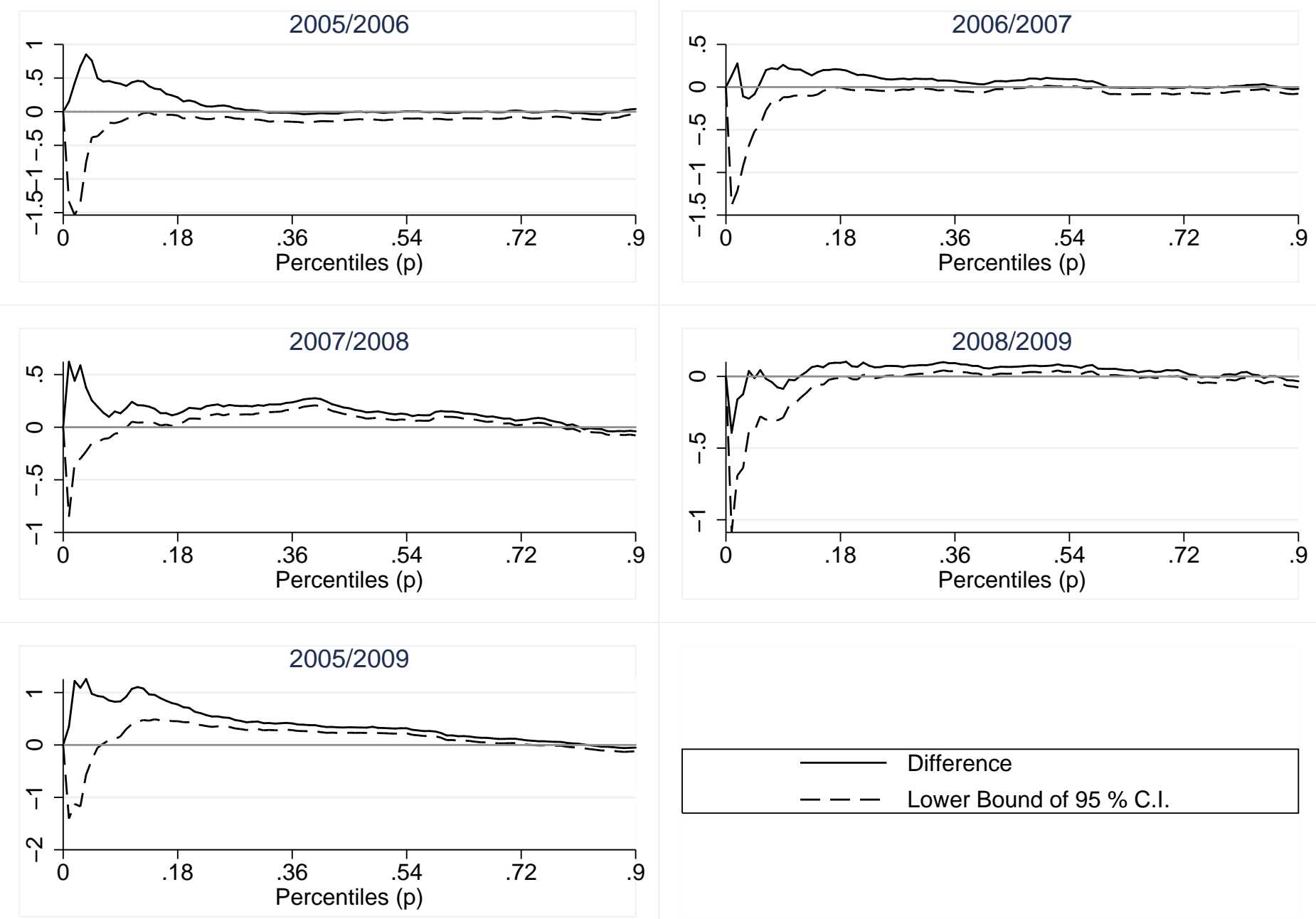
Figure BOL-10: Second order relatively pro-poor : Bolivia 2005/09

Primal approach: $\left(\left(P_{2}((1+g) z, \alpha=1)-P_{1}(z, \alpha=1)\right)\right.$
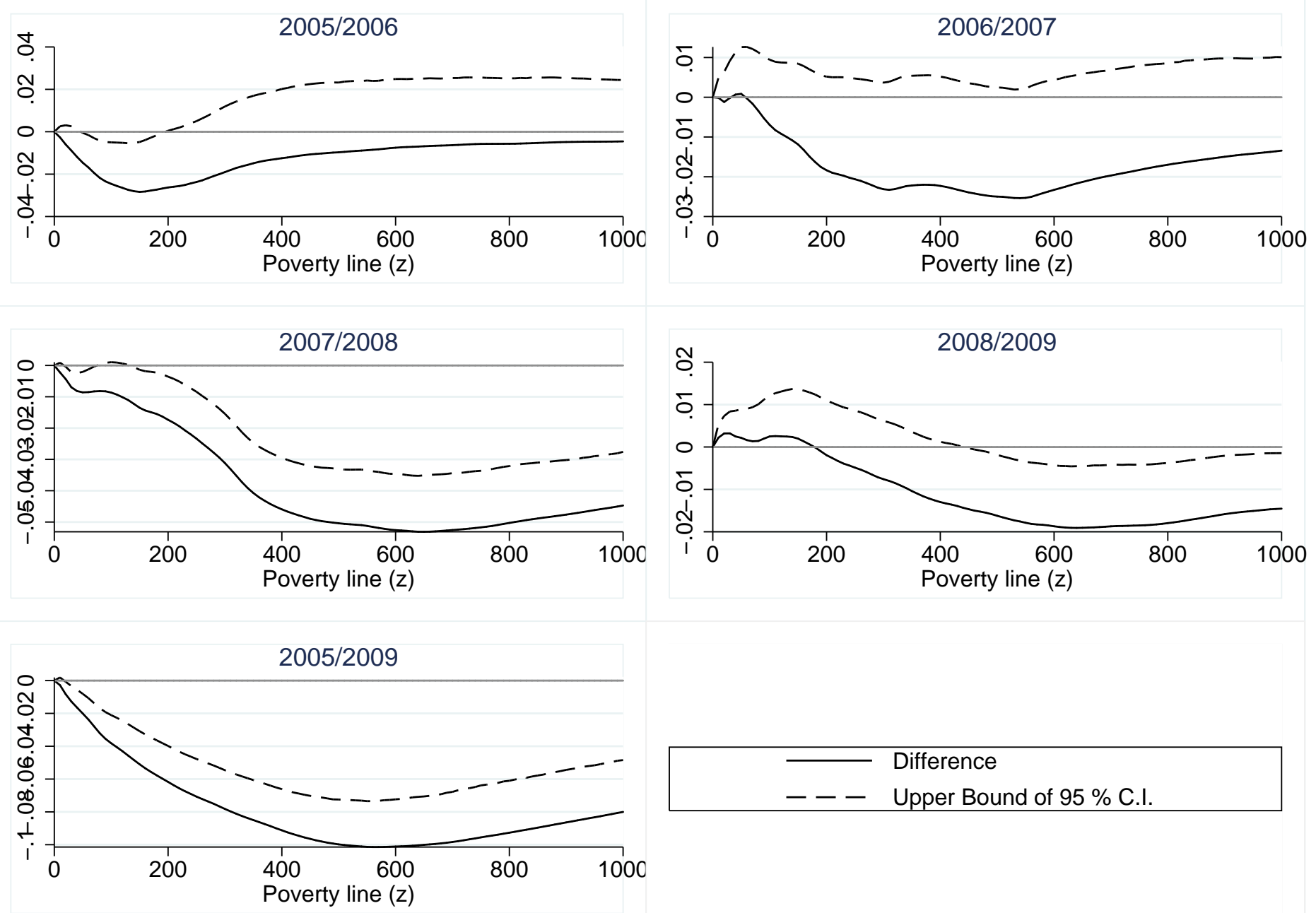
Figure BOL-11: Second order relatively pro-poor : Bolivia 2005/09

Dual approach: $\left(\left(G L_{2}(p) / G L_{1}(p)-\mu_{2} / \mu_{1}\right)\right)$
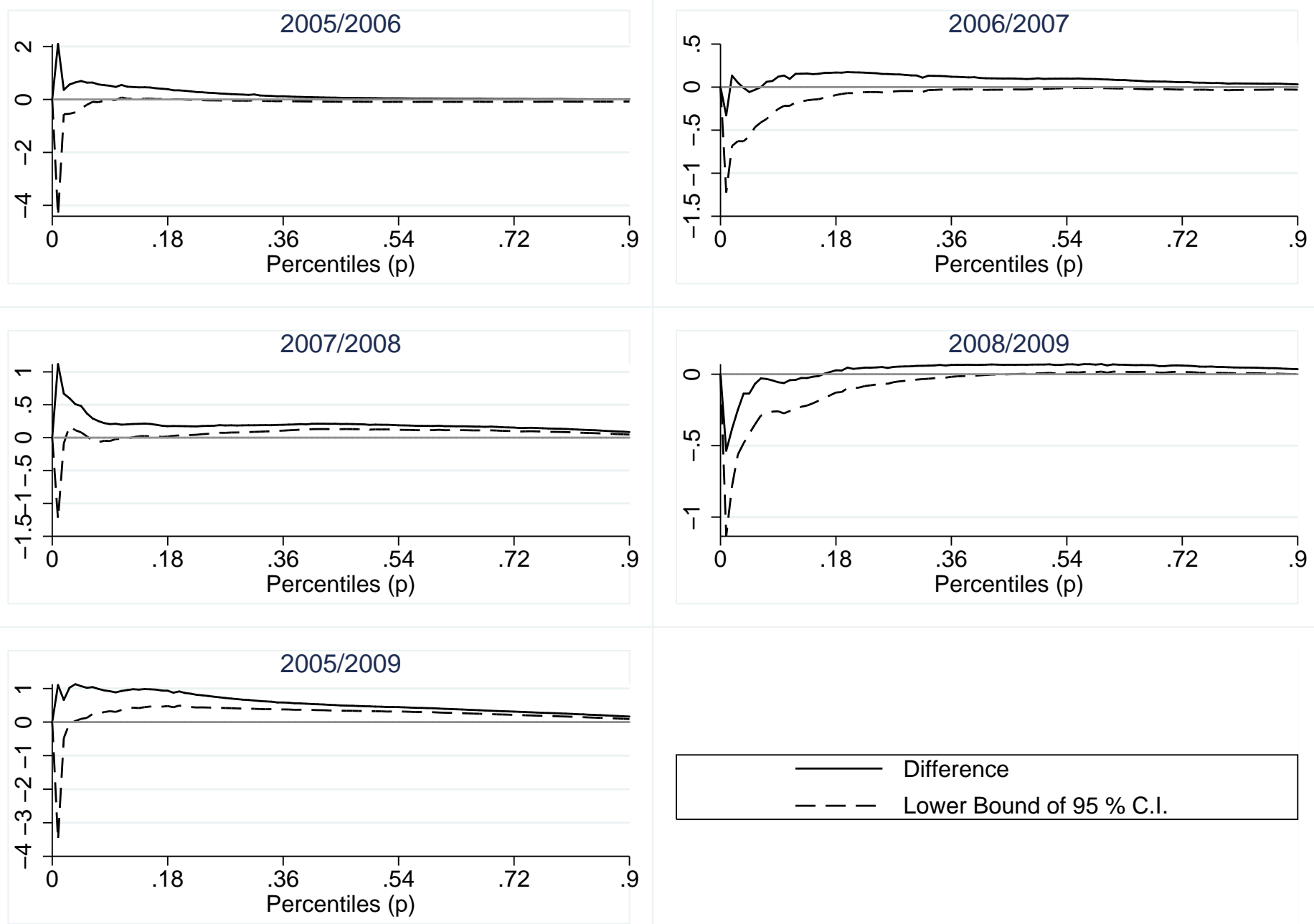
Figure BOL-12: First order relatively pro-poor : Bolivia 2005/09

Primal approach: $\left(\left(P_{2}((1+g) z, \alpha=0)-P_{1}(z, \alpha=0)\right)\right.$
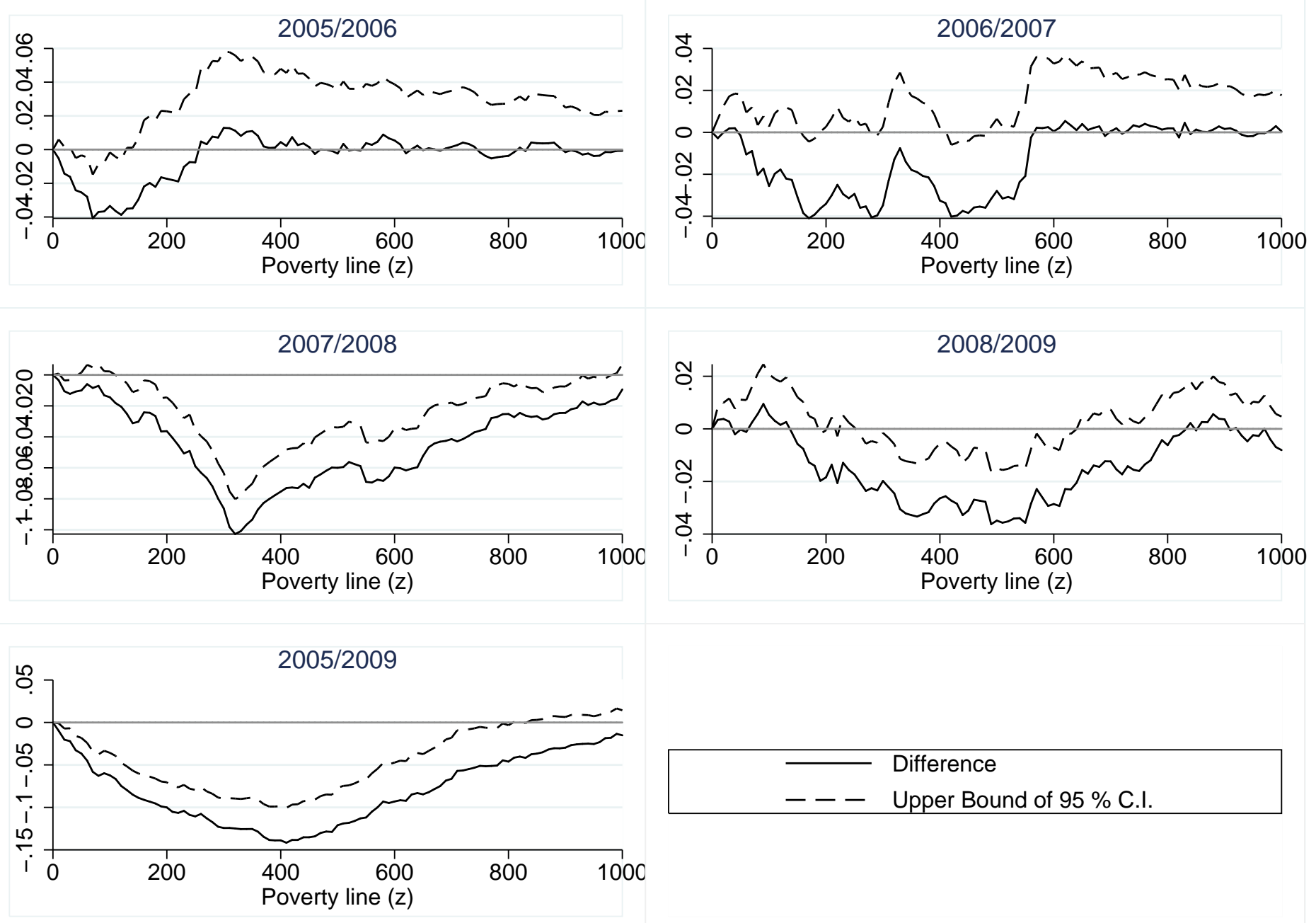
Figure BOL-13: First order relatively pro-poor : Bolivia 2005/09

Dual approach: $\left(\left(Q_{2}(p) / Q_{1}(p)-\mu_{2} / \mu_{1}\right)\right)$
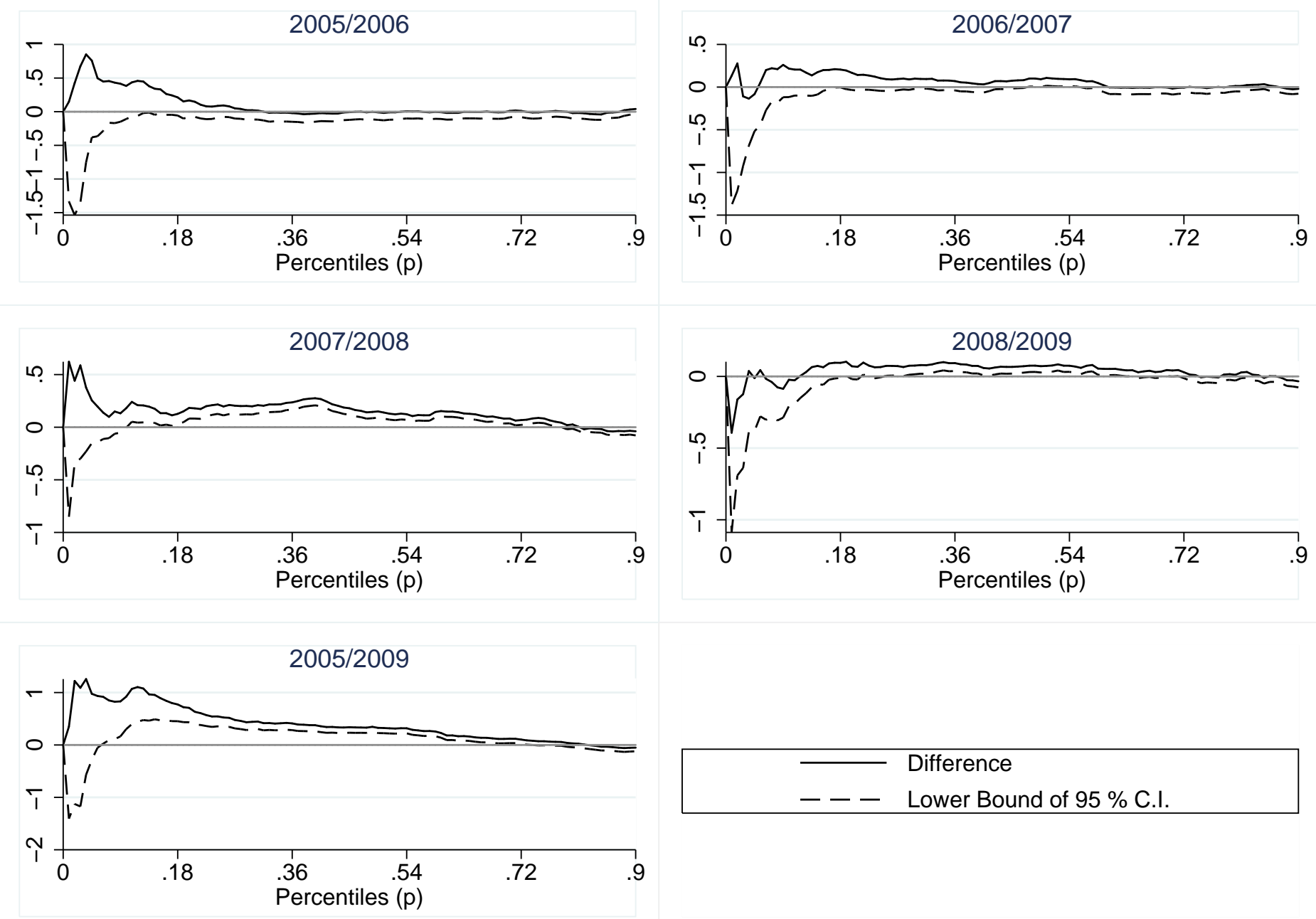
Figure BOL-14: Second order relatively pro-poor : Bolivia 2005/09

Primal approach: $\left(\left(P_{2}((1+g) z, \alpha=1)-P_{1}(z, \alpha=1)\right)\right.$
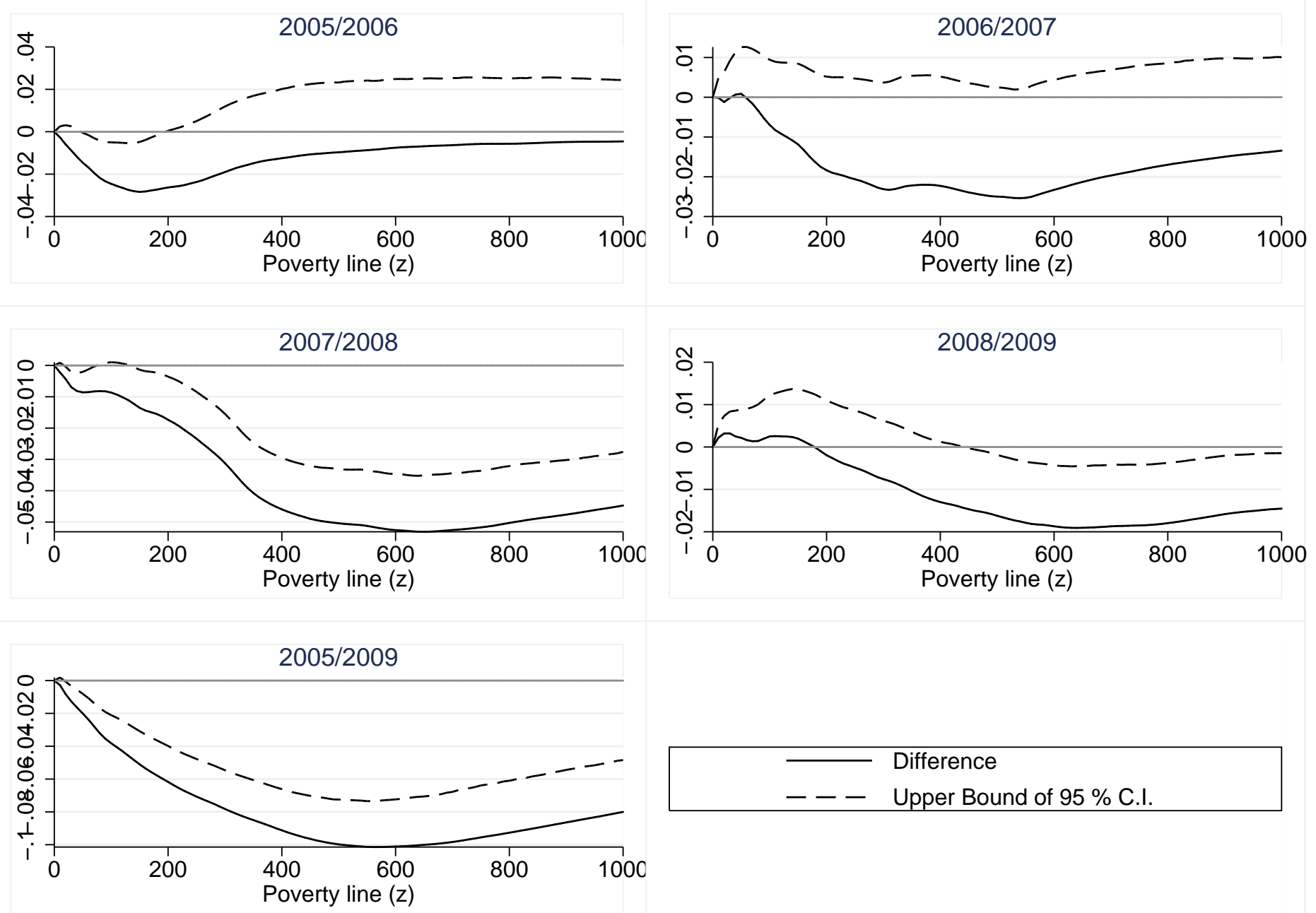
Figure BOL-15: Second order relatively pro-poor : Bolivia 2005/09

Dual approach: $\left(\left(G L_{2}(p) / G L_{1}(p)-\mu_{2} / \mu_{1}\right)\right)$
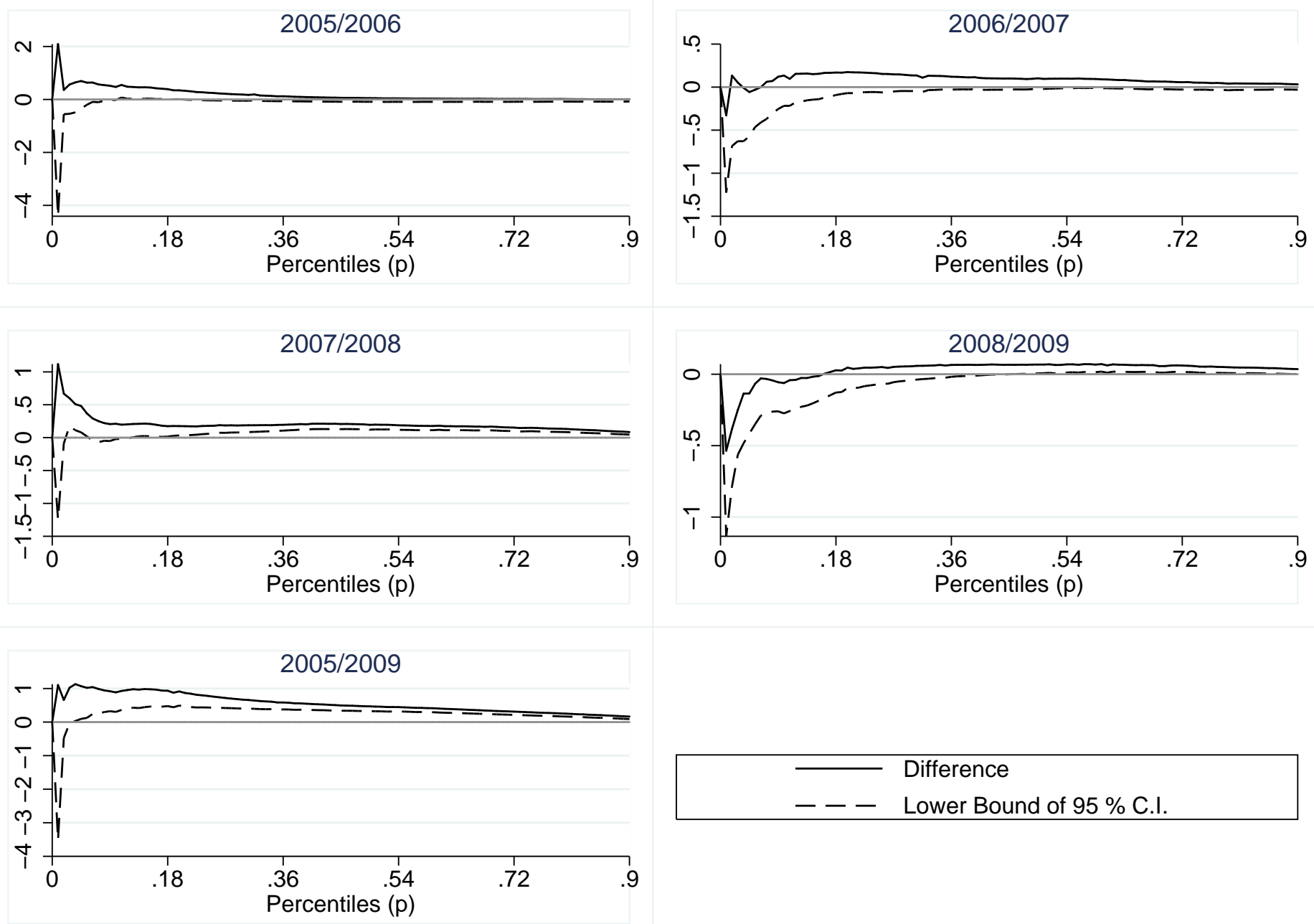


\section{The Venezuelan results}


Table VEN-1: Trend of average per capita income, poverty and inequality: Venezuela 2005/10

\begin{tabular}{l|rl|rl|rl|rl}
\hline Year & $\begin{array}{r}\text { Average } \\
\text { income }\end{array}$ & $\begin{array}{l}\text { Yearly } \\
\text { variation }\end{array}$ & Headcount & $\begin{array}{l}\text { Yearly } \\
\text { variation }\end{array}$ & $\begin{array}{r}\text { Poverty } \\
\text { gap }\end{array}$ & $\begin{array}{l}\text { Yearly } \\
\text { variation }\end{array}$ & $\begin{array}{r}\text { Gini } \\
\text { index }\end{array}$ & $\begin{array}{l}\text { Yearly } \\
\text { variation }\end{array}$ \\
\hline 2005 & 805.1 & & 43.79 & & 19.8 & & 0.461 & \\
2006 & 901.2 & $96.05 * * *$ & 36.28 & $-7.51 * * *$ & 13.7 & $-6.01 * * *$ & 0.422 & $-0.039 * * *$ \\
2007 & 918.8 & 17.7 & 33.59 & $-2.69 * * *$ & 12.3 & $-1.46 * * *$ & 0.406 & $-0.016 * * *$ \\
2008 & 958.1 & $39.25 * * *$ & 32.53 & -1.06 & 12.5 & 0.21 & 0.404 & -0.0020 \\
2009 & 923.6 & $-34.47 * * *$ & 31.78 & -0.75 & 11.4 & $-1.10 * * *$ & 0.392 & $-0.012 * * *$ \\
2010 & 884.3 & $-39.27 * * *$ & 32.23 & 0.45 & 11.1 & -0.34 & 0.371 & $-0.021 * * *$ \\
\hline
\end{tabular}

Sampling design is fully taken into account in computing the standard errors.

${ }^{*} p \leq 0.10,{ }^{* *} p \leq 0.05,{ }^{* * *} p \leq 0.01$. 
Table VEN-2: Decomposition of change in poverty gap into pro-poor growth components

Kraay (2004) approach - Ecuador 2005/10

\begin{tabular}{r|rrr|rr|rr}
\hline \multirow{2}{*}{ Period } & $\begin{array}{r}\text { Poverty } \\
\text { Change } \\
(\Delta P(\alpha=1))\end{array}$ & $\begin{array}{r}\text { C1: Average } \\
\text { growth } \\
(g)\end{array}$ & $\begin{array}{r}\text { C2: Sensitivity } \\
\text { to growth } \\
\left(\int \eta(p)\right)\end{array}$ & $\begin{array}{r}\text { C1C2 } \\
\text { Absolute } \\
\text { Contribution }\end{array}$ & $\begin{array}{r}\text { C3: Pattern of growth in relative incomes } \\
\text { Contribution } \\
\text { Absolute }\end{array}$ & $\begin{array}{r}\text { Relative } \\
\text { Contribution }\end{array}$ & $\begin{array}{r}\text { Contribution } \\
\hline\end{array}$ \\
\hline $2005 / 06$ & -0.0601 & 0.1193 & -0.2204 & -0.0263 & 44 & -0.0338 & 71 \\
$2006 / 07$ & -0.0146 & 0.0196 & -0.2138 & -0.0042 & 29 & -0.0104 & 677 \\
$2007 / 08$ & 0.0021 & 0.0427 & -0.2839 & -0.0121 & -577 & 0.0142 & 165 \\
$2008 / 09$ & -0.0110 & -0.0360 & -0.1995 & 0.0072 & -65 & -0.0182 & 394 \\
\hline
\end{tabular}

Table VEN-3: Decomposition of change in poverty gap into pro-poor growth components New approach - Ecuador 2005/10

\begin{tabular}{|c|c|c|c|c|c|c|c|c|}
\hline \multirow[b]{2}{*}{ Period } & \multirow{2}{*}{$\begin{array}{r}\text { Poverty } \\
\text { Change } \\
(\Delta P(\alpha=1))\end{array}$} & \multirow{2}{*}{$\begin{array}{l}\text { C1: Average } \\
\text { growth rates } \\
(\bar{g})\end{array}$} & \multirow{2}{*}{$\begin{array}{r}\text { C2: Sensitivity } \\
\text { to growth } \\
\left(\int \eta(p)\right)\end{array}$} & \multirow{2}{*}{$\begin{array}{r}\text { Correlation } \\
\operatorname{Corr}(\eta(p), g(p))\end{array}$} & \multicolumn{2}{|c|}{$\mathrm{C} 1 \mathrm{C} 2$} & \multicolumn{2}{|c|}{ C3 } \\
\hline & & & & & $\begin{array}{r}\text { Absolute } \\
\text { Contribution }\end{array}$ & $\begin{array}{r}\text { Relative } \\
\text { Contribution }\end{array}$ & $\begin{array}{r}\text { Absolute } \\
\text { Contribution }\end{array}$ & $\begin{array}{r}\text { Relative } \\
\text { Contribution }\end{array}$ \\
\hline $2005 / 06$ & -0.0601 & 0.1914 & -0.2200 & -0.1485 & -0.0421 & 70 & -0.0180 & 30 \\
\hline $2006 / 07$ & -0.0146 & 0.0281 & -0.2134 & -0.6111 & -0.0060 & 41 & -0.0086 & 59 \\
\hline $2007 / 08$ & 0.0021 & -0.0231 & -0.2892 & -0.0782 & 0.0067 & 318 & -0.0046 & -218 \\
\hline $2008 / 09$ & -0.0110 & 0.0608 & -0.2002 & 0.0100 & -0.0122 & 110 & 0.0011 & -10 \\
\hline $2009 / 10$ & -0.0034 & 0.0095 & -0.2334 & -0.0648 & -0.0022 & 66 & -0.0011 & 34 \\
\hline
\end{tabular}


Figure VEN-1: Change in Headcount, growth and redistribution: Ecuador $2005 / 10$

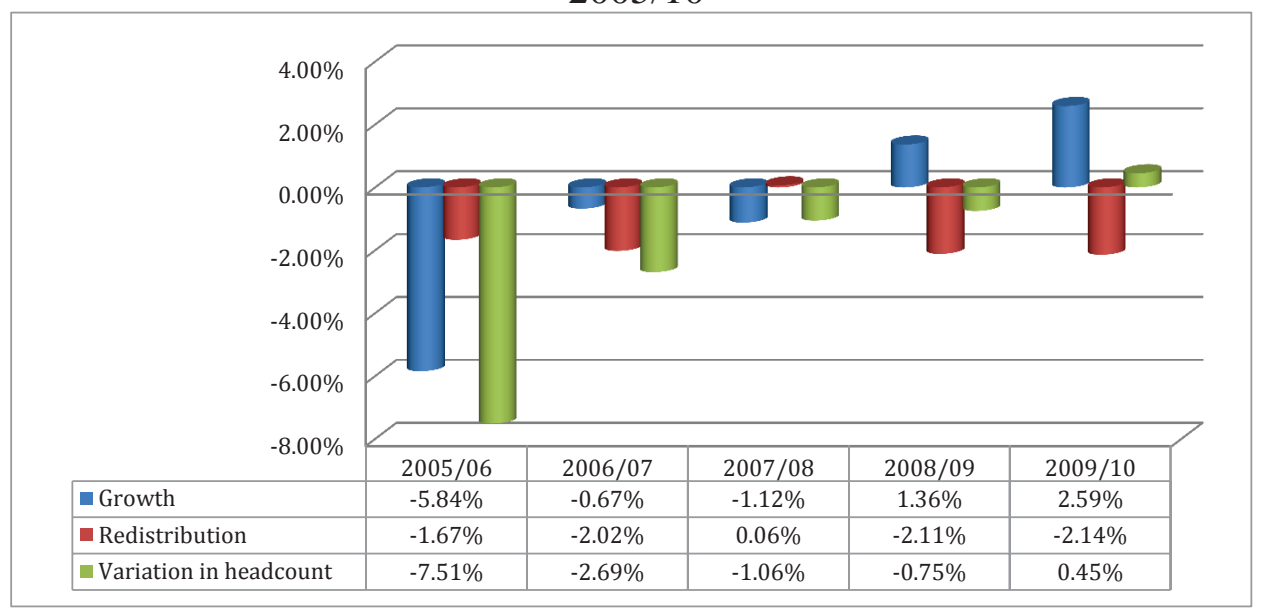

Figure VEN-2: Change in poverty gap, growth and redistribution: Ecuador

\begin{tabular}{|l|l|c|c|c|c|}
\hline & & \\
\hline
\end{tabular}


Figure VEN-3: Growth incidence curves in Ecuador : $\left(Q_{2}(p)-Q_{1}(p)\right) / Q_{1}(p)$
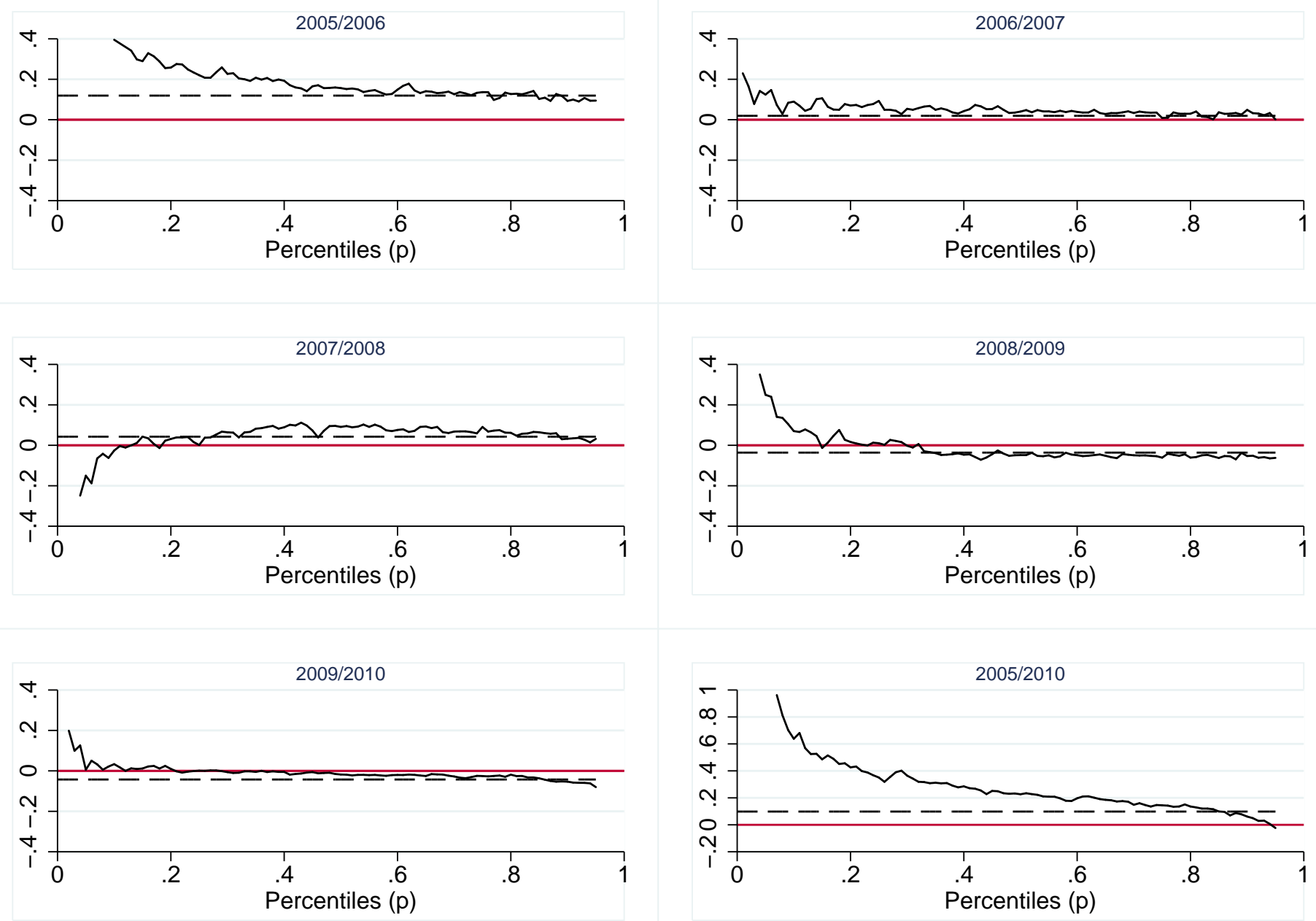
Figure VEN-4: First order absolutely pro-poor : Venezuela 2005/10

Primal approach: $\left(\left(P_{2}(z, \alpha=0)-P_{1}(z, \alpha=0)\right)\right.$
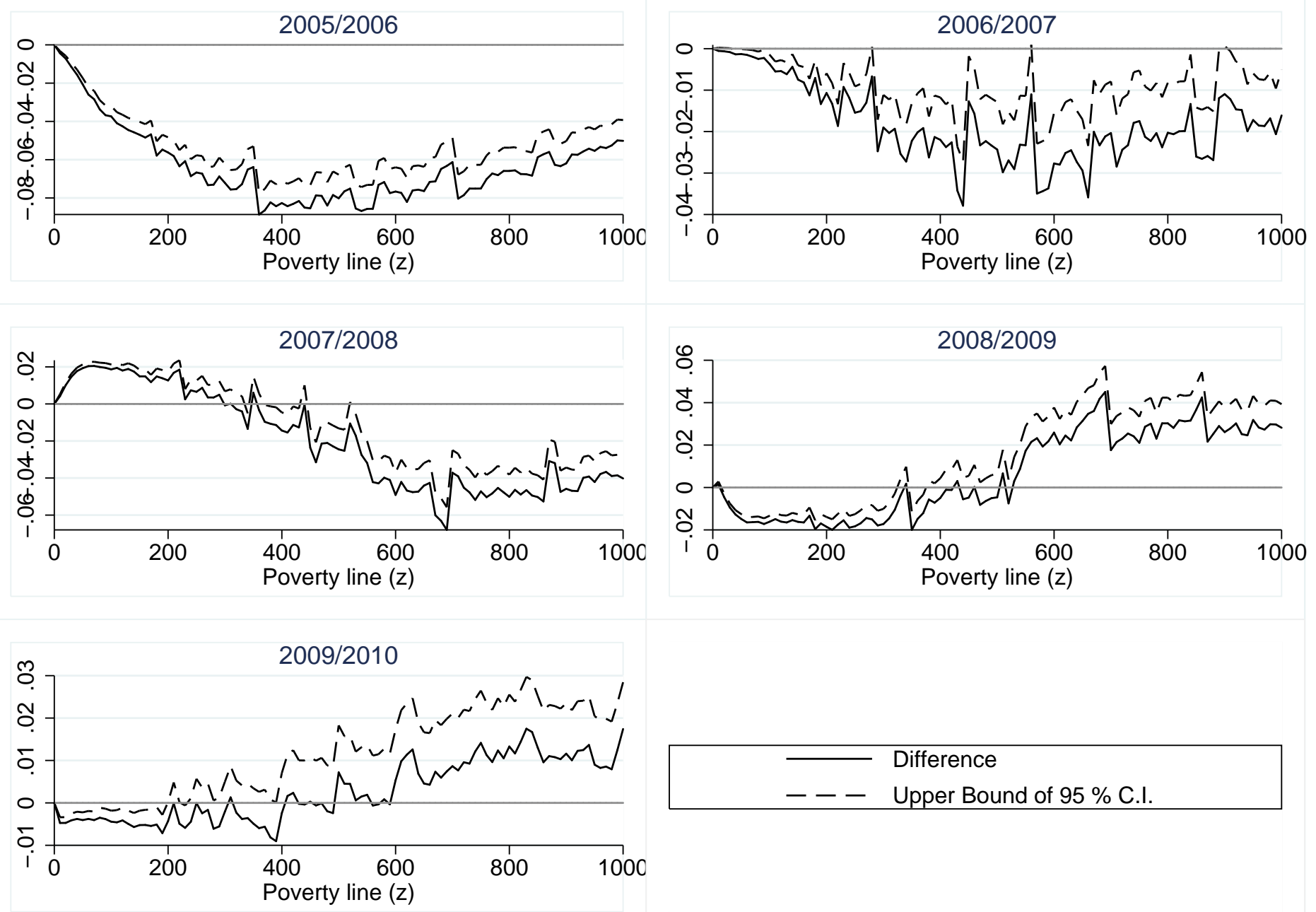
Figure VEN-5: First order absolutely pro-poor : Venezuela 2005/10

Dual approach: $\left(\left(Q_{2}(p)-Q_{1}(p)\right)\right)$
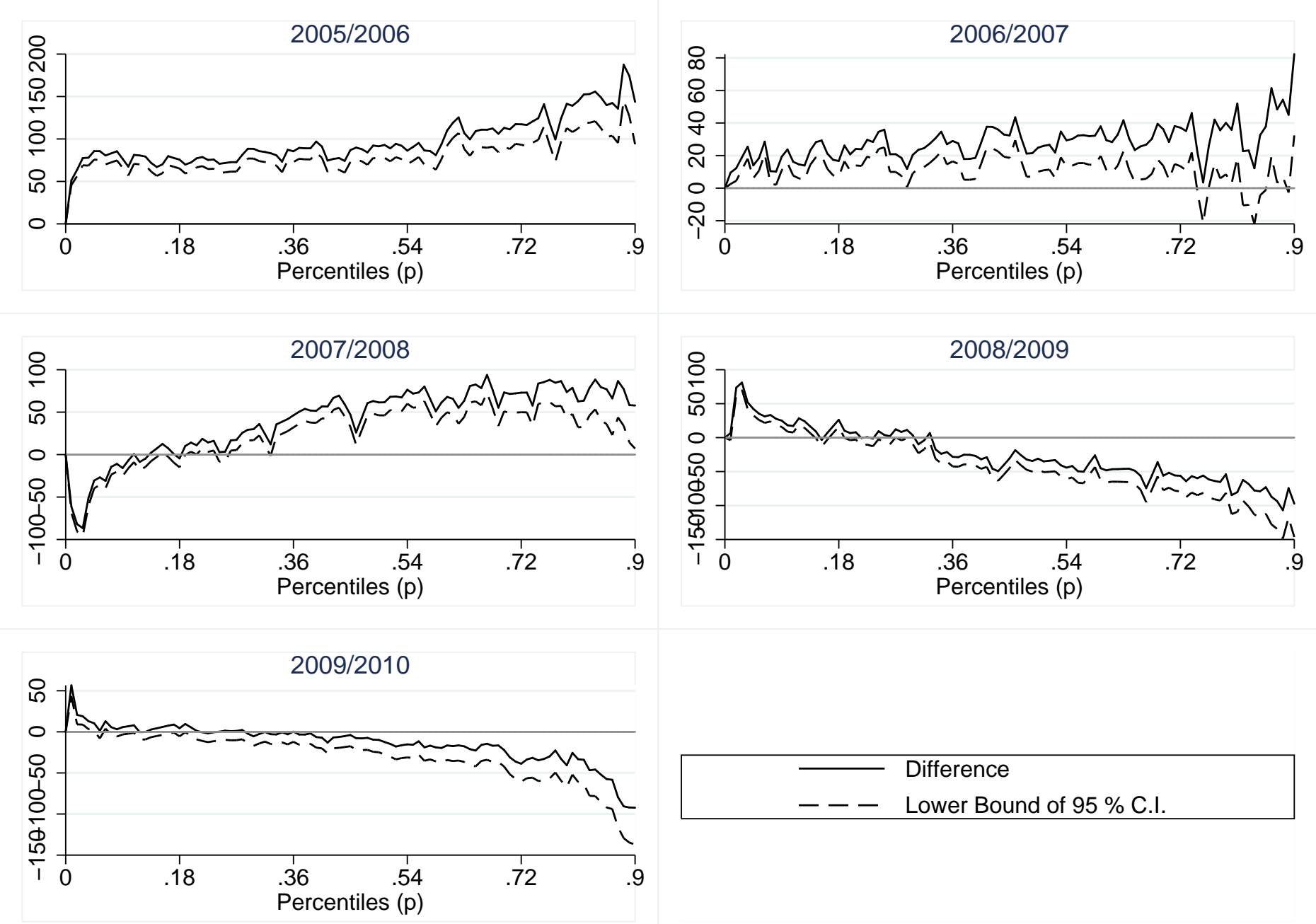
Figure VEN-6: Second order absolutely pro-poor : Venezuela 2005/10

Primal approach: $\left(z\left(P_{2}(z, \alpha=1)-z P_{1}(z, \alpha=1)\right)\right.$
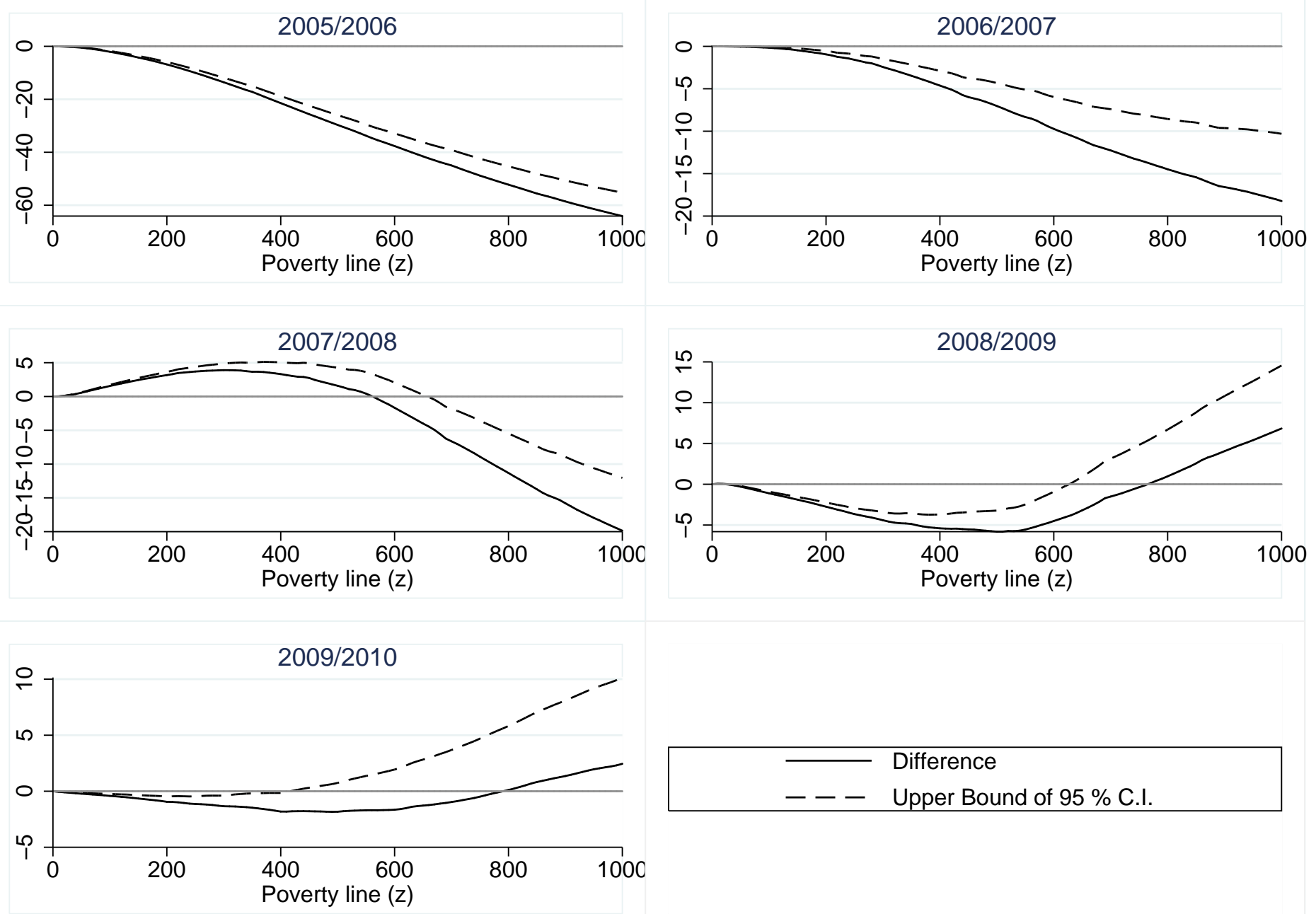
Figure VEN-7: Second order absolutely pro-poor : Venezuela 2005/10

Dual approach: $\left(\left(G L_{2}(p)-G L_{1}(p)\right)\right)$
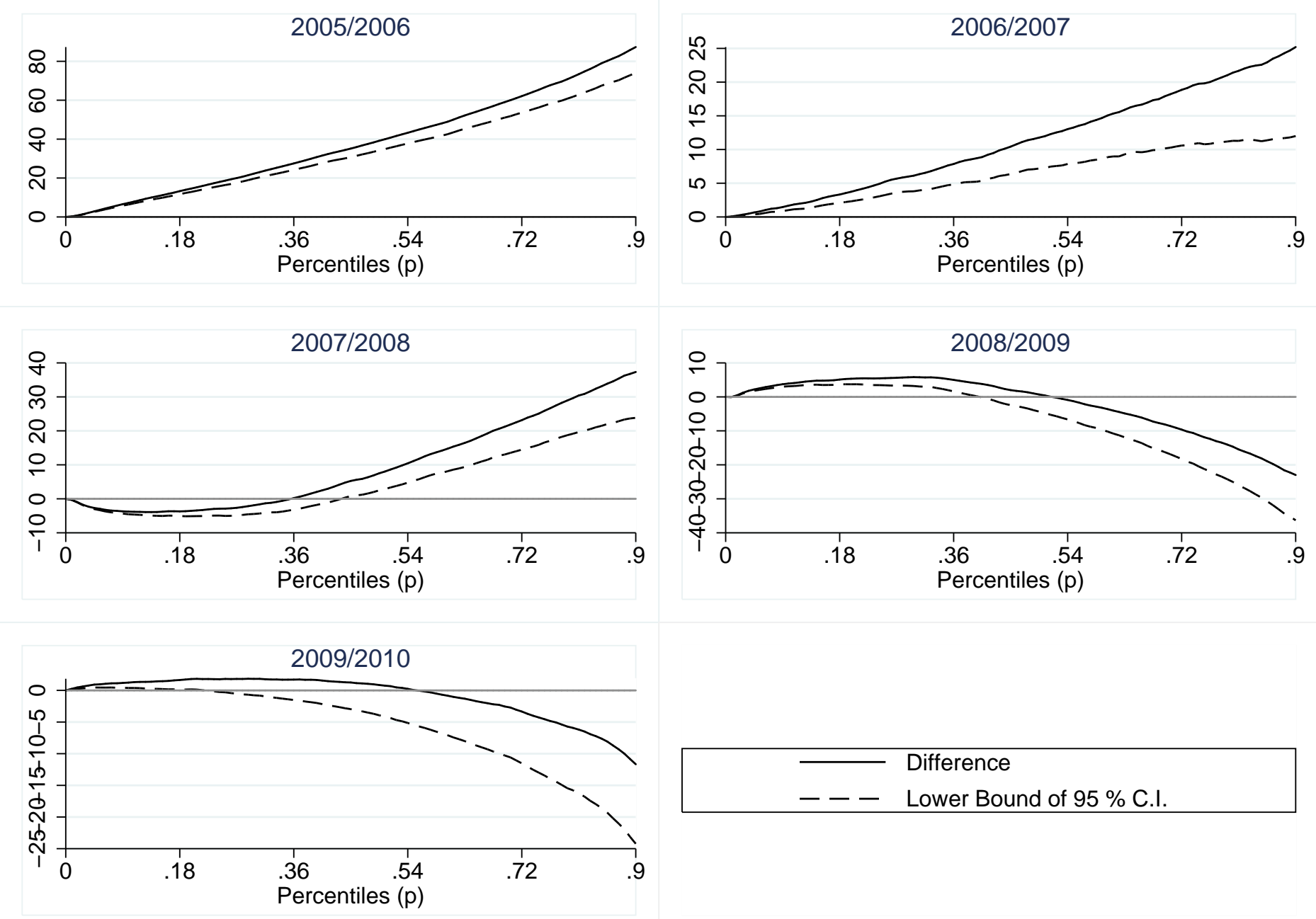
Figure VEN-8: First order relatively pro-poor : Venezuela 2005/10

Primal approach: $\left(\left(P_{2}((1+g) z, \alpha=0)-P_{1}(z, \alpha=0)\right)\right.$
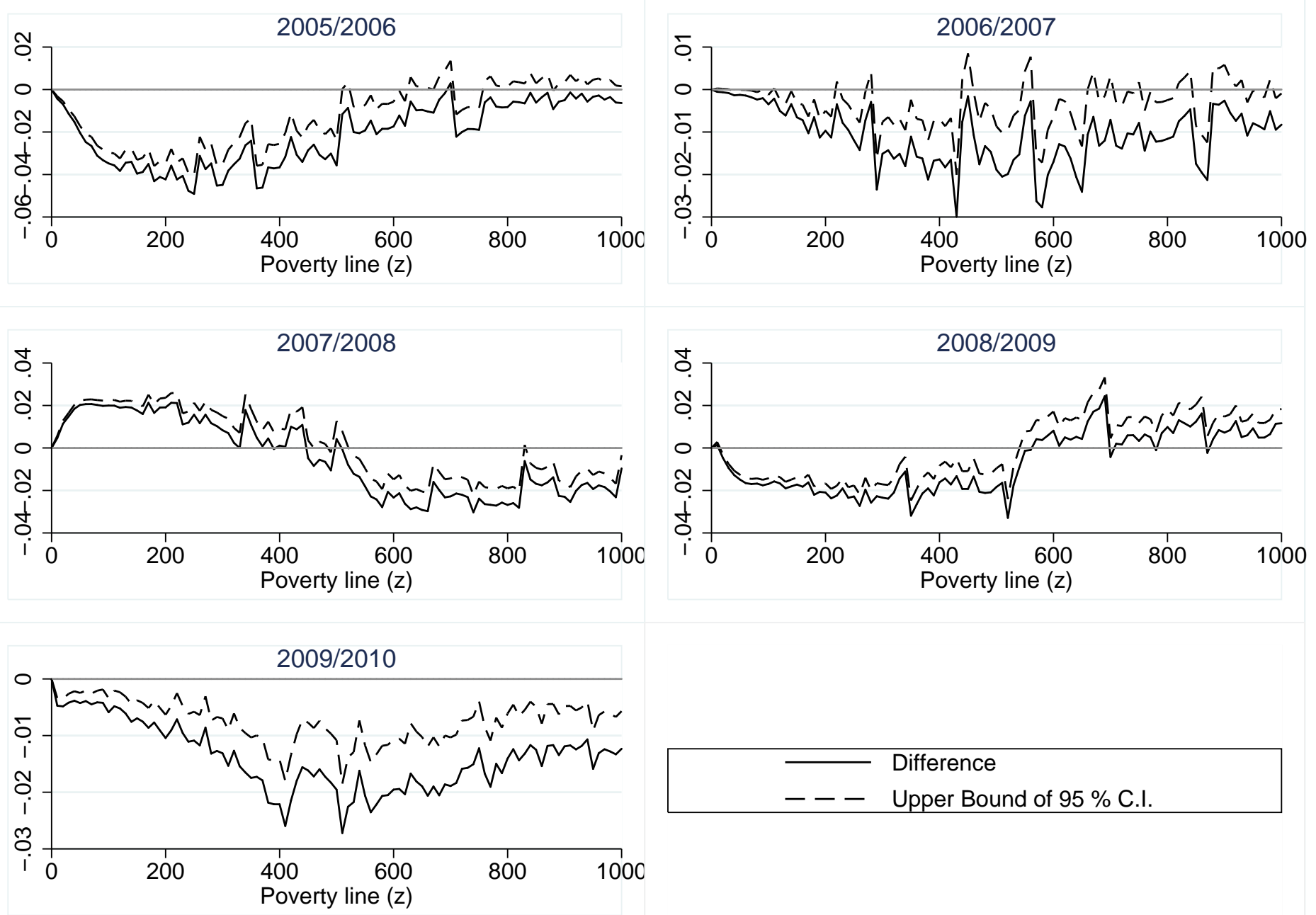
Figure VEN-9: First order relatively pro-poor : Venezuela 2005/10

Dual approach: $\left(\left(Q_{2}(p) / Q_{1}(p)-\mu_{2} / \mu_{1}\right)\right)$
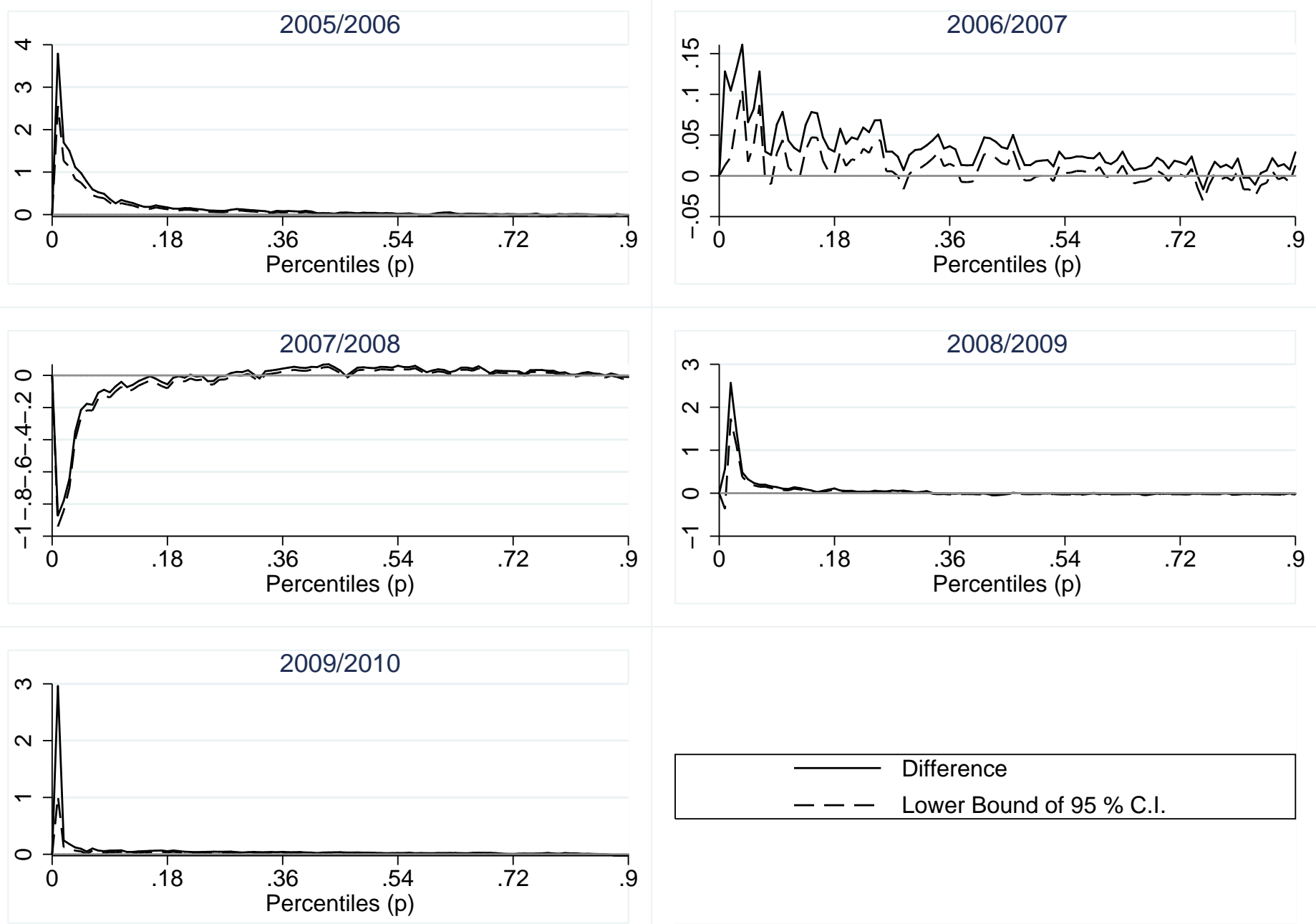
Figure VEN-10: Second order relatively pro-poor : Venezuela 2005/10

Primal approach: $\left(\left(P_{2}((1+g) z, \alpha=1)-P_{1}(z, \alpha=1)\right)\right.$
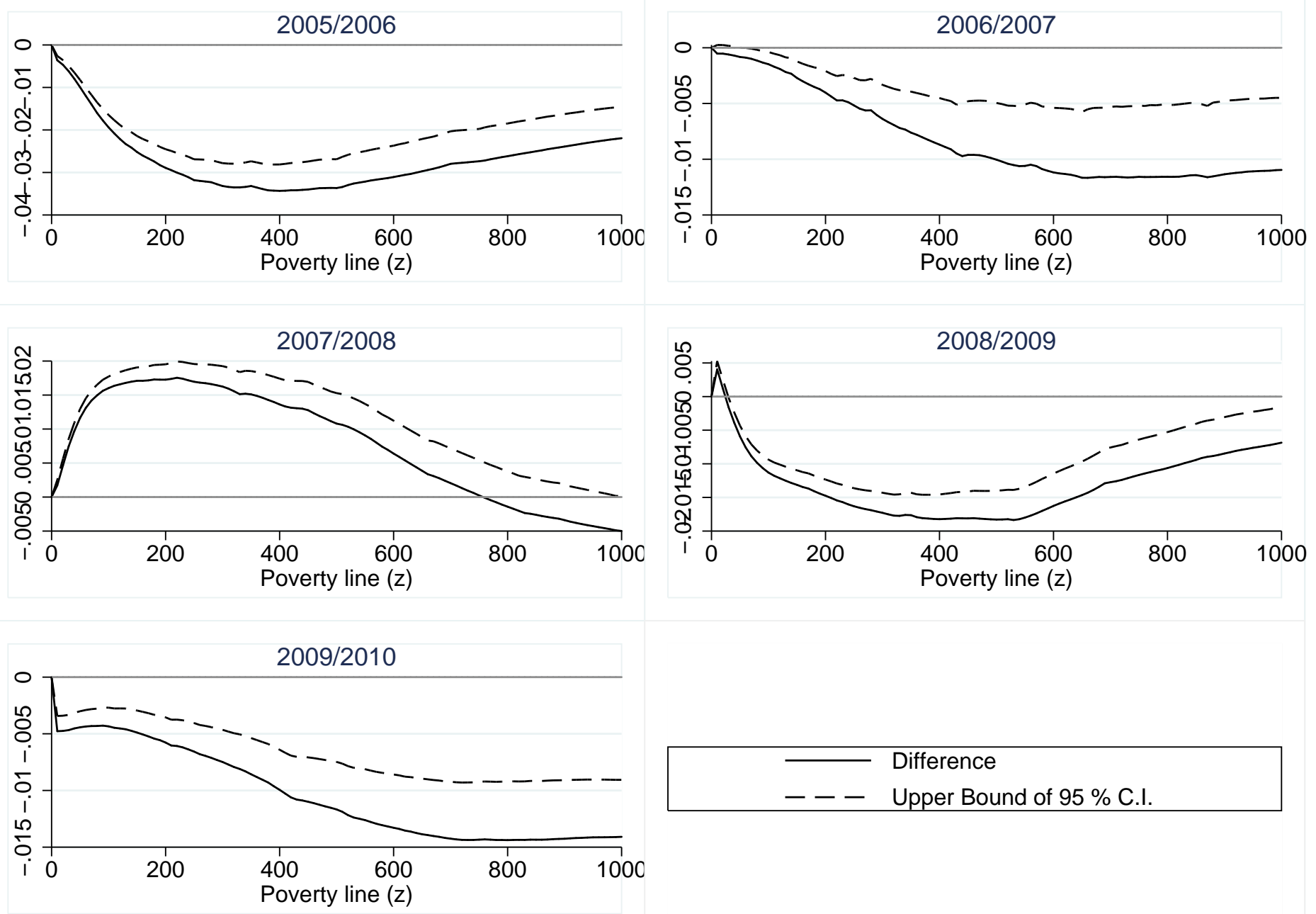
Figure VEN-11: Second order relatively pro-poor : Venezuela 2005/10

Dual approach: $\left(\left(G L_{2}(p) / G L_{1}(p)-\mu_{2} / \mu_{1}\right)\right)$
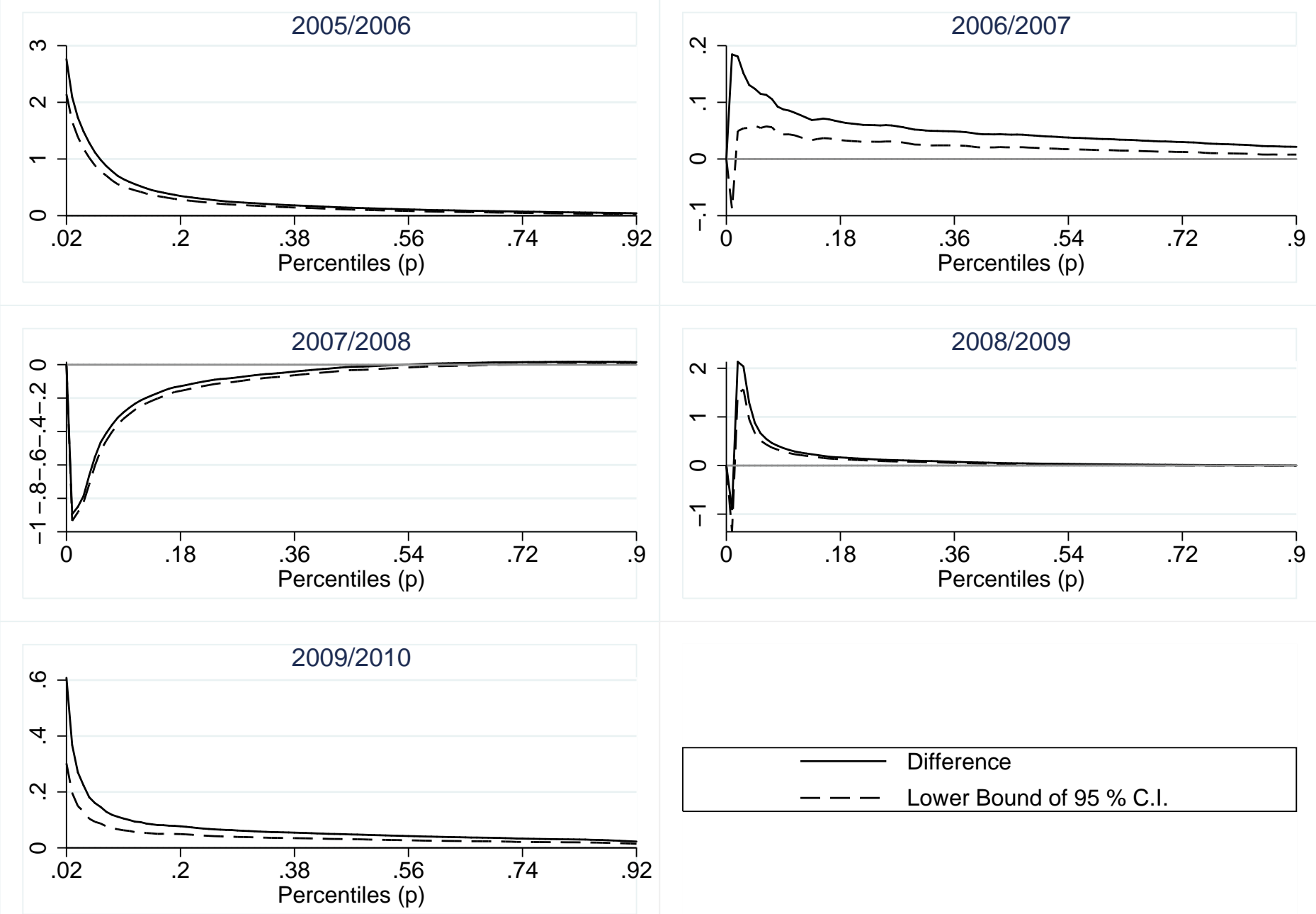
Figure VEN-12: First order absolute pro-poor: Venezuela 2005-2010

Primal approach: $\left(\left(P_{2}(z, \alpha=0)-P_{1}(z, \alpha=0)\right)\right.$

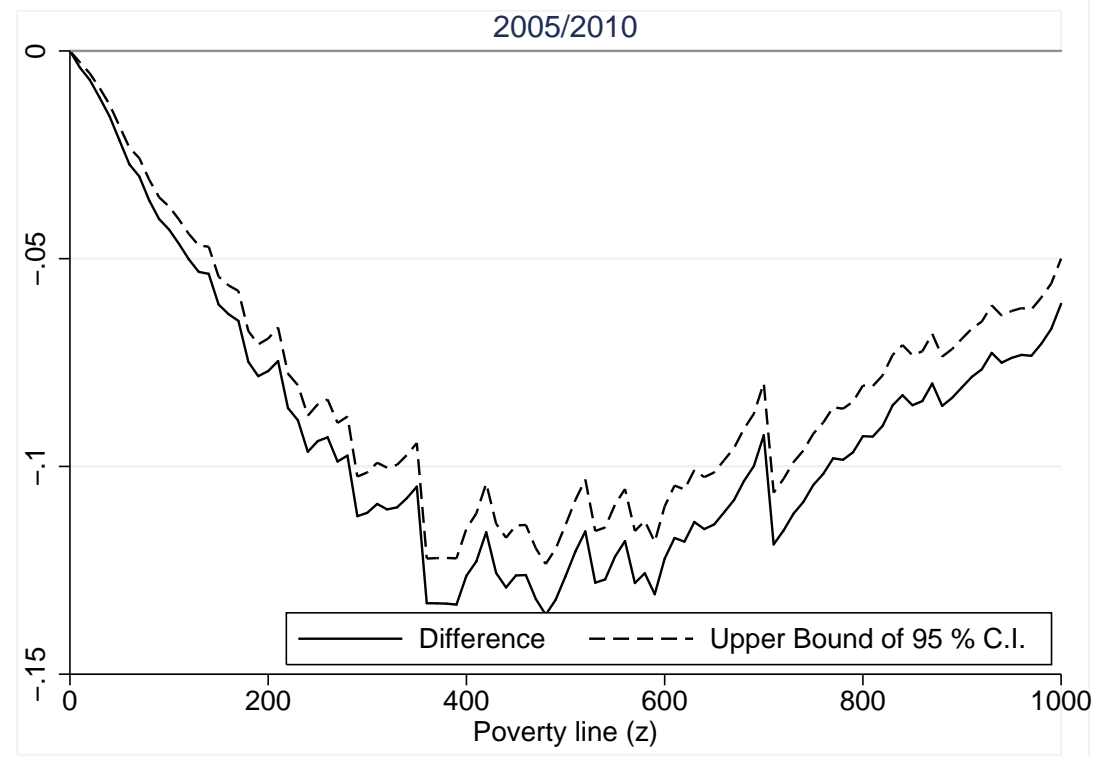

Figure VEN-13: First order relatively pro-poor: Venezuela 2005-2010

Primal approach: $\left(\left(P_{2}((1+g) z, \alpha=0)-P_{1}(z, \alpha=0)\right)\right.$

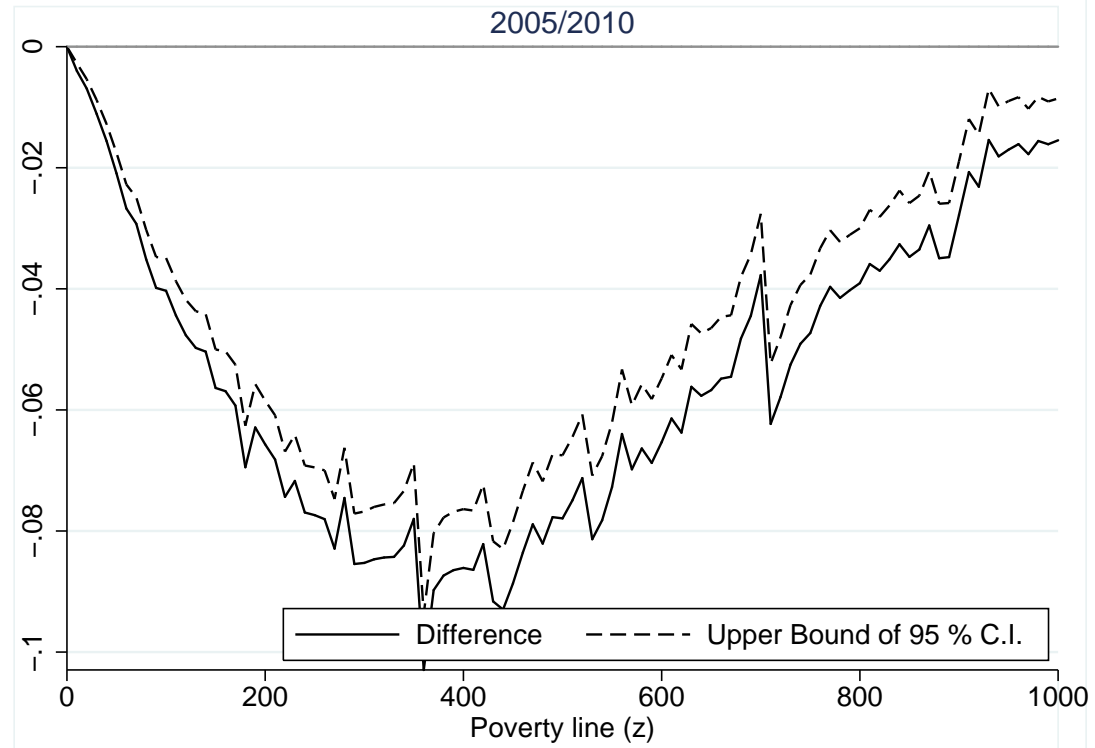




\section{The Colombian results}


Table COL-1: Trend of average per capita income, poverty and inequality: Colombia 2004/10

\begin{tabular}{l|rl|rl|ll|rl}
\hline Year & $\begin{array}{r}\text { Average } \\
\text { income }\end{array}$ & $\begin{array}{l}\text { Yearly } \\
\text { variation }\end{array}$ & Headcount & $\begin{array}{l}\text { Yearly } \\
\text { variation }\end{array}$ & $\begin{array}{r}\text { Poverty } \\
\text { gap }\end{array}$ & $\begin{array}{l}\text { Yearly } \\
\text { variation }\end{array}$ & $\begin{array}{r}\text { Gini } \\
\text { index }\end{array}$ & $\begin{array}{l}\text { Yearly } \\
\text { variation }\end{array}$ \\
\hline 2004 & 338137.0 & & $47.36 \%$ & & $19.82 \%$ & & 0.5295 & \\
2005 & 357753.5 & $19616.48 * * *$ & $44.95 \%$ & $-2.40 * * *$ & $18.38 \%$ & $-1.44 * * *$ & 0.5306 & 0.0010 \\
2008 & 390182.1 & $32428.72 * * *$ & $42.00 \%$ & $-2.95 * * *$ & $18.36 \%$ & -0.02 & 0.5430 & $0.012 * * *$ \\
2009 & 399621.0 & $9438.75 * *$ & $40.22 \%$ & $-1.79 * * *$ & $16.74 \%$ & $-1.62 * * *$ & 0.5331 & $-0.010 * * *$ \\
2010 & 429667.6 & $30046.60 * * *$ & $37.17 \%$ & $-3.04 * * *$ & $15.12 \%$ & $-1.62 * * *$ & 0.5359 & 0.0030 \\
\hline
\end{tabular}

Sampling design is fully taken into account in computing the standard errors.

${ }^{*} p \leq 0.10,{ }^{* *} p \leq 0.05,{ }^{* * *} p \leq 0.01$. 
Table COL-2: Decomposition of change in poverty gap into pro-poor growth components Kraay (2004) approach - Colombia 2004/010

\begin{tabular}{r|rrr|rr|rr}
\hline \multirow{2}{*}{ Period } & $\begin{array}{r}\text { Poverty } \\
\text { Change } \\
(\Delta P(\alpha=1))\end{array}$ & $\begin{array}{r}\text { C1: Average } \\
\text { growth } \\
(g)\end{array}$ & $\begin{array}{r}\text { C2: Sensitivity } \\
\text { to growth } \\
\left(\int \eta(p)\right)\end{array}$ & $\begin{array}{r}\text { C1C2 } \\
\text { Absolute } \\
\text { Contribution }\end{array}$ & $\begin{array}{r}\text { Relative } \\
\text { Contribution }\end{array}$ & $\begin{array}{r}\text { Pattern of growth in relative incomes } \\
\text { Absolute } \\
\text { Contribution }\end{array}$ & $\begin{array}{r}\text { Relative } \\
\text { Contribution }\end{array}$ \\
\hline $2004 / 2005$ & -0.0144 & 0.058 & -0.2639 & -0.0153 & 107 & 0.0009 & -7 \\
$2005 / 2008$ & -0.0002 & 0.0906 & -0.2649 & -0.024 & 12000 & 0.0238 & -11900 \\
$2008 / 2009$ & -0.0162 & 0.0242 & -0.2309 & -0.0056 & 34 & -0.0106 & 66 \\
$2009 / 2010$ & -0.0162 & 0.0752 & -0.219 & -0.0165 & 102 & 0.0003 & -2 \\
\hline
\end{tabular}

Table COL-3: Decomposition of change in poverty gap into pro-poor growth components New approach - Colombia 2004/010

\begin{tabular}{|c|c|c|c|c|c|c|c|c|}
\hline \multirow[b]{2}{*}{ Period } & \multirow{2}{*}{$\begin{array}{r}\text { Poverty } \\
\text { Change } \\
(\Delta P(\alpha=1))\end{array}$} & \multirow{2}{*}{$\begin{array}{r}\mathrm{C} 1: \text { Average } \\
\text { growth rates } \\
(\bar{g})\end{array}$} & \multirow{2}{*}{$\begin{array}{r}\text { C2: Sensitivity } \\
\text { to growth } \\
\left(\int \eta(p)\right)\end{array}$} & \multirow{2}{*}{$\begin{array}{r}\text { Correlation } \\
\operatorname{Corr}(\eta(p), g(p))\end{array}$} & \multicolumn{2}{|c|}{$\mathrm{C} 1 \mathrm{C} 2$} & \multicolumn{2}{|c|}{$\mathrm{C} 3$} \\
\hline & & & & & $\begin{array}{r}\text { Absolute } \\
\text { Contribution }\end{array}$ & $\begin{array}{r}\text { Relative } \\
\text { Contribution }\end{array}$ & $\begin{array}{r}\text { Absolute } \\
\text { Contribution }\end{array}$ & $\begin{array}{l}\text { Relative } \\
\text { Contribution }\end{array}$ \\
\hline $2004 / 05$ & -0.0144 & 0.0278 & -0.2639 & -0.6562 & -0.0073 & 51 & -0.0071 & 49 \\
\hline $2005 / 08$ & -0.0002 & -0.0185 & -0.2649 & -0.1853 & 0.0049 & -2882 & -0.0051 & 2982 \\
\hline $2008 / 09$ & -0.0162 & 0.0437 & -0.2309 & -0.1726 & -0.0101 & 62 & -0.0061 & 38 \\
\hline $2009 / 10$ & -0.0162 & 0.0354 & -0.2190 & -0.2951 & -0.0078 & 48 & -0.0084 & 52 \\
\hline
\end{tabular}


Figure COL-1: Change in headcount, growth and redistribution: Colombia

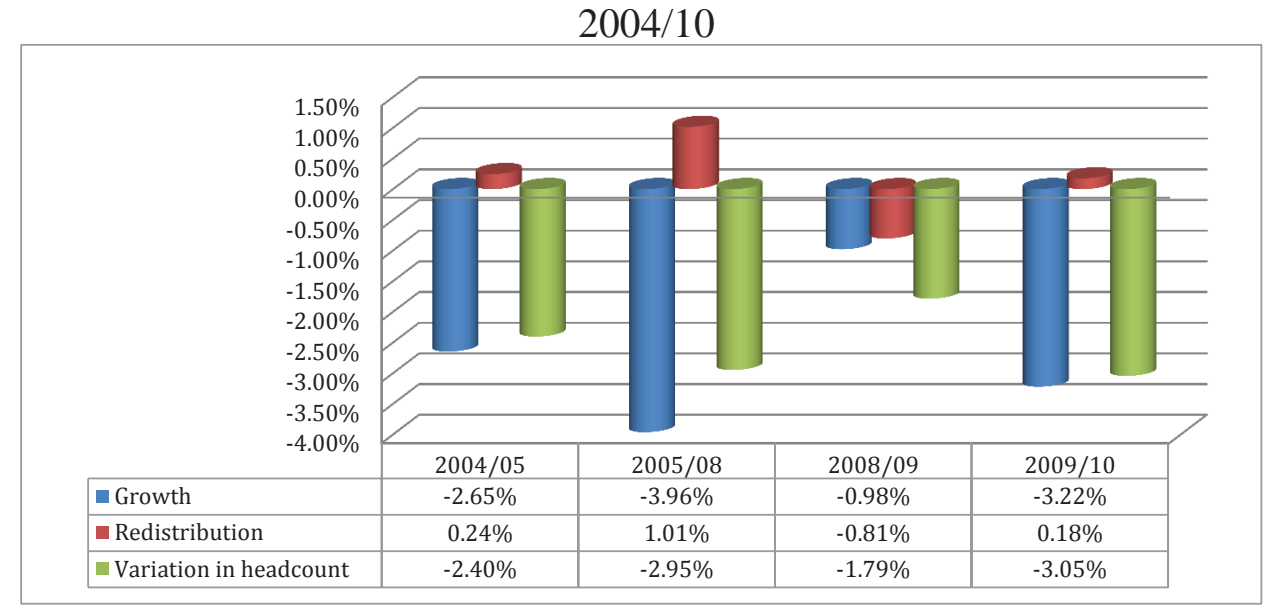

Figure COL-2: Change in poverty gap, growth and redistribution: Colombia

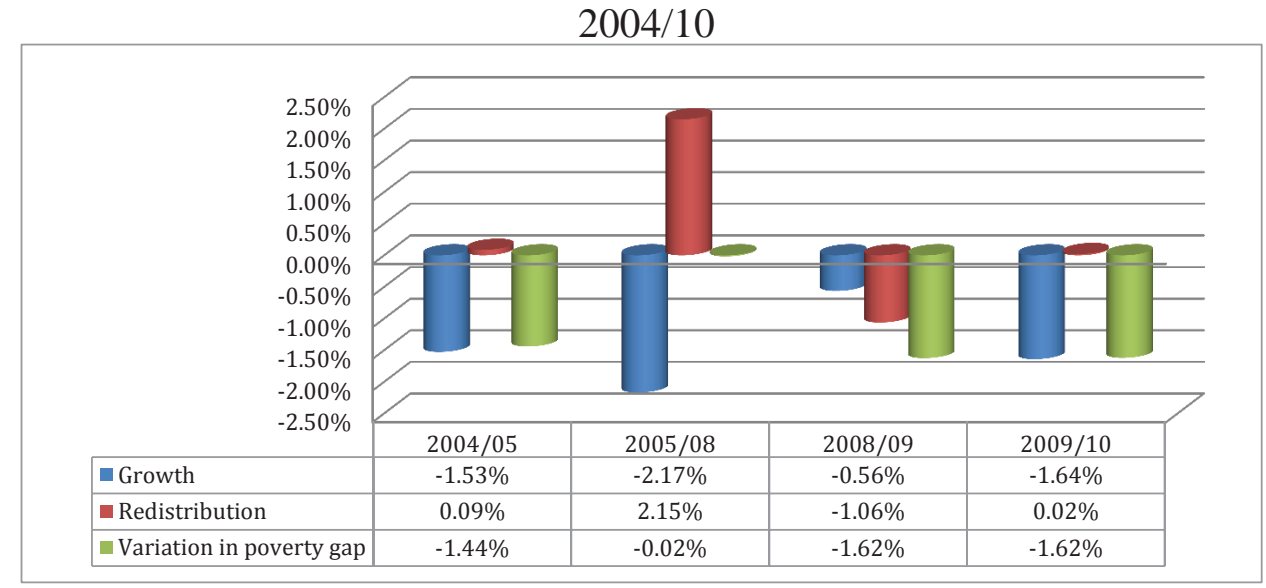


Figure COL-3: Growth incidence curves in Colombia : $\left(Q_{2}(p)-Q_{1}(p)\right) / Q_{1}(p)$

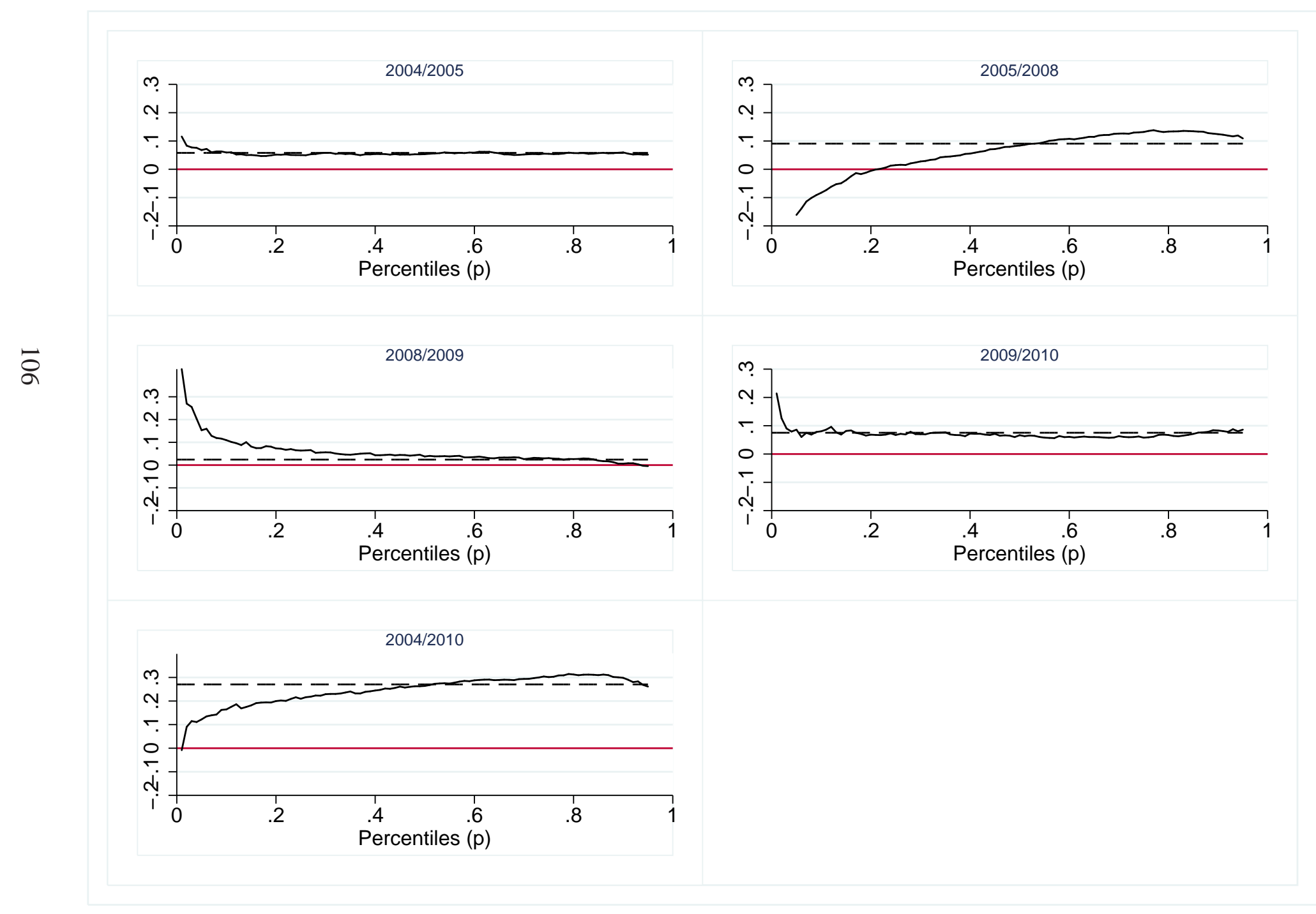


Figure COL-4: First order absolutely pro-poor : Colombia 2004/10

Primal approach: $\left(\left(P_{2}(z, \alpha=0)-P_{1}(z, \alpha=0)\right)\right.$
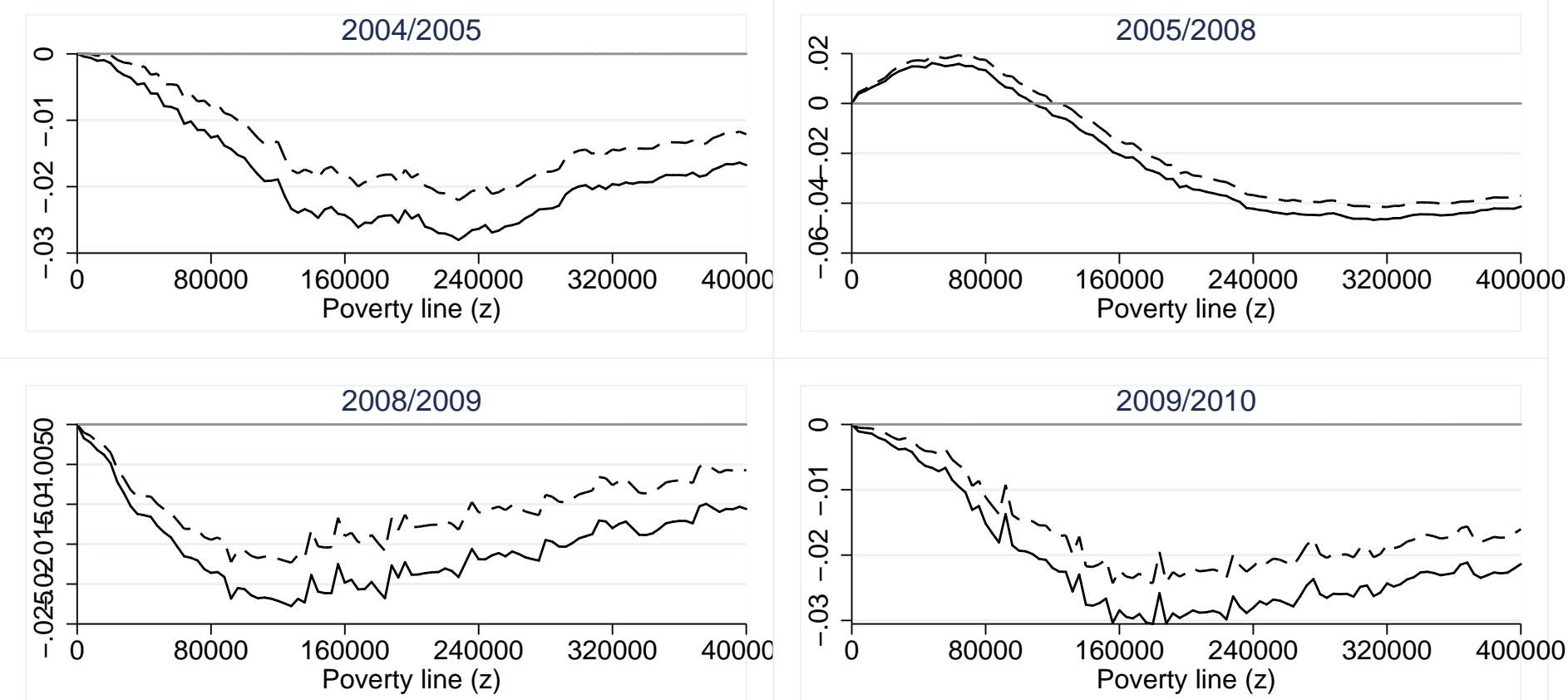

$$
\begin{array}{ll}
- & \text { Difference } \\
-\ldots- & \text { Upper Bound of } 95 \% \text { C.I. }
\end{array}
$$


Figure COL-5: First order absolutely pro-poor : Colombia 2004/10 Dual approach: $\left(\left(Q_{2}(p)-Q_{1}(p)\right)\right)$
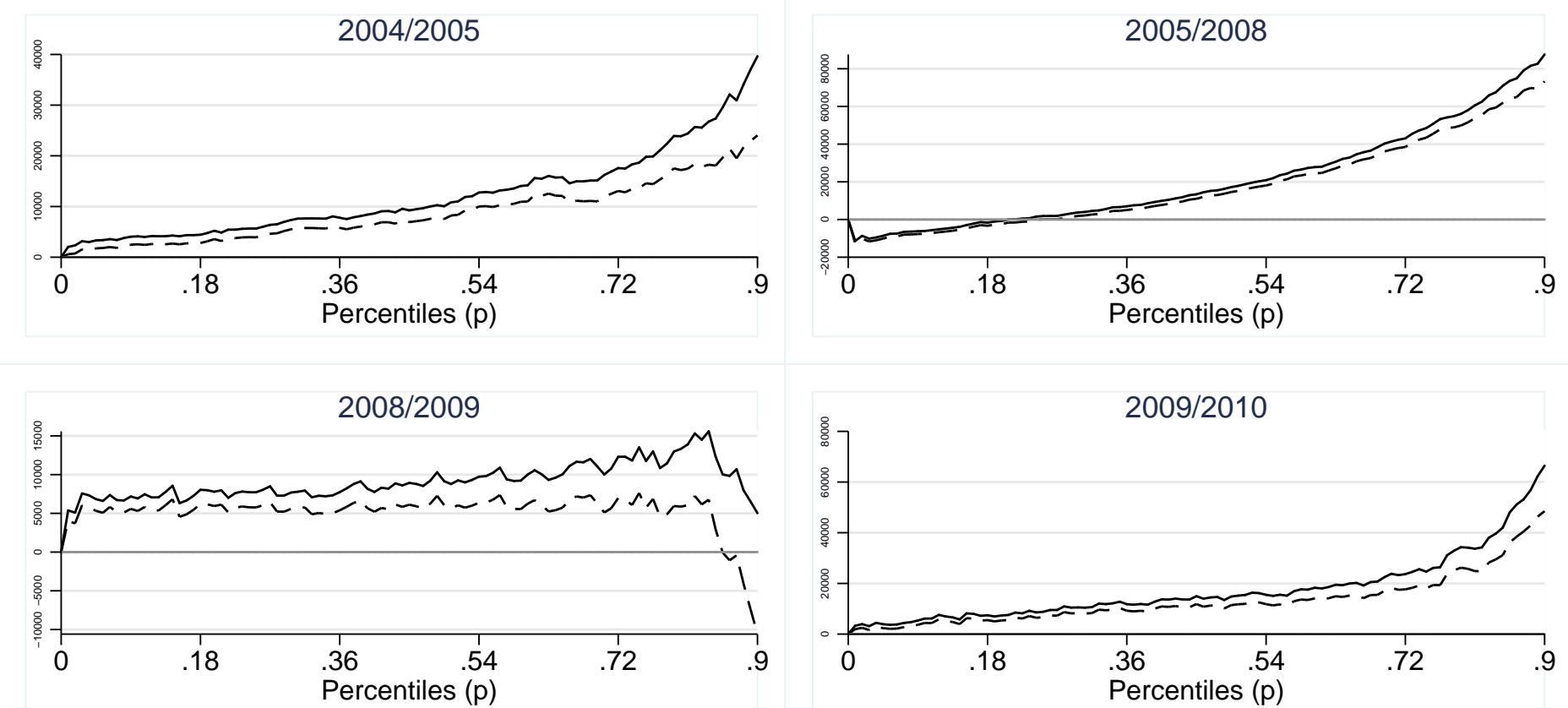

$\begin{array}{ll}- & \text { Difference } \\ --- & \text { Lower Bound of } 95 \% \text { C.I. }\end{array}$ 
Figure COL-6: Second order absolutely pro-poor : Colombia 2004/10

Primal approach: $\left(z\left(P_{2}(z, \alpha=1)-z P_{1}(z, \alpha=1)\right)\right.$

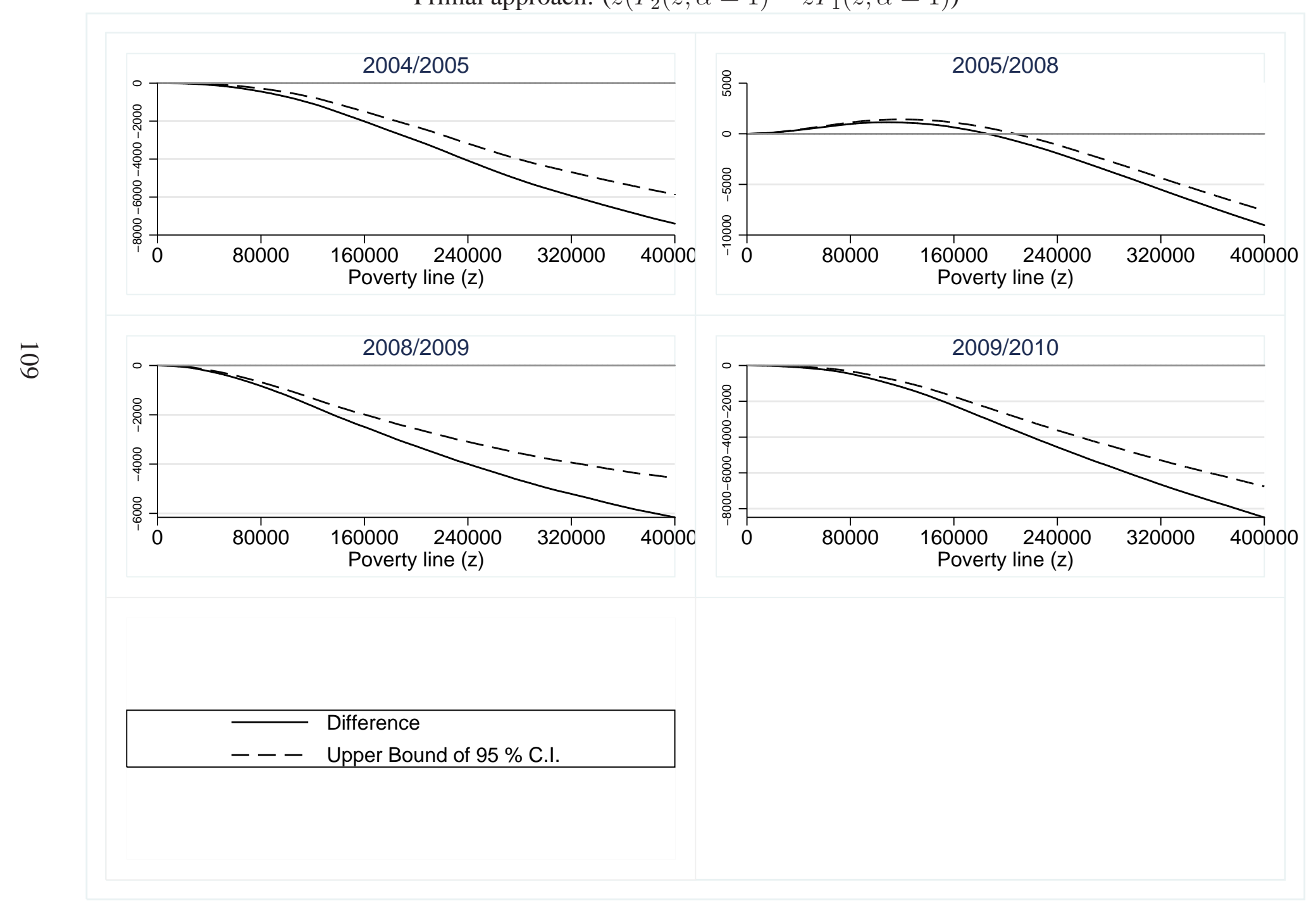




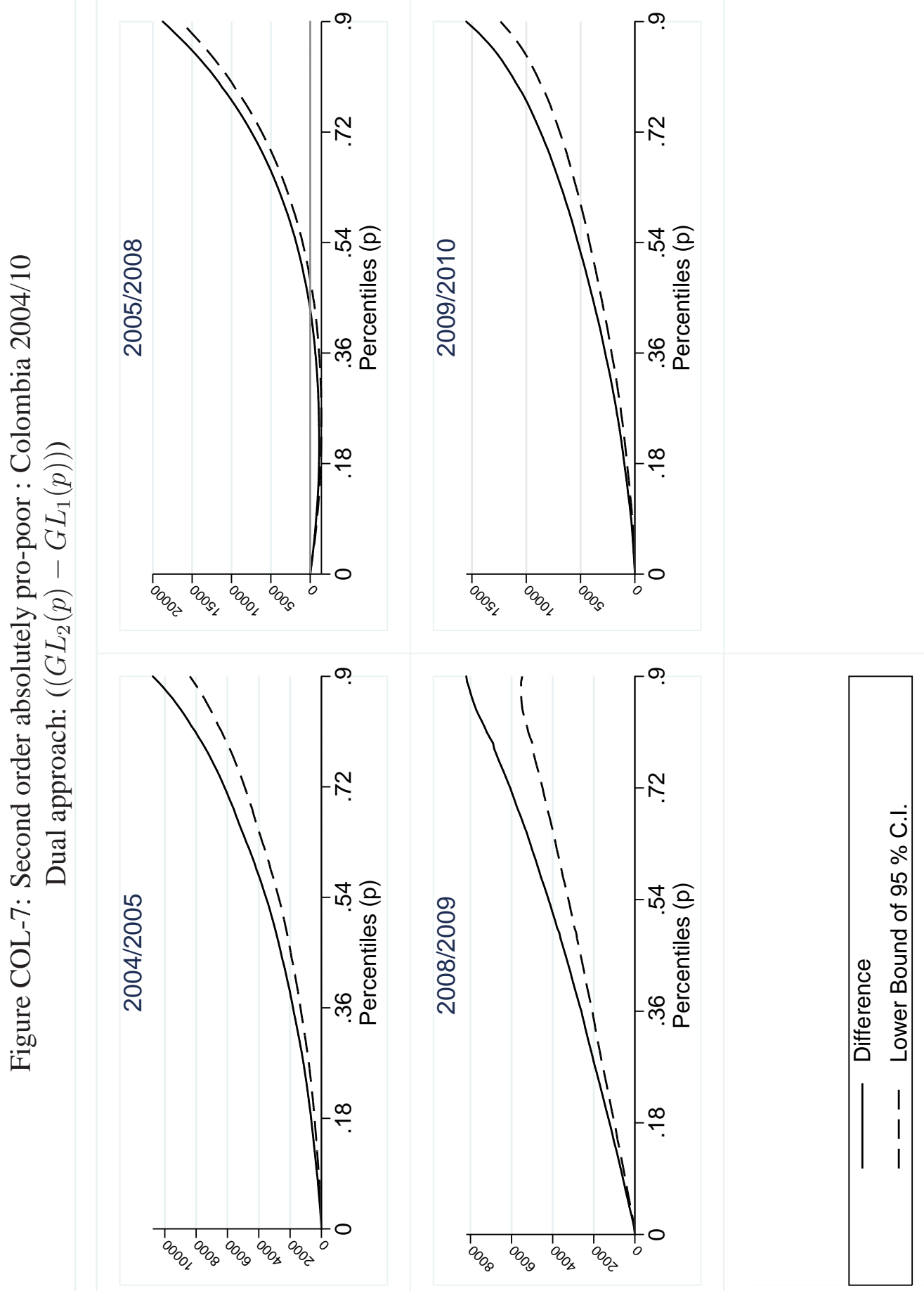


Figure COL-8: First order relatively pro-poor : Colombia 2004/10

Primal approach: $\left(\left(P_{2}((1+g) z, \alpha=0)-P_{1}(z, \alpha=0)\right)\right.$
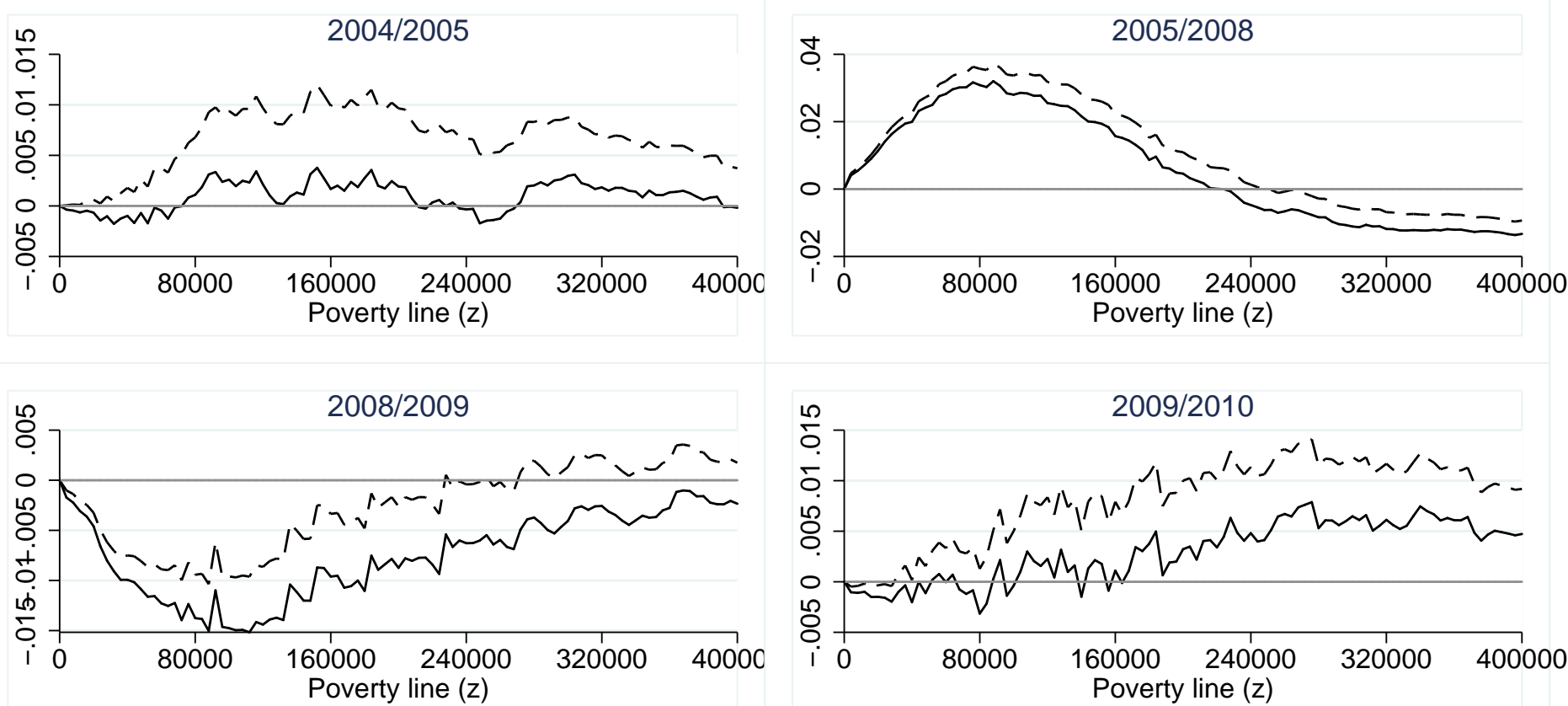

$\begin{array}{ll}- & \text { Difference } \\ --- & \text { Upper Bound of } 95 \% \text { C.I. }\end{array}$ 
Figure COL-9: First order relatively pro-poor : Colombia 2004/10

Dual approach: $\left(\left(Q_{2}(p) / Q_{1}(p)-\mu_{2} / \mu_{1}\right)\right)$
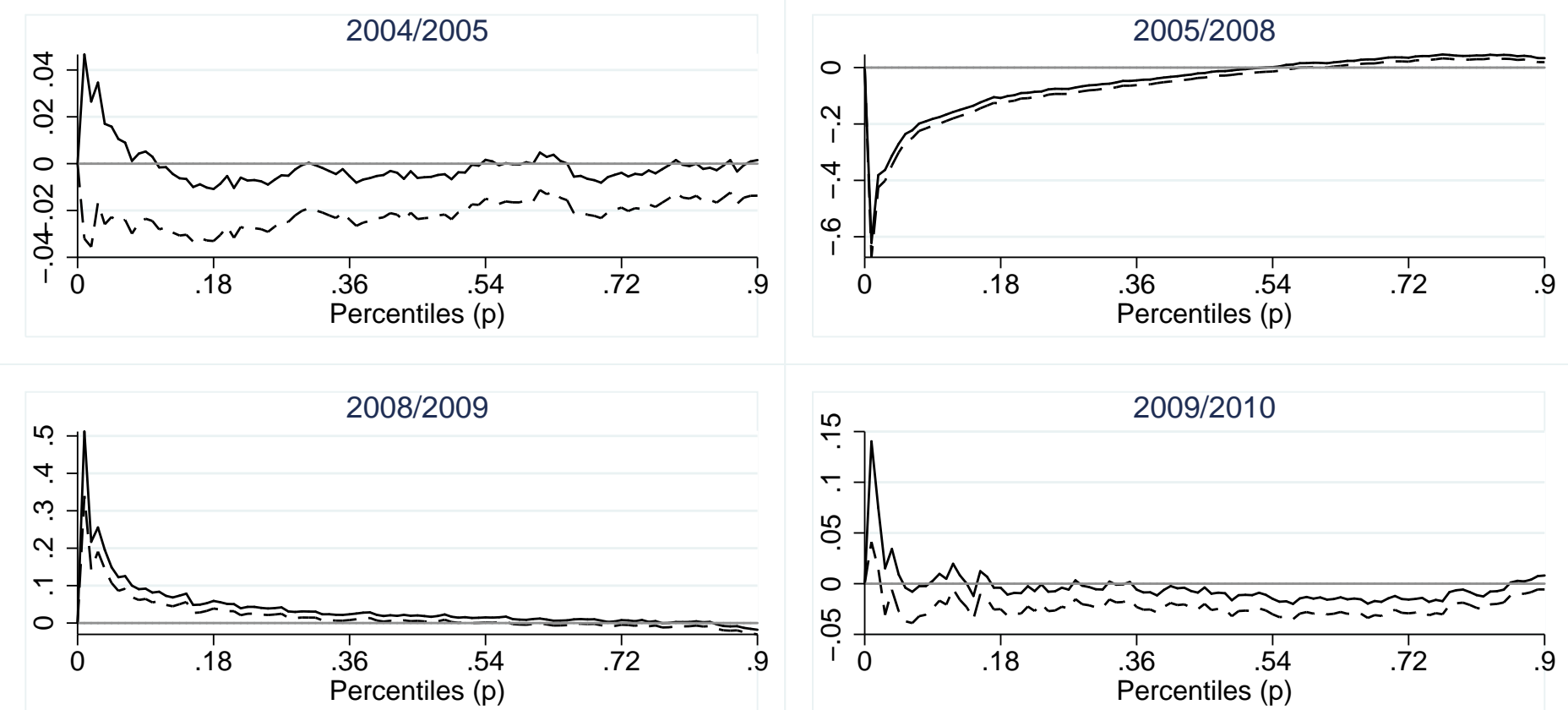

$\begin{array}{ll}- & \text { Difference } \\ --- & \text { Lower Bound of } 95 \% \text { C.I. }\end{array}$ 
Figure COL-10: Second order relatively pro-poor : Colombia 2004/10

Primal approach: $\left(\left(P_{2}((1+g) z, \alpha=1)-P_{1}(z, \alpha=1)\right)\right.$
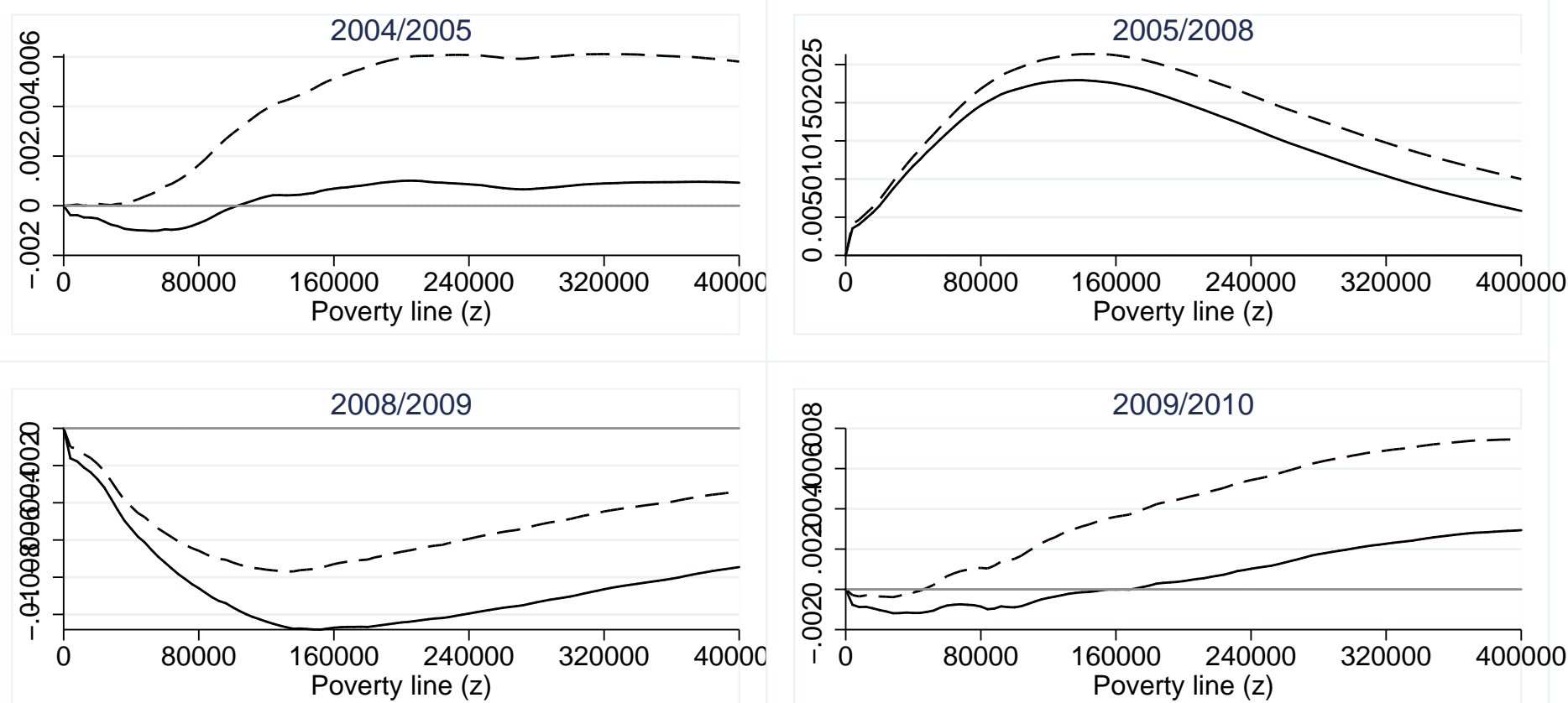

$\begin{array}{ll}- & \text { Difference } \\ --- & \text { Upper Bound of } 95 \% \text { C.I. }\end{array}$ 
Figure COL-11: Second order relatively pro-poor : Colombia 2004/10

Dual approach: $\left(\left(G L_{2}(p) / G L_{1}(p)-\mu_{2} / \mu_{1}\right)\right)$
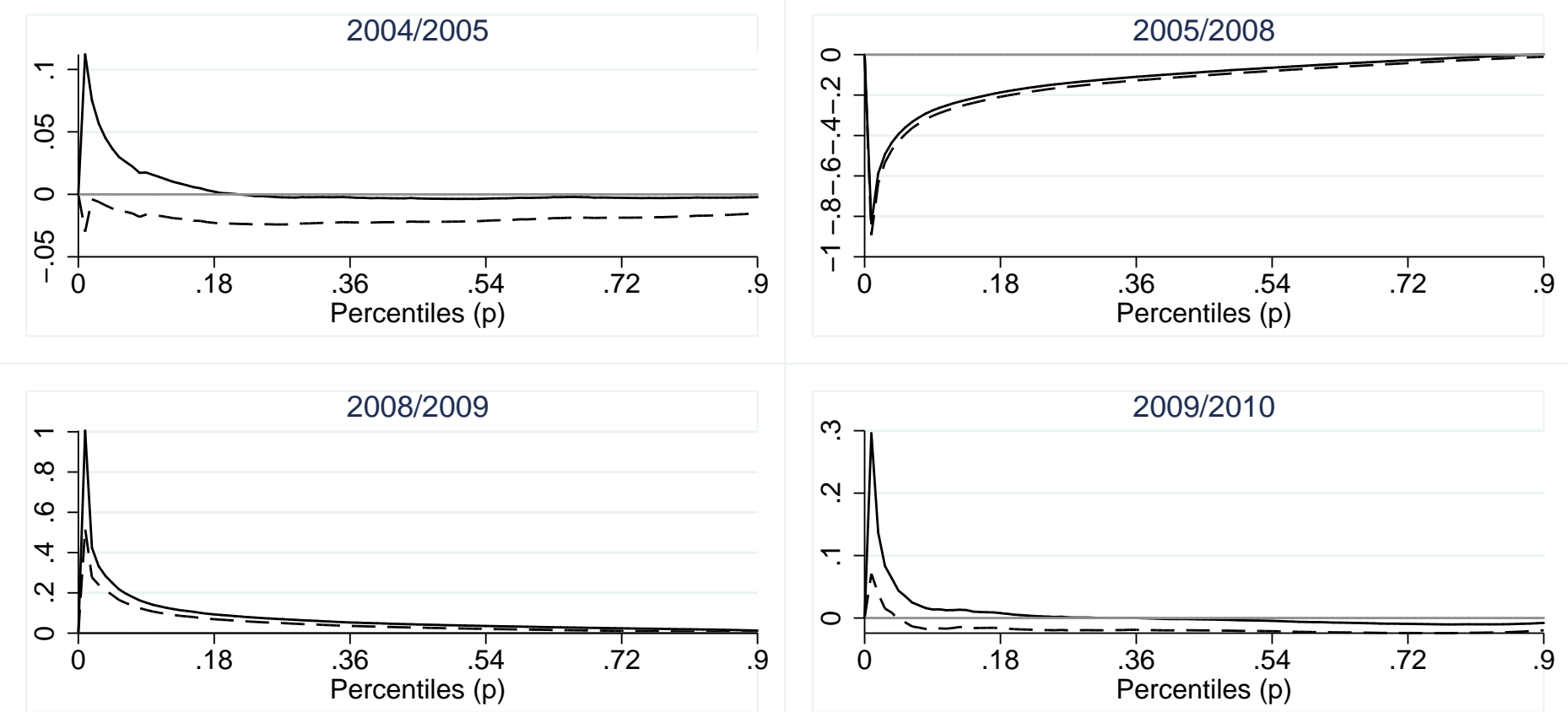

$\begin{array}{ll}- & \text { Difference } \\ --- & \text { Lower Bound of } 95 \% \text { C.I. }\end{array}$ 
Figure COL-12: First order absolute pro-poor: Colombia 2005-2010 Primal approach: $\left(\left(P_{2}(z, \alpha=0)-P_{1}(z, \alpha=0)\right)\right.$

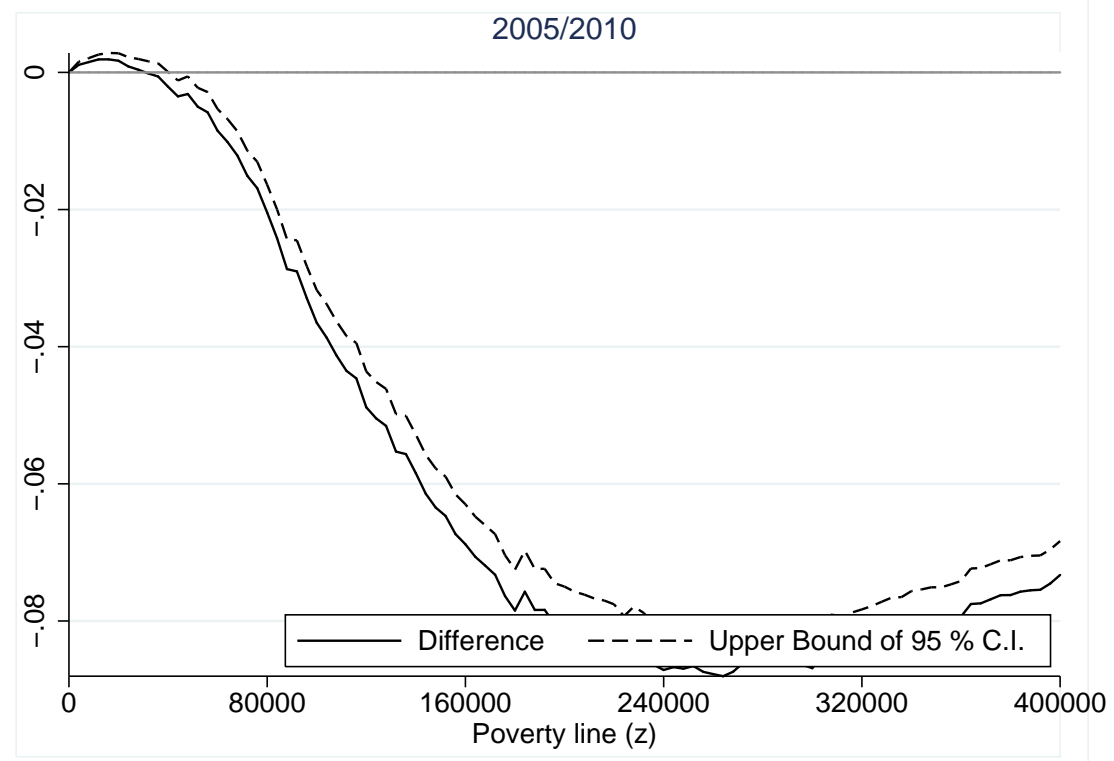

Figure COL-13: First order relatively pro-poor: Colombia 2005-2010

Primal approach: $\left(\left(P_{2}((1+g) z, \alpha=0)-P_{1}(z, \alpha=0)\right)\right.$

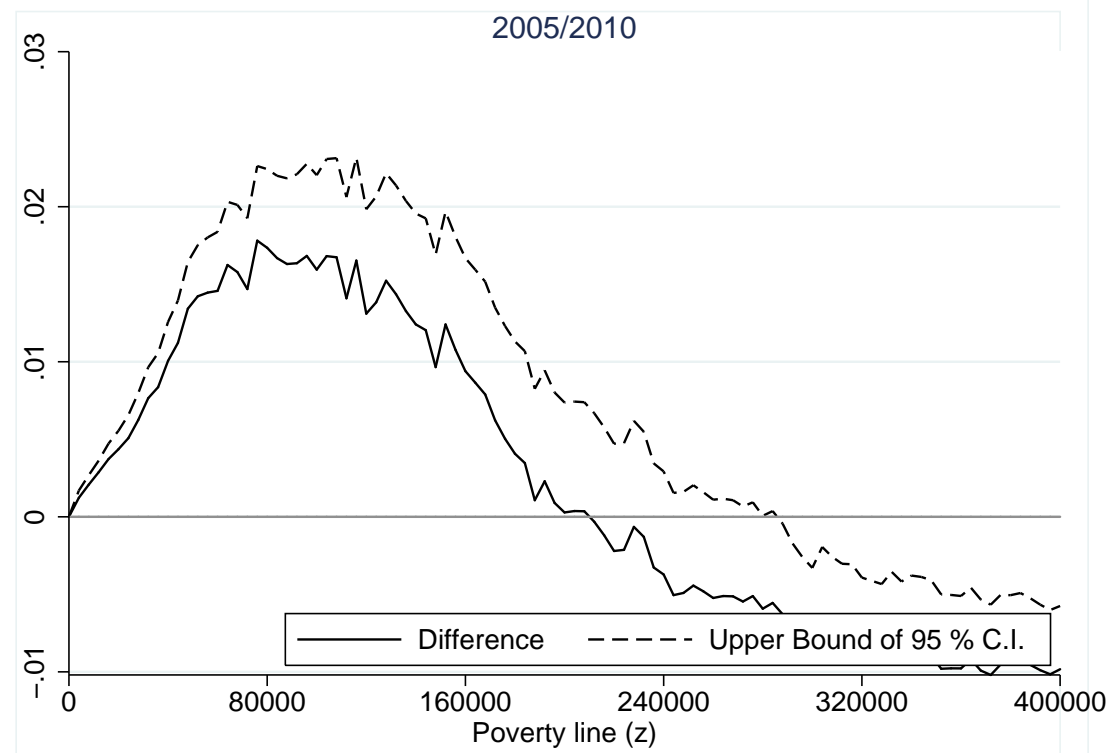




\section{Latino American Andean Countries results}


Table LAA-1: First order dominance of prop-poor growth in the Latino American Andean countries

\begin{tabular}{|c|c|c|c|c|c|c|c|c|c|c|}
\hline \multirow{6}{*}{$\begin{array}{l}\text { Period } \\
2005 / 06 \\
2006 / 07 \\
2007 / 08 \\
2008 / 09 \\
2009 / 10 \\
\end{array}$} & \multicolumn{2}{|c|}{ Bolivia } & \multicolumn{2}{|c|}{ Colombia } & \multicolumn{2}{|c|}{ Ecuador } & \multicolumn{2}{|c|}{ Peru } & \multicolumn{2}{|c|}{ Venezuela } \\
\hline & Absolute & Relative & Absolute & Relative & $\underset{\sqrt{ }}{\text { Absolute }}$ & Relative & Absolute & Relative & $\underset{\sqrt{ }}{\text { Absolute }}$ & $\underset{\sqrt{ }}{\text { Relative }}$ \\
\hline & & $\sqrt{ }$ & & & & & $\sqrt{ }$ & & $\sqrt{ }$ & \\
\hline & & $\sqrt{ }$ & & & & $\sqrt{ }$ & $\sqrt{ }$ & & & \\
\hline & & & $\sqrt{ }$ & $\sqrt{ }$ & & $\sqrt{ }$ & & & & $\sqrt{ }$ \\
\hline & & & $\sqrt{ }$ & & $\sqrt{ }$ & & $\sqrt{ }$ & & & $\sqrt{ }$ \\
\hline All period & $\sqrt{ }$ & $\sqrt{ }$ & $\sqrt{ }$ & $\sqrt{ }$ & $\sqrt{ }$ & $\sqrt{ }$ & $\sqrt{ }$ & $\sqrt{ }$ & $\sqrt{ }$ & $\sqrt{ }$ \\
\hline
\end{tabular}


Table LAA-2: Second order dominance of prop-poor growth in the Latino American Andean countries

\begin{tabular}{|c|c|c|c|c|c|c|c|c|c|c|}
\hline & \multicolumn{2}{|c|}{ Bolivia } & \multicolumn{2}{|c|}{ Colombia } & \multicolumn{2}{|c|}{ Ecuador } & \multicolumn{2}{|c|}{ Peru } & \multicolumn{2}{|c|}{ Venezuela } \\
\hline Period & Absolute & Relative & Absolute & Relative & Absolute & Relative & Absolute & Relative & Absolute & Relative \\
\hline $2005 / 06$ & & & & & $\sqrt{ }$ & & & & $\sqrt{ }$ & $\sqrt{ }$ \\
\hline 2006/07 & & & & & & & $\sqrt{ }$ & & $\sqrt{ }$ & $\sqrt{ }$ \\
\hline $2007 / 08$ & $\sqrt{ }$ & $\sqrt{ }$ & & & & $\sqrt{ }$ & $\sqrt{ }$ & $\sqrt{ }$ & & \\
\hline $2008 / 09$ & $\sqrt{ }$ & $\sqrt{ }$ & $\sqrt{ }$ & $\sqrt{ }$ & $\sqrt{ }$ & $\sqrt{ }$ & & & $\sqrt{ }$ & $\sqrt{ }$ \\
\hline $2009 / 10$ & & & $\sqrt{ }$ & & $\sqrt{ }$ & & $\sqrt{ }$ & & & $\sqrt{ }$ \\
\hline All period & $\sqrt{ }$ & $\sqrt{ }$ & $\sqrt{ }$ & $\sqrt{ }$ & $\sqrt{ }$ & $\sqrt{ }$ & $\sqrt{ }$ & $\sqrt{ }$ & $\sqrt{ }$ & $\sqrt{ }$ \\
\hline
\end{tabular}


Figure LAA-1: The trend of growth in GDP in the Latino American Andean countries

(2005 to 2010)

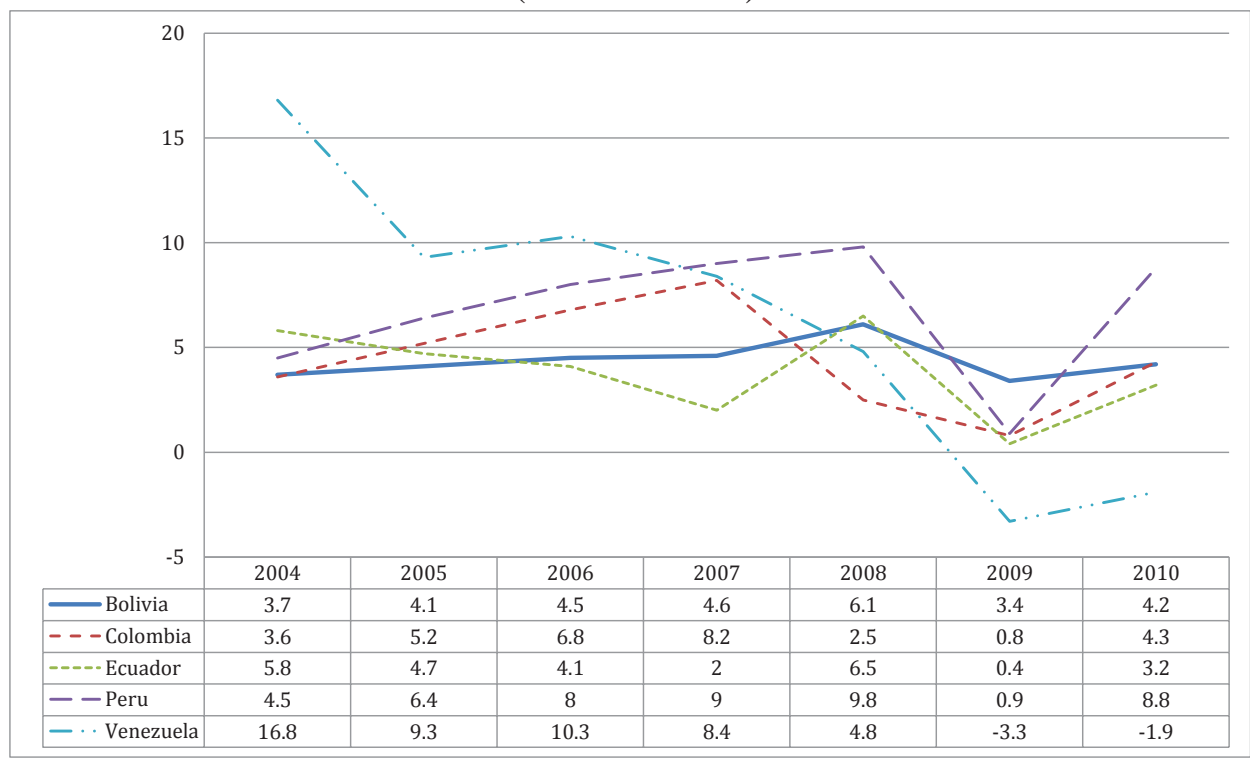

Figure LAA-2: The trend of growth in per capita income/consumption in the Latino American Andean countries

(2005 to 2010)

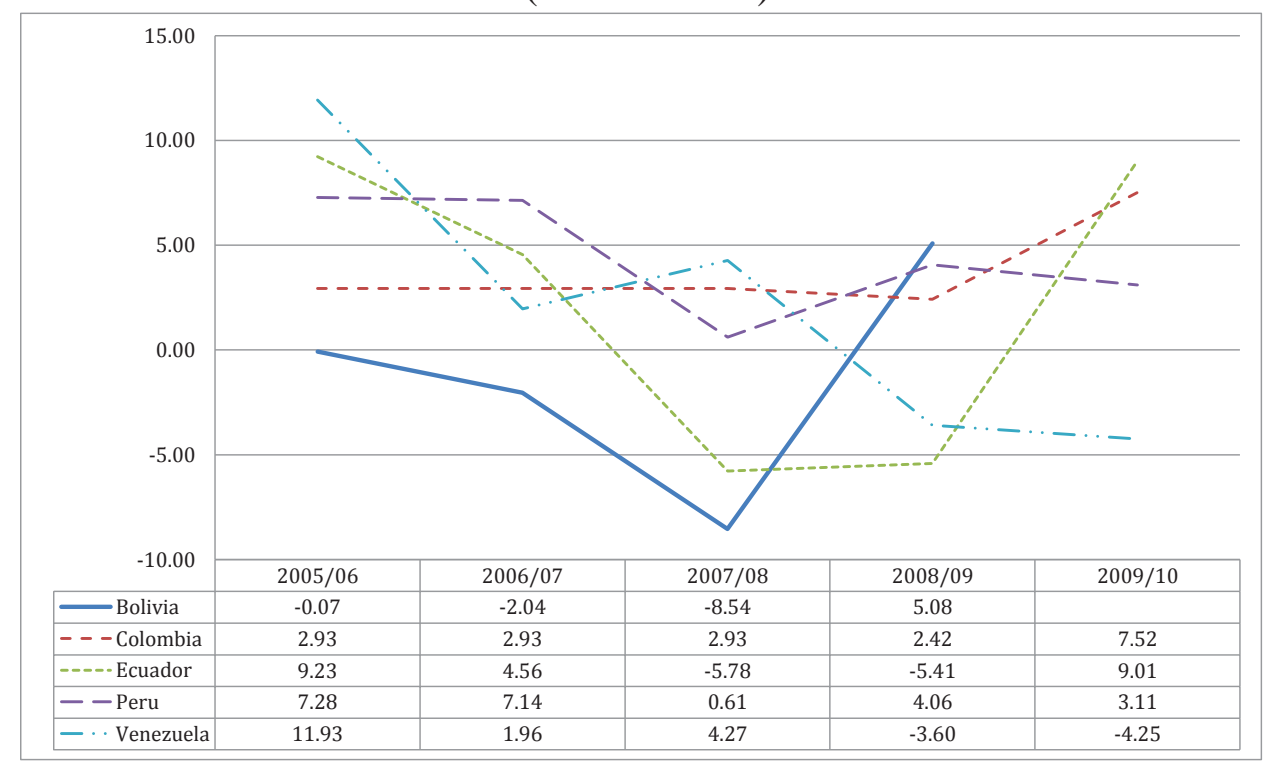


Figure LAA-3: The trend of headcount in the Latino American Andean countries

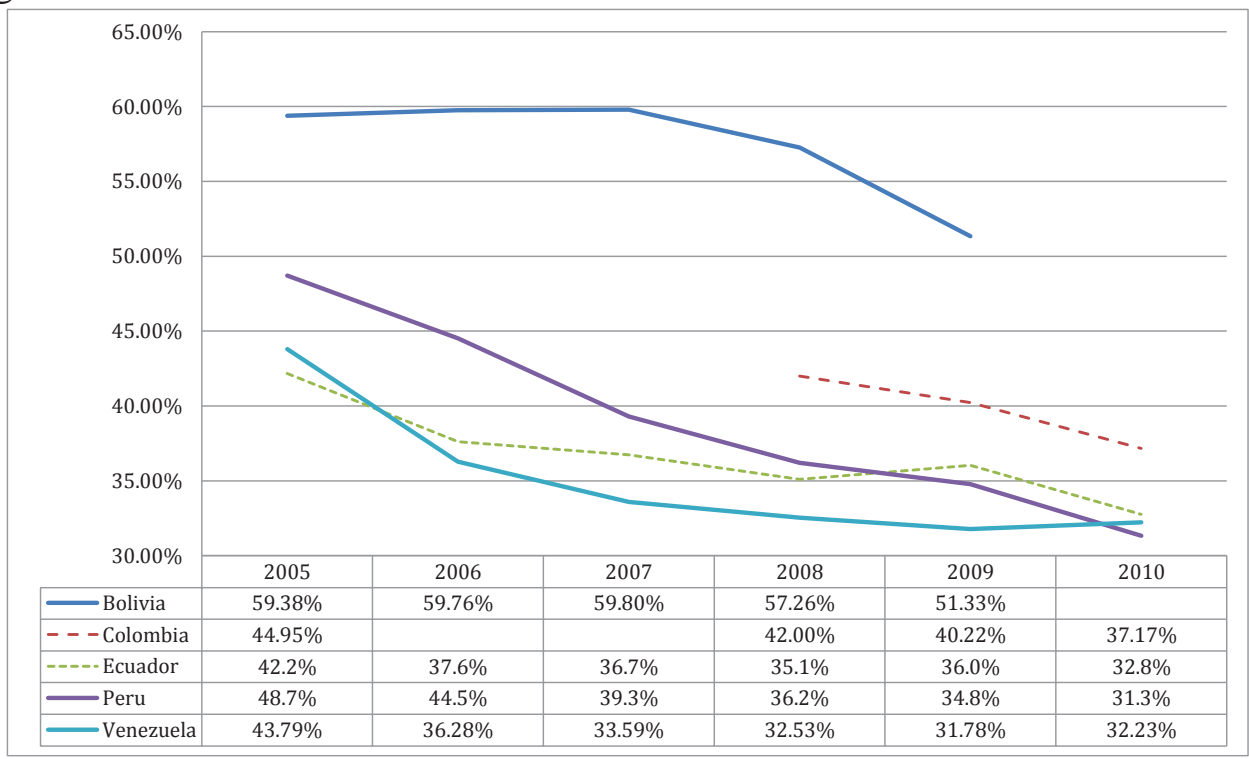

Figure LAA-4: The trend of inequality in the Latino American Andean countries

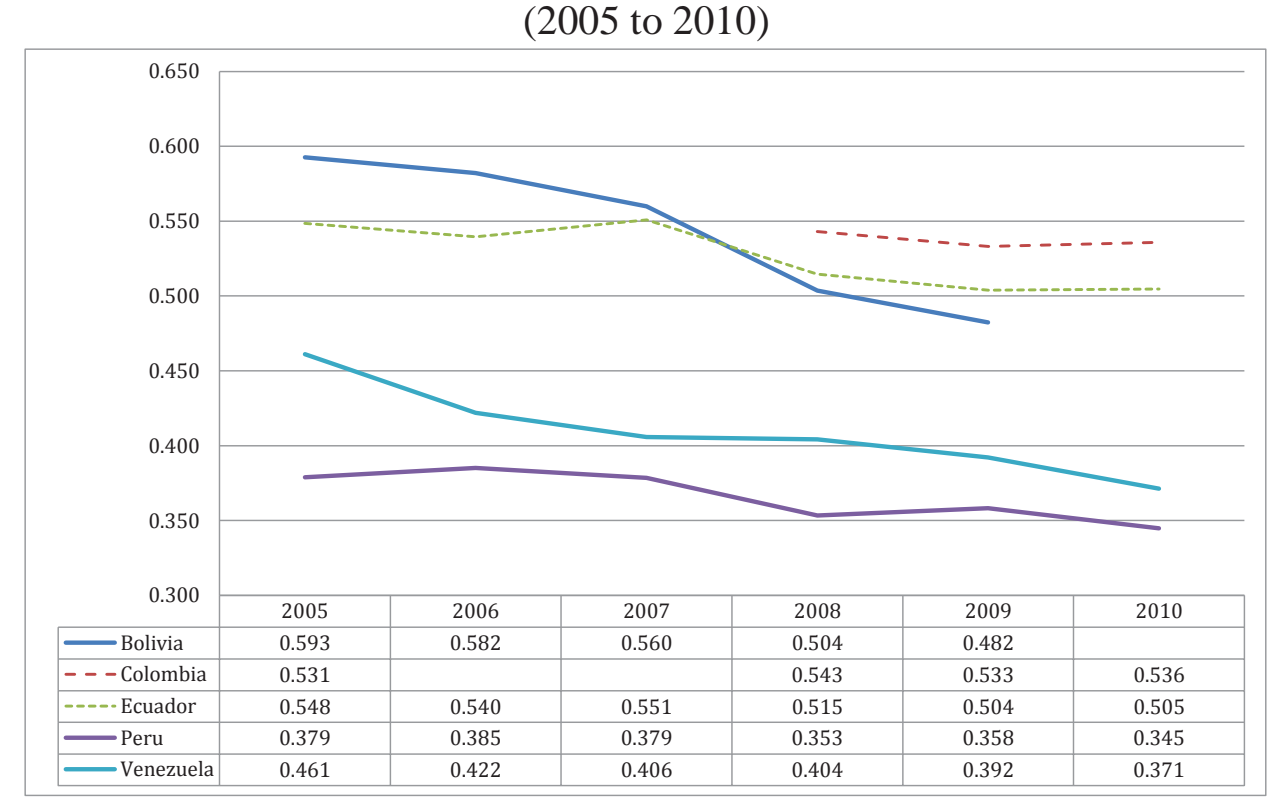


Figure LAA-5: The growth incidence curves for the period of 2008 to 2009

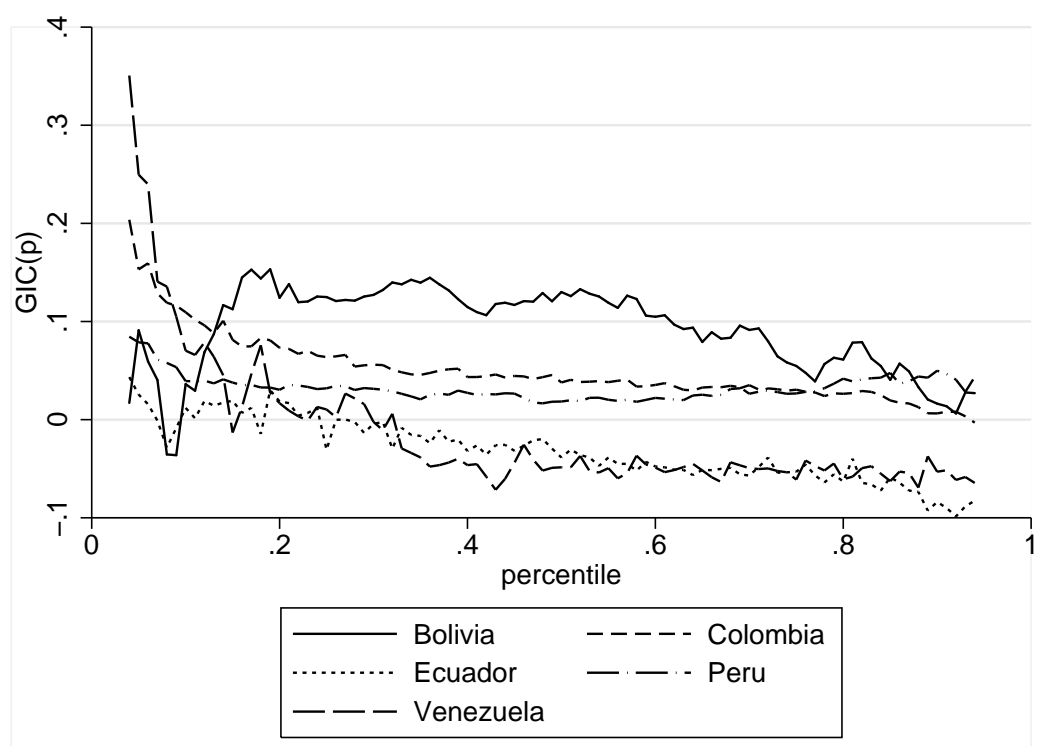

Figure LAA-6: The growth incidence curves for the period of 2009 to 2010

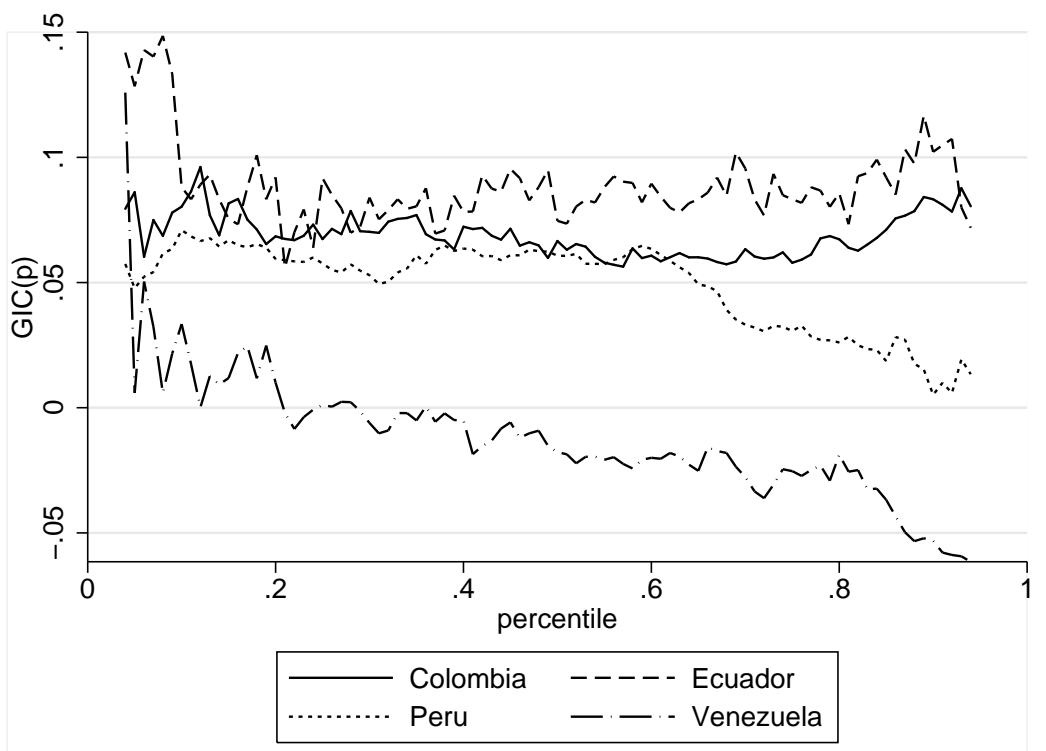




\section{References}

Alesina, A. AND D. RodriK (1994): "Distributive Policies and Economic Growth," Quarterly Journal of Economics, 109, 465-490.

AraAr, A., J.-Y. Duclos, M. Audet, And P. Makdissi (2007): "Has Mexican growth been pro-poor?" Tech. rep., Université Laval.

- (2009): "Testing For Pro-Poorness Of Growth, With An Application To Mexico," Review of Income and Wealth, 55, 853-881.

Atkinson, A., B. Cantillon, E. Marlier, And B. Nolan (2002): Social Indicators - The EU and Social Inclusion, Oxford: Oxford University Press.

BAHADUR, R. (1966): “A Note on Quantiles in Large Samples,” Annals of Mathematical Statistics, 37.

Bourguignon, F. (2003): "The Poverty-Growth-Inequality Triangle," in Conference on Poverty, Inequality and Growth, Paris: Agence française de développement.

- (2011): "Non-anonymous growth incidence curves, income mobility and social welfare dominance," Journal of Economic Inequality, 9, 605627.

Bruno, M., M. Ravallion, And L. SQuire (1998): "Equity and Growth in Developing Countries: Old and New Perspectives on the Policy Issues," in Income Distribution and High-Quality Growth, ed. by V. Tanzi and K. C. (eds.), Cambridge: MIT Press.

DATT, G. AND M. RAVALLiON (1992): “Growth and Redistribution Components of Changes in Poverty Measures: a Decomposition with Applications to Brazil and India in the 1980's," Journal of Development Economics, 38, 275-295.

DAVIDSON, R. AND J.-Y. DuClos (1997): "Statistical Inference for the Measurement of the Incidence of Taxes and Transfers," Econometrica, $65,1453-65$.

Deininger, K. AND L. SQuire (1998): "New Ways of Looking at Old Issues: Inequality and Growth," Journal of Development Economics, 38, 259-87.

Dollar, D. AND A. KRAAY (2002): “Growth Is Good for the Poor," Journal of Economic Growth, 7, 195-225. 
Duclos, J.-Y. (2009): "What is "Pro-Poor"?" Social Choice and Welfare, $32,37-58$.

Duclos, J.-Y. AND Q. WODON (2004): "What is \&quot;ProPoor\&quot;?" Tech. rep.

EAstwood, R. And M. LiPTON (2001): "Pro-poor Growth and ProGrowth Poverty Reduction: What do they Mean? What does the Evidence Mean? What can Policymakers do?" Asian Development Review, 19, 1-37.

ESSAMA-NSSAH, B. (2005): "A unified framework for pro-poor growth analysis," Economics Letters, 89, 216-221.

ESSAMA-NSSAH, B. AND P. J. LAMBERT (forthcoming): "Measuring propoorness: a unifying approach with new results," Review of Income and Wealth.

Foster, J., J. Greer, And E. Thorbecke (1984): “A Class of Decomposable Poverty Measures," Econometrica, 52, 761-776.

Grimm, M. (2007a): "Removing the anonymity axiom in assessing propoor growth,” Journal of Economic Inequality, 5, 179-197.

(2007b): "Removing the anonymity axiom in assessing pro-poor growth," Journal of Economic Inequality, 5, 179-197.

JENKINS, S. P. AND P. V. KERM (2006): "Trends in income inequality, propoor income growth, and income mobility," Oxford Economic Papers, $58,531-548$.

KaKwAni, N., S. KhandKer, And H. Son (2003): "Poverty Equivalent Growth Rate: With Applications to Korea and Thailand," Tech. rep., Economic Commission for Africa.

Kakwani, N. And E. Pernia (2000): "What is Pro Poor Growth?" Asian Development Review, 18, 1-16.

KeRM, P. V. (2009): “Income mobility profiles," Economics Letters, 102, 93-95.

Klasen, S. (2004): "In Search of the Holy Grail: How to Achieve Pro-Poor Growth?" in Toward Pro Poor Policies-Aid, Institutions, and Globalization, ed. by B. Tungodden, N. Stern, and I. Kolstad, New York: Oxford University Press, 63-94. 
(2008): "Economic Growth and Poverty Reduction: Measurement Issues in Income and Non-Income Dimensions," World Development, 36, 420-45.

KRAAY, A. (2004): "When is growth pro-poor? Cross-country evidence," Policy Research Working Paper Series 3225, The World Bank.

McCulloch, N. AND B. BAulch (1999): "Tracking pro-poor growth," Tech. Rep. ID21 insights \#31,, Sussex, Institute of Development Studies. (2000): “Tracking Pro-poor Growth,” Tech. rep., ID21 Insights No. 31, Institute of Development Studies, Sussex.

Ravallion, M. And S. Chen (2003): "Measuring Pro-poor Growth," Economics Letters, 78, 93-99.

Ravallion, M. And G. DATT (2002): "Why Has Economic Growth Been More Pro-poor in Some States of India Than Others?" Journal of Development Economics, 68, 381-400.

Rawls, J. (1971): A Theory of Justice, Cambridge: MA: Harvard University Press.

SHORROCKS, A. (1999): "Decomposition procedures for distributional analysis: A unified framework based on the Shapley value," Tech. rep., University of Essex.

Shorrocks, A. F. (1978): "Income Inequality and Income Mobility," Journal of Economic Theory, 19, 376-393.

Son, H. (2004): “A note on pro-poor growth,” Economics Letters, 82, 307314.

United Nations (2000): A Better World for All, New York.

WORLD BANK (2000): The Quality of Growth, New York: Oxford University Press. 